Aus der Klinik für Psychiatrie und Psychotherapie

(Prof. Dr. med. J. Wiltfang)

der Medizinischen Fakultät der Universität Göttingen

In-vivo-Screen verschiedener Aggregationsmodulatoren in transgenen

Drosophila melanogaster Alzheimermodellen

\author{
INAUGURAL-DISSERTATION \\ zur Erlangung des Doktorgrades \\ der Medizinischen Fakultät der \\ Georg-August-Universität zu Göttingen
}

vorgelegt von

Petra Maria Theodora Bernharda Wilken

aus Cloppenburg

Göttingen 2016 
Dekan:

Prof. Dr. rer. nat. H. K. Kroemer

I. Berichterstatter/in: Prof. Dr. A. Schneider

II. Berichterstatter/in: PD Dr. Oliver Wirths

III. Berichterstatter/in: Prof. Dr. M. Zweckstetter

Tag der mündlichen Prüfung: 15.12.2016 


\section{Eidesstattliche Versicherung}

Hiermit erkläre ich, dass ich die beigefügte Dissertation selbstständig verfasst und keine anderen als die angegebenen Hilfsmittel genutzt habe.

Alle wörtlich oder inhaltlich übernommenen Stellen habe ich als solche gekennzeichnet.

Göttingen, 08.04.2016

Petra Wilken 



\section{Inhaltsverzeichnis}

Inhaltsverzeichnis

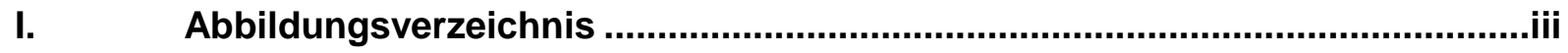

II. Tabellenverzeichnis ..................................................................................

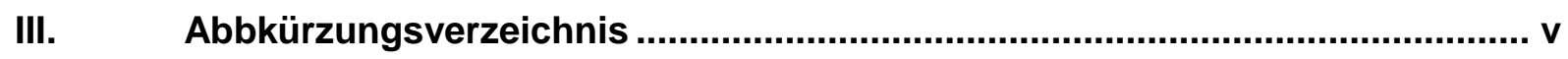

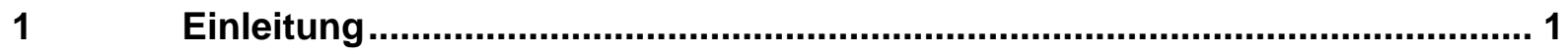



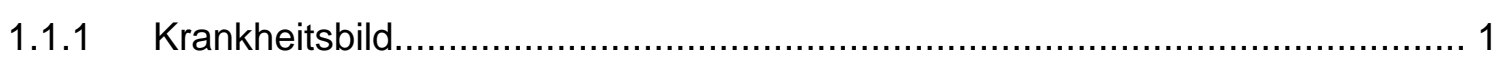

1.1.2 Genetische und weitere Risikofaktoren .................................................. 2

1.1.3 Molekulare Grundlagen der Alzheimer-Erkrankung .................................... 3

1.1.3.1 Amyloid-Precursor-Protein .......................................................... 3

1.1.3.1.1 Amyloidogene Prozessierung von APP ........................................... 4



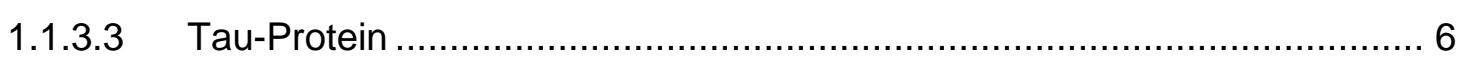

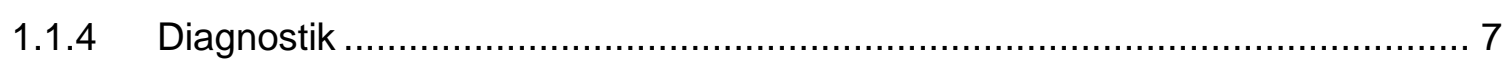

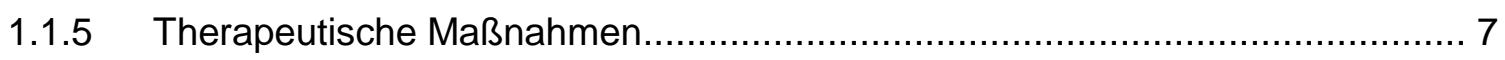

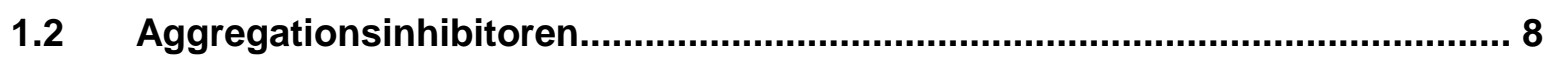

1.3 Oligomermodulatoren................................................................................ 9

1.4 Drosophila melanogaster als Tiermodell für neurodegenerative Erkrankungen

1.4.1 Alzheimer-Modelle im transgenen Fliegenmodell ........................................12

1.5 Ziel der Arbeit.............................................................................................15

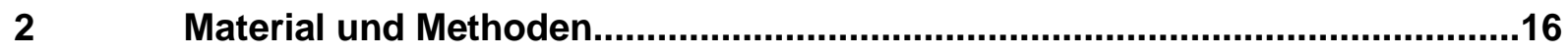

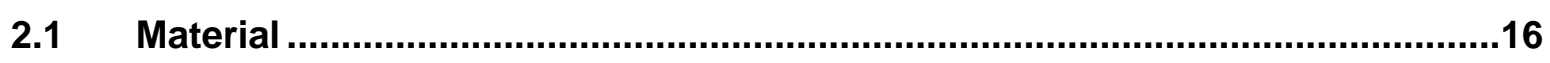

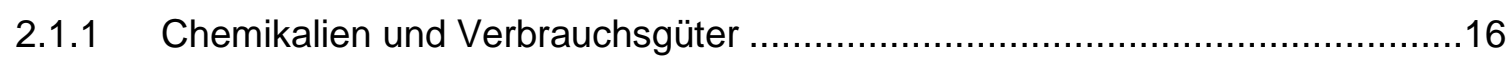

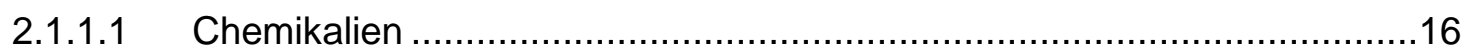

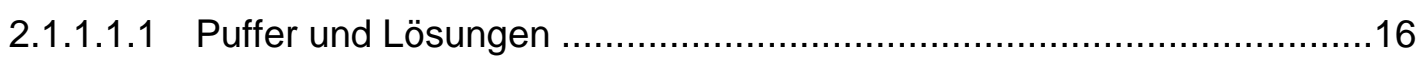

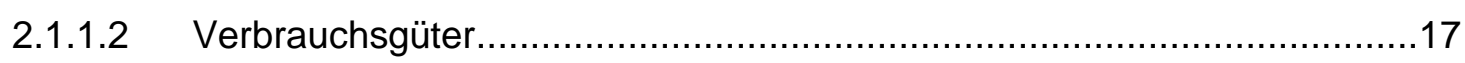

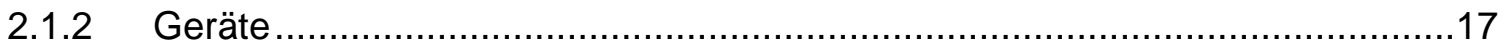

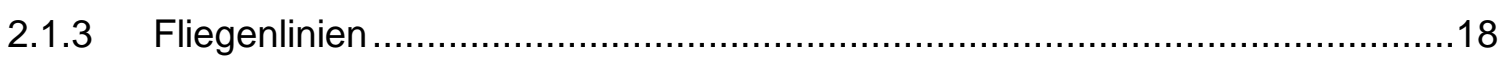

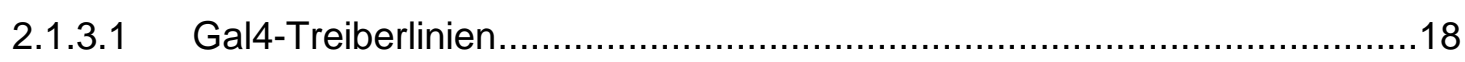

2.1.3.2 UAS-spezifische Drosophila-Linien ............................................. 18

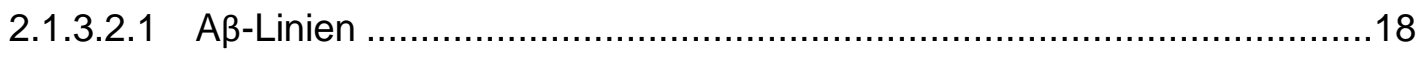

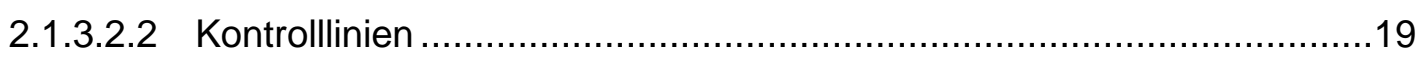

2.2 Methoden.....................................................................................................20

2.2.1 Zucht- und Haltebedingungen von Drosophila melanogaster ........................20



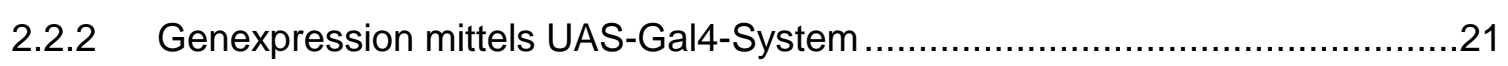

2.2.3 Erstellung doppelt homozygoter Treiberlinien ..........................................22 


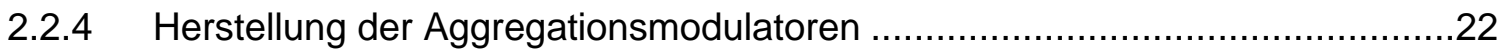

2.2.5 Bestimmung der Überlebensdauer ......................................................23

2.2.6 $A \beta_{42}$-Überexpression in retinalen Ganglienzellen.......................................23





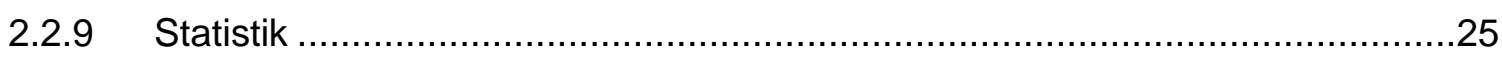

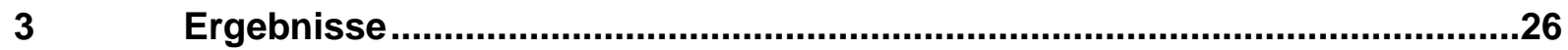

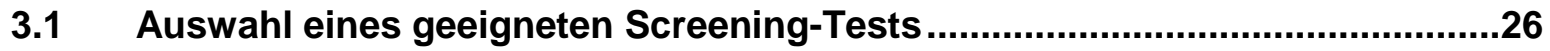



3.3 Kontrolle der Expression mit der Treiberline elavGal4;tubGal80[ts]...............28

3.4 Analyse der Überlebensdauer von $A \beta_{42}$-exprimierenden Fliegen ...................29

3.4.1 Analyse der Überlebensdauer ohne Zugabe von Wirkstoffen ..........................29

3.4.2 Analyse der Überlebensdauer unter Zugabe von Wirkstoffen ..........................30

3.5 Einfluss der getesteten Wirkstoffe auf lösliches und unlösliches-A $\beta_{42} \ldots \ldots . . . .37$

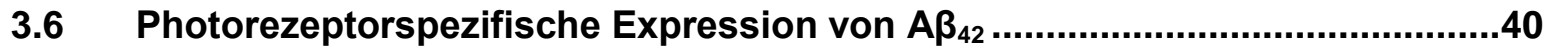



3.6.2 Pathologischer Augenphänotyp............................................................ 41

3.6.2.1 Augenphänotyp von GMR/arc2e unter Verwendung der Wirkstoffe anle138b und anle138c sowie der Negativkontrolle DMSO ....................................41

3.6.2.2 Augenphänotyp der Kontrolle GMR/CyO unter Verwendung der Wirkstoffe anle138b und anle138c sowie der Negativkontrolle DMSO.....................................42

3.6.2.3 Augenphänotyp der Kontrolle elav GMR/eGFP unter Verwendung der Wirkstoffe anle138b und anle138c sowie der Negativkontrolle DMSO. .....................43

4

Diskussion.

4.1 Auswahlverfahren verschiedener Mutanten ..................................................44

4.2 Einfluss der Wirkstoffe auf das Überleben und Aggregationsverhalten der transgen veränderten Fliegen............................................................................45

4.2.1 Auswirkungen der Wirkstoffe auf das Überleben der Fliegen ..........................45

4.2.1.1 Auswirkungen der Wirkstoffe auf Fliegen mit dem Genotyp elavGal4/tubGal80[ts],lacz

4.2.1.2 Auswirkung der Wirkstoffe im arctic - und im sporadischen Fliegenmodell 45

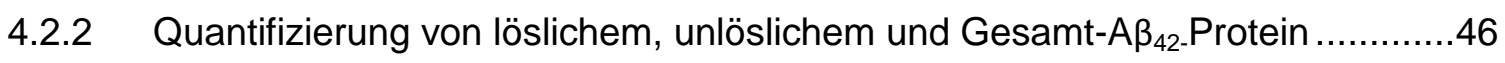

4.3 Lokale Expression von $\mathrm{A}_{42}$ im Auge von Drosophila melanogaster .............46

4.4 Mögliche Anwendung für die Klinik....................................................................48

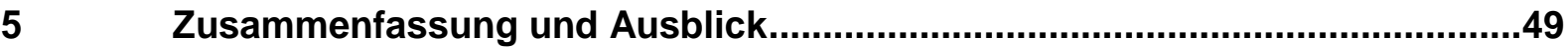

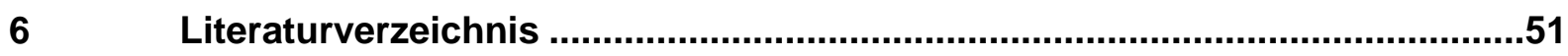

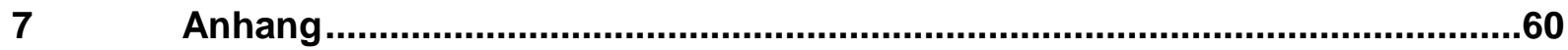




\section{Abbildungsverzeichnis}

Abb. 1: Mikroskopische Darstellung der Neuropathologie bei der Alzheimer-Erkrankung...... 3

Abb. 2: Schematische Darstellung der APP-Prozessierung und A $\beta$-Akkumulierung. ............. 5

Abb. 3: Zusammenfassende Darstellung der experimentellen Strategie zur Identifizierung ..10

Abb. 4: Schematische Darstellung der beteiligten Komponenten bei der Alzheimer-

Erkrankung am Beispiel des Menschen und Drosophila melanogaster.

Abb. 5: Schematische Darstellung der Funktionsweise des UAS-Gal4-Systems am Beispiel des $A \beta_{42}$-Peptids.

Abb. 6: Verkreuzungsschema der temperaturabhängigen Treiberlinie elavGal4;tubGal80[ts]

Abb. 7: Schematische Darstellung des MSD human $A \beta_{42}$ ELISA ....................................25

Abb. 8: Überlebensdauer der transgenen $A \beta$-Linien unter elavC155 ..............................27

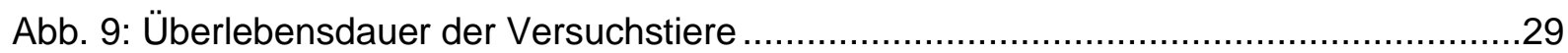

Abb. 10: Überlebensdauer der Kontrolle elavGal4;tubGal80[ts] lacz unter Wirkstoffzugabe .31

Abb. 11: Überlebensdauer der Kontrolle elavGal4;tubGal80[ts] lacz unter Zugabe von

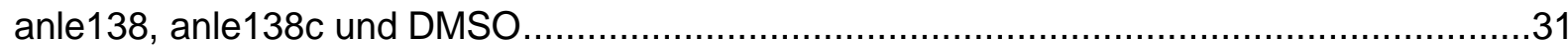

Abb. 12: Überlebensdauer von elavGal4/alz3;tubGal80[ts]/alz8 unter Wirkstoffzugabe ........33 Abb. 13: Überlebensdauer von elavGal4/alz3;tubGal80[ts]/alz8 unter Zugabe von anle138b,

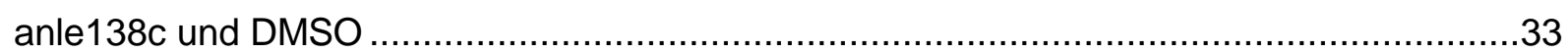

Abb. 14: Überlebensdauer von elavGal4/arc2e;tubGal80[ts] unter Wirkstoffzugabe .............35

Abb. 15: Überlebensdauer von elavGal4/arc2e;tubGal80[ts] unter Wirkstoffzugabe .............35

Abb. 16: Darstellung der $A \beta_{42}$-Proteinmenge am Bsp. des Genotyps

elavGal4/alz3;tubGal80[ts] /alz8

Abb. 17: Darstellung der $A \beta_{42}$-Proteinmenge am Bsp. des Genotyps elavGal4/arc2e;tubGal80[ts] .38

Abb. 18: Darstellung des Verhältnisses von unlöslichem zum Gesamt-A $\beta_{42} \ldots \ldots \ldots \ldots \ldots \ldots \ldots . . . . . . . . . . .39$

Abb. 19: Darstellung des physiologischen Augenphänotyps verschiedener Fliegenlinien .....40

Abb. 20: Augenphänotyp mit dem Genotyp GMR/arc2e unter $29^{\circ} \mathrm{C}$

Abb. 21: Augenphänotyp der Fliegenlinie GMR/CyO unter $29^{\circ} \mathrm{C}$ .42

Abb. 22: Augenphänotyp des Genotyps GMR/CD8eGFP(eGFP) unter $29{ }^{\circ} \mathrm{C}$ .43 


\section{Tabellenverzeichnis}

Tab. 1: Darstellung der verwendeten Modulatoren und deren Molekulargewicht .23

Tab. 2: Darstellung der mittleren Überlebenswahrscheinlichkeit der transgenen A $\beta$-Linien unter elavC155

Tab. 3: Darstellung der untersuchten Temperaturbedingungen während der Verkreuzung und im adulten Stadium .28

Tab. 4: Mittelwerte für die Überlebenszeit der Fliegen unter Verwendung der Treiberlinie....30

Tab. 5: Mittelwerte für die Überlebenszeit des Genotyps elavGal4;tubGal80[ts],lacz..... .32

Tab. 6: Mittlere Überlebenswahrscheinlichkeit im paarweisen Vergleich unter Zugabe von Modulatoren .32

Tab. 7: Mittelwerte für die Überlebenszeit des Genotyps elavGal4/alz3;tubGal80[ts]/alz8 ....34 Tab. 8: Mittlere Überlebenswahrscheinlichkeit im paarweisen Vergleich unter Zugabe von Modulatoren .34

Tab. 9: Mittelwerte für die Überlebenszeit des Genotyps elavGal4/arc2e;tubGal80[ts] .... .36

Tab. 10: Mittlere Überlebenswahrscheinlichkeit im paarweisen Vergleich unter Zugabe von Modulatoren .36

Tab. 11: Mittelwerte und Mediane für die Überlebenszeit verschiedener Linien .63

Tab. 12: Mittlere Überlebenswahrscheinlichkeit im paarweisen Vergleich unter Zugabe von Modulatoren 


\section{Abbkürzungsverzeichnis}

$\%$

${ }^{\circ} \mathrm{C}$

Abb.

AchE-Inhibitoren

AICD

anle138b

anle138c

anle145c

anle253b

$\mathrm{APH}-1$

ApoE2

ApoE3

ApoE4

APP

APPL

AS

AUC

$A \beta$

$A \beta_{40}$

$A \beta_{42}$

AßGlu22Gly

BACE1

bzw.

C9orf72

cCT

CMRT

$\mathrm{CO}_{2}$

$\mathrm{CSF}$
Prozent

Grad Celsius

Abbildung

Acetylcholinesterase Inhibitoren

APP intracellular domain

3-(1,3-Benzodioxol-5-yl)-5-(3-bromophenyl)-1H-

pyrazole

3-(3-Bromophenyl)-5-(3, 4-dihydroxyphenyl)-1Hpyrazole

3-(3,5-Dibromophenyl)-5-(3,4,5trihydroxyphenyl)$1 \mathrm{H}$-pyrazole hydrobromide

3-(3-Bromophenyl)-5-[4-(dimethylamino) phenyl]$1 \mathrm{H}$-pyrazole

anterior pharynx defective protein-1

Apolipoprotein E ع2-Allel

Apolipoprotein E ع3-Allel

Apolipoprotein E ع4-Allel

amyloid precursor protein

amyloid precursor protein like

Aminosäuren

area under the curve

Amyloid- $\beta$

Beta-Amyloid mit einer Länge von 40 Aminosäuren

Beta-Amyloid mit einer Länge von 42 Aminosäuren

familiäre Alzheimer-Mutante "Arctic“;

Punktmutation mit Austausch von Glutaminsäure gegen Glycin

$\beta$-site APP cleaving enzyme 1

beziehungsweise

Chromosome 9 open reading frame 72

zerebrale Computertomographie

zerebrale Magnetresonanztomographie

Kohlendioxid

Zerebrospinalflüssigkeit 
dAPPL

DMSO

DPP

EDTA

EGCG

et al.

F1- Generation

FAD

FTDP-17

g

GFP

GnHCl

$\mathrm{h}$

$\mathrm{H}_{2} \mathrm{O}$

HPLC

i.p.

$\mathrm{kDa}$

$\mathrm{kg}$

Konz.

I

$\mathrm{M}$

M. Alzheimer

M. Parkinson

$\mathrm{mg}$

$\min$

$\mathrm{ml}$

msd

NBB

NMDA-Rez.Antagonisten

PEN-2

PET-CT

$\mathrm{pH}$

PHF

PrPC

PrPSc
Drosophila amyloid precursor like protein

Dimethylsulfoxid

3, 5-Di-Phenyl-Pyrazole

Ethylendiamintetraessigsäure

Epi-Gallocatechine-3-Gallate

et alii

Filialgeneration 1

familiäre Alzheimer-Demenz

frontotemporale Demenz mit Parkinsonismus

gekoppelt mit Chromosom 17

Gramm

grün fluoreszierendes Protein

Guanidiumhydrochlorid

Stunde

Wasser

Hochleistungsflüssigkeitschromatographie

intraperitoneal

Kilodalton

Kilogramm

Konzentration

Liter

Molar

Morbus Alzheimer

Morbus Parkinson

Milligramm

Minute

Milliliter

meso scale discovery

$\mathrm{N}$-Benzylidene-Benzohydrazaide

N-Methyl-D-Aspartat-Rezeptor-Antagonisten

presenilin enhancer protein 2

Positronenemissionstomographie in Kombination

mit Computertomographie

potentia hydrogenii

paarige helikale Filamente

Prion Protein cellular

Prion Protein Scrapie 


\begin{tabular}{|c|c|}
\hline PSN1 & Präsenilin 1 \\
\hline PSN2 & Präsenilin 2 \\
\hline RNA Polymerase II & Ribonukleinsäuren Polymerase II \\
\hline rpm & revolutions per minute \\
\hline s.c. & subkutan \\
\hline sAPPa & secreted amyloid precursor protein alpha \\
\hline sAPP $\beta$ & secreted amyloid precursor protein beta \\
\hline sek & Sekunde \\
\hline sery118 & $\begin{array}{l}\text { 3-(3,4-Dihydroxyphenyl)-5-(3-fluorophenyl)-1H- } \\
\text { pyrazole }\end{array}$ \\
\hline sery313b & $\begin{array}{l}\text { 3-(1,3-Benzodioxol-5-yl)-5-(3-chlorophenyl)-1H- } \\
\text { pyrazole }\end{array}$ \\
\hline sery335b & $\begin{array}{l}\text { 3-(1,3-benzodioxol-5-yl)-5-(3-bromophenyl)-1- } \\
\text { methyl-1H-pyrazole }\end{array}$ \\
\hline sery392b & $\begin{array}{l}\text { 3-(1,3-Benzodioxol-5-yl)-5-(3-hydroxyphenyl)-1H- } \\
\text { pyrazole }\end{array}$ \\
\hline sery85 & $\begin{array}{l}\text { 5-(3,4-Dihydroxyphenyl)-3-(4-hydroxyphenyl) } \\
\text { isoxazole }\end{array}$ \\
\hline SIFT & scanning for intensely fluorescent targets \\
\hline Tab. & Tabelle \\
\hline Temp. & Temperatur \\
\hline UAS & upstream activating sequence \\
\hline z.B. & zum Beispiel \\
\hline ZNS & zentrales Nervensystem \\
\hline$\mu g$ & Mikrogramm \\
\hline$\mu l$ & Mikroliter \\
\hline
\end{tabular}




\section{Einleitung}

\subsection{Morbus Alzheimer}

Morbus Alzheimer (M. Alzheimer), eine Unterform der Demenzerkrankungen, bedingt einen großen Anteil der neurodegenerativen Erkrankungen im höheren Lebensalter. Prozentual macht sie dabei mehr als 70\% aller Demenzerkrankungen aus (Puglielli, Tanzi et al., 2003). Die Prävalenz der Erkrankung ist zunehmend, sodass nach aktuellen Prognosen die Anzahl der weltweit erkrankten Personen im Jahr 2035 auf ca. 60 Millionen ansteigen wird (Jahn, 2013). Das vermehrte Auftreten ist vor allem der steigenden Lebenserwartung, die den größten Risikofaktor für diese Erkrankung darstellt, geschuldet (Lindsay, Laurin et al., 2002). Erstmals beschrieben wurde die Erkrankung 1907 von Alois Alzheimer, der bei seiner Patientin Auguste Deter starke Persönlichkeitsveränderungen, Verfolgungs- und Eifersuchtswahn sowie eine fehlende Orientierung zu Ort und Zeit feststellte (Alzheimer, 1907).

Bei der Post-mortem-Untersuchung des Gehirns der Patientin fand Alois Alzheimer morphologische Veränderungen in Form von Proteinablagerungen (Amyloide Plaques und neurofibrilläre Bündel) in der Hirnrinde. Außerdem stellte er eine Atrophie des Gehirns, bedingt durch einen massiven Nervenzelluntergang, fest.

\subsubsection{Krankheitsbild}

Im Vordergrund stehen bei der Alzheimerschen Erkrankung zunächst Kurzzeitgedächtnisstörungen. Häufig folgen Defizite bei der zeitlichen und örtlichen Orientierung sowie ein nachlassendes Urteilsvermögen. Im Verlauf zeigt sich ein progredienter Abbau in sämtlichen kognitiven Bereichen mit Störungen der Affektkontrolle und der Alltagskompetenz aufgrund der eingeschränkten praktischen Fertigkeiten (Weintraub, Wicklund et al., 2012). Zusätzlich treten emotionale, sprachliche und motorische Dysfunktionen auf.

Im Endstadium sind die Patienten schließlich vollständig auf Hilfe angewiesen (Amieva, Le Goff et al., 2008; Forstl and Kurz, 1999). Zum aktuellen Zeitpunkt existiert keine wirksame Therapie, die die Erkrankung heilen, ihr Fortschreiten verhindern oder verlangsamen kann. 


\subsubsection{Genetische und weitere Risikofaktoren}

Es handelt sich bei M. Alzheimer um eine Erkrankung multifaktorieller Ätiologie, bei der genetische, epigenetische und umweltbedingte Faktoren zusammenwirken (Huang and Mucke, 2012). Der Großteil der an Alzheimer erkrankten Patienten leidet unter der sporadischen Variante (Tanzi, 2012). Der Zeitpunkt des Auftretens erster Krankheitssymptome ist hierbei von entscheidener Bedeutung. Betroffene mit einem präsenilen Manifestationsalter (30-65 Lebensjahr) werden der Gruppe early onset (ca. 5\%), Betroffene mit familiär gehäufter Symptomatik nach dem 65. Lebensjahr der Gruppe late onset (ca. 95\%) zugeordnet (Bird, 2008). Der frühe Krankheitsausbruch korreliert zumeist mit einem schnelleren klinischen Verlauf (Wu, Rosa-Neto et al., 2012). Es ist davon auszugehen, dass die Neurodegeneration ca. 20-30 Jahre vor der Erstmanifestation klinischer Symptome beginnt (Bateman, Xiong et al., 2012; Goedert and Spillantini, 2006; Jack and Holtzman, 2013).

Bei den familiär betroffenen Alzheimer-Patienten (unter 1\%) finden sich Mutationen mit autosomal dominantem Erbgang. Die betroffenen Gene kodieren für Presenilin 1 (PSN1), Presenilin 2 (PSN2) und für Amyloid-Precursor-Protein (Duara, Loewenstein et al.), die unter anderem für die A $\beta$ - Synthese verantwortlich sind (De Jonghe, Esselens et al., 2001; Goate, Chartier-Harlin et al., 1991; Jiao, Tang et al., 2014; Mahley, Weisgraber et al., 2006) (Sherrington, Rogaev et al., 1995).

Kardiovaskuläre Risikofaktoren wie Diabetes mellitus, arterielle Hypertonie, Rauchen sowie ein insgesamt niedriges Bildungsniveau mit geringer kognitiver Beanspruchung, verminderte körperliche Aktivität und Depression im mittleren Lebensalter stellen z.T. modifizierbare Risikofaktoren der sporadischen Alzheimer-Erkrankung dar (Barnes and Yaffe, 2011; Lee, Back et al., 2010; Savva, Stephan et al., 2010; Sundstrom, Nilsson et al., 2007). Risikogene, die mit dem gehäuften Auftreten sporadischer Alzheimer-Erkrankungen assoziiert sind, wurden in einer Übersichtsarbeit von Karch\&Goate 2015 besprochen und umfassen u.a. ApoE4 (Karch and Goate, 2015). Die sporadische Form der Alzheimer-Erkrankung wird anhand des Erstmanifestationsalters noch in die frühe und die späte Form (> 65.Lebensjahr) unterteilt. 


\subsubsection{Molekulare Grundlagen der Alzheimer-Erkrankung}

In Post-mortem-Untersuchungen der Gehirne an Alzheimer erkrankter Patienten zeigten sich neuropathologisch intra- und extrazelluläre Proteinablagerungen (Ramirez-Bermudez, 2012). Bei den Proteinablagerungen (siehe Abb.1) handelt es sich um extrazellulär lokalisierte A $\beta$ Plaques, die aus dem $A \beta$-Peptid entstehen, sowie intrazellulär lokalisierte neurofibrilliäre Bündel, die vorwiegend aus hyperphosphoyliertem Tau-Protein aufgebaut sind (Anand, Gill et al., 2014). Diese Ablagerungen stellen bis heute die histomorphologischen Charackteristika der Alzheimer-Erkrankung dar (Dickson, 1997; Glenner and Wong, 1984; Grundke-lqbal, lqbal et al., 1986a; Grundke-lqbal, lqbal et al., 1986b; Mandelkow, von Bergen et al., 2007; Mandelkow and Mandelkow, 1998).

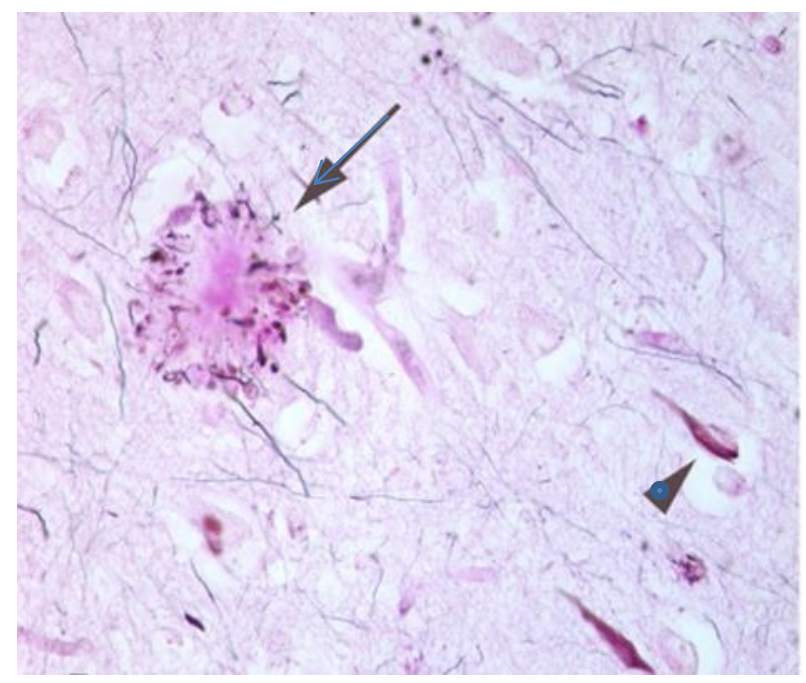

Abb. 1: Mikroskopische Darstellung der Neuropathologie bei der Alzheimer-Erkrankung. Darstellung einer neuritischen Plaque (Pfeil) und neurofibrilliärer Bündel (Pfeilspitze) mittels HE Färbung.

[Abb. modifiziert nach (Walker and LeVine, 2012), Seite 33110]

\subsubsection{Amyloid-Precursor-Protein}

Bei dem Amyloid-Precursor-Protein (APP) handelt es sich um ein ca. 110-130 kDa großes Typ-1-Transmembranprotein (Kang, Lemaire et al., 1987). Das APP-Gen ist auf dem Chromosom 21 (21q21) lokalisiert und besteht aus 19 Exonen. Es existieren verschiedene Isoformen, von denen APP695 fast ausschließlich in den Neuronen gebildet wird (Mills and Reiner, 1999). Ortholge Gene (APPL) konnten u.a. bei Drosophila melanogaster gefunden werden (Rosen, Martin-Morris et al., 1989; Zheng, Zhao et al., 2011).

Die physiologische Funktion des APP ist noch nicht vollständig geklärt. Diskutiert wird eine Funktion bei der synaptischen Plastizität, dem axonalen Transport und der Stimulation 
neuronaler Stammzellen. Zudem weist eine schon frühe Expression während der Gehirnentwicklung auf einen wesentlichen Einfluss bei der Neurogenese hin.

Im Tiermodell konnte eine Beteiligung bei der Differenzierung, Migration und Proliferation der Neurone dargestellt werden (Muller, Pietrzik et al., 2012; Nicolas and Hassan, 2014; Shariati, Lau et al., 2013; Tyan, Shih et al., 2012).

\subsection{Amyloidogene Prozessierung von APP}

Das Aß-Peptid entsteht durch proteolytische Spaltung des APPs. APP kann über zwei unterschiedliche Wege prozessiert werden, an denen drei Sekretasen, $\alpha-, \beta-$ und $\gamma^{-}$ Sekretase, beteiligt sind. (siehe Abb.2, Seite 5). Bei der nicht-amyloidogenen Prozessierung schneidet zunächst die $\alpha$-Sekretase innerhalb der $A \beta$-Domäne, sodass kein $A \beta$-Peptid generiert wird (Esler and Wolfe, 2001).

Das dabei entstehende extrazelluläre Produkt (sAPPa, secreted amyloid precursor protein $\alpha$ ) wirkt neuroprotektiv und stimulierend auf die Synaptogenese und das Neuritenwachstum (Haass and Selkoe, 2007; Rose, Peoc'h et al., 2012; Young-Pearse, Chen et al., 2008)

Anschließend spaltet der $\mathrm{Y}$-Sekretase Komplex das zuvor entstandene C-terminale Fragment C83 in die APP intrazelluläre Domäne (AICD; APP intracellular domain) und in das p3Peptid. Die Funktion der intrazellulären Domäne des APP wird kontrovers diskutiert. Es gibt Hinweise, dass die AICD neurotoxisch wirkt. Zudem wird die Eigenschaft als Transkriptionsfaktor diskutiert (Muller, Pietrzik et al., 2012; Pardossi-Piquard and Checler, 2012).

Unter physiologischen Bedingungen wird APP vorwiegend über diesen Weg prozessiert.

Die amyloidogene Spaltung des APP erfolgt über die $\beta$ - und $\gamma$ - Sekretase und führt zur Produktion von $A \beta$ mit vorwiegender Bildung von 40 bzw. 42 Aminosäuren langen Peptiden $\left(A \beta_{40}\right.$ und $\left.A \beta_{42}\right)$. Bei der $\beta$-Sekretase $(\beta$-site APP cleaving enzyme $1, B A C E-1)$ handelt es sich um eine Aspartylprotease, die das APP im extrazellulär liegenden Bereich spaltet. Durch die Spaltung entsteht das lösliche SAPP $\beta$ und ein C-terminales Fragment, bestehend aus 99 Aminosäuren (C99) (Jarrett, Berger et al., 1993).

Im darauffolgenden Schritt spaltet die $\mathrm{Y}$-Sekretase innerhalb der Transmembrandomäne, wodurch je nach Schnittstelle unterschiedlich lange $A \beta$-Peptide entstehen $\left(A \beta_{38}\right.$ bis $\left.A \beta_{43}\right)$ (Citron, Diehl et al., 1996; Qi-Takahara, Morishima-Kawashima et al., 2005; Takami, Nagashima et al., 2009). Die Y-Sekretase beinhaltet als Enzymkomplex verschiedene Untereinheiten. Hierzu zählen das Presenilin 1 (PSN1) oder 2 (PSN2), Nicastrin, Presenilinenhancer 2- (PEN 2) sowie APH-1 (Francis, McGrath et al., 2002; Smolarkiewicz, Skrzypczak et al., 2013). 


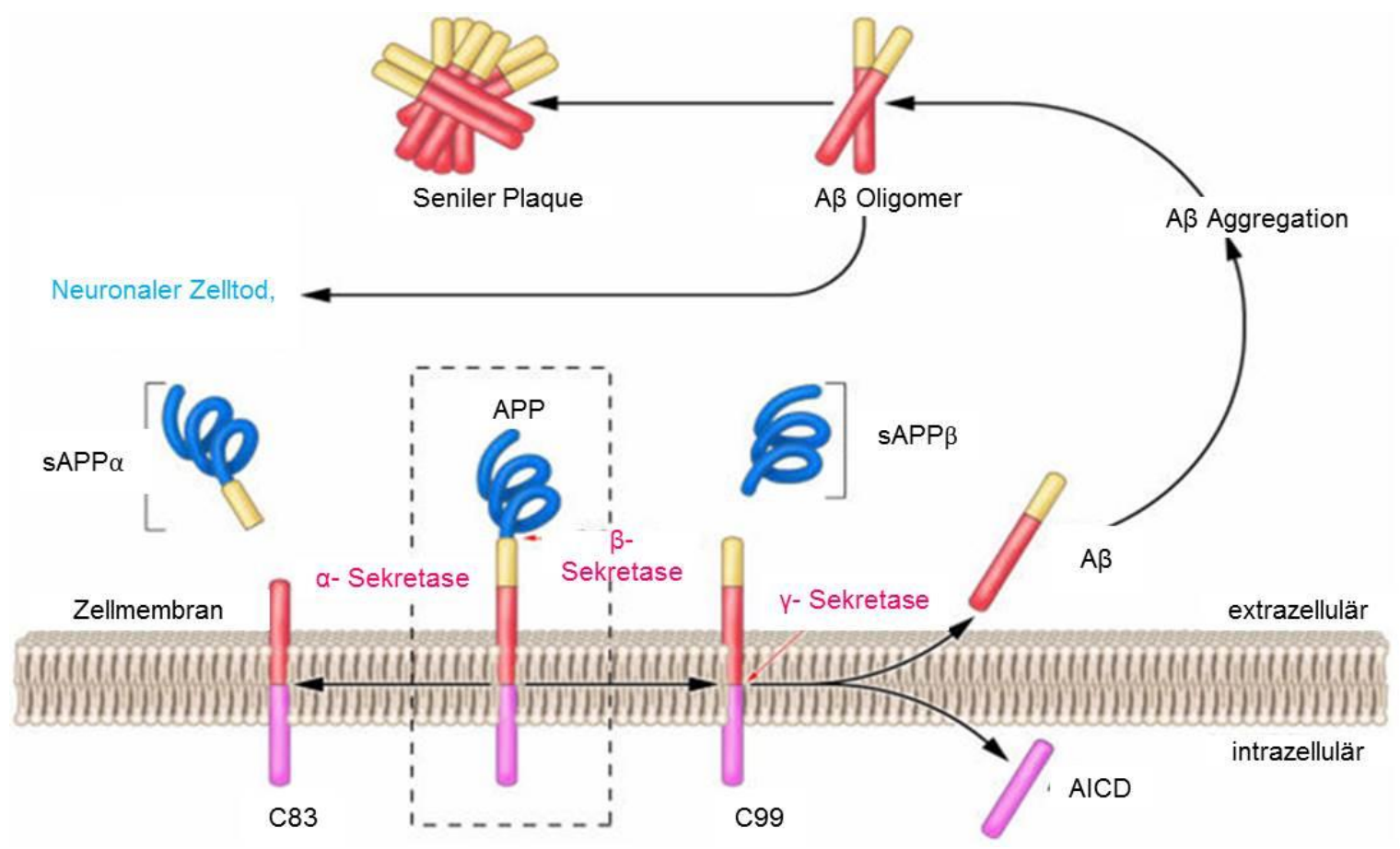

Abb. 2: Schematische Darstellung der APP-Prozessierung und A $\beta$-Akkumulierung.

Abgebildet sind die beiden möglichen Prozessierungswege des APP mittels $\alpha$ - und $\gamma$-Sekretase mit Entstehung des sAPPa und des C83 sowie über $\beta$ - und $\gamma$ - Sekretase mit Bildung des sAPP $\beta$ und C99. Das A $\beta$-Peptid aggregiert zu neurotoxisch wirkenden Oligomeren und schließlich zu senilen Plaques. [Abb. modifiziert nach (Gandy, 2005), Seite 1122]

\subsubsection{Zytotoxizität des Amyloid- $\beta$}

Aggregierte zytotoxische Peptide stellen ein typisches Merkmal vieler neurodegenerativer Erkrankungen dar (Jucker and Walker, 2013). Das mittels $\beta$ - und $y$-Sekretasen entstehende $A \beta_{42}$ weist ein deutlich aggregierendes Verhalten auf und bedingt den Großteil der Amyloidplaques (Glenner and Wong, 1984; Hardy, 1997; Zimmermann, Gardoni et al., 2005). In diversen Studien wurde der zytotoxische Effekt des $A \beta$ mit dem Auftreten von oxidativem Stress, Entzündungsreaktionen, synaptischen und mitochondiralen Dysfunktionen sowie dem Interagieren mit Rezeptoren (NMDA, AMPA, cholinerge Rezeptoren) und Membranen beschrieben (Butterfield, Reed et al., 2007; Canevari, Clark et al., 1999; Lin, Bhatia et al., 2001; Rosales-Corral, Tan et al., 2004; Salminen, Ojala et al., 2008).

Die Zytotoxizität geht bei der Alzheimer-Erkrankung nicht von den Plaques, sondern von den oligomeren Vorstufen aus (Benilova, Karran et al., 2012), wobei bis heute nicht abschließend geklärt ist, welche dieser Oligomere/Protofibrillen toxisch sind. 
Den Monomeren konnte keine Neurotoxizität, hingegen jedoch neuroprotektive Charackteristika nachgwiesen werden (Giuffrida, Caraci et al., 2009; Shankar, Li et al., 2008; Zou, Gong et al., 2002). Im Mausmodell zeigte sich eine Beeinträchtigung der synaptischen Plastizität im Bereich des Hippocampus durch Dimere (Shankar, Li et al., 2008). Insbesondere die löslichen Oligomere begründen jedoch die Toxizität des $A \beta$ (Lesne, Koh et al., 2006; McLean, Cherny et al., 1999; Walsh and Selkoe, 2007). In experimentellen Studien zeigte sich zudem, dass die Neurotoxizität konzentrationsabhängig ist (Selkoe, 2008).

Der Verlust der kognitiven Fähigkeiten korreliert nur wenig mit der Menge der amyloidogenen Plaque-Last (Duyckaerts, Delatour et al., 2009; Nelson, Alafuzoff et al., 2012; Thal, CapetilloZarate et al., 2006; Thal, Rub et al., 2002).

\subsubsection{Tau-Protein}

Das Mikrotubulus-assoziierte Protein Tau hat eine Größe von 352-757 Aminosäuren (AS) und moduliert die Stabilität von Mikrotubuli und darüber den axonalen Transport (Goedert, Klug et al., 2006; Mandelkow, von Bergen et al., 2007; Weingarten, Lockwood et al., 1975). Tau wird durch das MAPT Gen, welches sich auf dem Chromosom 17q21 befindet, kodiert. Durch alternatives Splicen der Exone 2, 3 und 10 entstehen 6 unterschiedliche Isoformen, die sich Isoform-abhängig zu pathologischen Aggregaten zusammen lagern können (Neve, Harris et al., 1986). Eine Verschiebung im Verhältnis der verschiedenen Isoformen wurde bei einer Reihe von neurodegenerativen Erkrankugen mit Tau-Pathologie beschrieben (z.B. der progressiven supranukleären Blickparese, der kortikobasalen Degeneration). Weiterhin wurden bei der FTDP-17 Mutationen beschrieben, die zu einer Dysbalance zwischen 3 und 4 Repeat haltigen Isoformen führen (Hong, Zhukareva et al., 1998).

Bei der Alzheimer-Erkrankung wird Tau möglicherweise infolge der $A \beta$-Toxizität in das somatodendritsche Kompartiment fehlsortiert und aggregiert. Die neurofibrillären Bündel der Alzheimererkrankung bestehen vorwiegend aus hyperphosphoryliertem Tau-Protein. Die intrazelluläre Aggregation von Tau ist neurotoxisch. Aus einer verminderten Stabilisierung der Mikrotubuli resultiert möglicherweise die Beeinträchtigung des anterograden axonalen Transports (Mandelkow and Mandelkow, 2012). 


\subsubsection{Diagnostik}

Bis zum heutigen Zeitpunkt handelt es sich bei der Erkrankung M. Alzheimer um eine Ausschlussdiagnose, die erst Post mortem bei der Obduktion des Gehirns sicher diagnostiziert werden kann. Die klinische Diagnostik umfasst eine neuropsychologische Testung, eine zerebrale Bildgebung (cCT, cMRT, ggf. PET-CT), eine ausführliche Blutuntersuchung zum Ausschluss anderer Ursachen sowie die Analyse entnommener Zerebrospinalflüssigkeit (CSF). Die aktuellen Diagnosekriterien richten sich nach dem National Institute on Aging \& the Alzheimer's Association workgroup (NIA-AA), bei denen die Wahrscheinlichkeit einer Alzheimer Demenz anhand des klinischen Verlaufs mit zunehmender kognitiver Verschlechterung, des Vorhandenseins einer kausativen genetischen Mutation, eines positiven Liquorbefundes und einer Bildgebung abgeschätzt werden (McKhann, Knopman et al., 2011).

\subsubsection{Therapeutische Maßnahmen}

Zugelassen zur symptomatischen Therapie ist die Gabe von Acetylcholinesterase Inhibitoren (AchE-Inhibitoren) bei leichter bis mittelschwerer Demenz sowie die Verordnung von N-Methyl-D-Aspartat-Rezeptor-Antagonisten (NMDA-Rezeptor-Antagonisten) bei mittelschwerer und schwerer Demenz.

Acetylcholinesterase Inhibitoren verzögern den Abbau des Acetylcholins im synaptischen Spalt. Dadurch wird die Konzentration des Acetylcholins am Rezeptor erhöht und ihre Wirkung verlängert, wodurch das durch Neurodegeneration, v.a. im Nucleus Basalis Meynert, entstandene cholinerge Defizit kompensiert werden soll (Lahiri, Farlow et al., 1997). Die Überstimulierung der NMDA-Rezeptoren spielt eine entscheidende Rolle bei neurodegenerativen Erkrankungen. NMDA-Rezeptor-Antagonisten verhindern die dauerhafte Aktivierung der Nervenzelle durch Glutamat, vermindern den Calciumeinstrom und greifen so stabilisierend und verzögernd in den Abbauprozess ein (Danysz, Parsons et al., 2000; Rogawski and Wenk, 2003). Die medikamentöse Therapie mit AChE- Inhibitoren führt optimalerweise zu einer Stabilisierung der kognitiven Fähigkeiten für bis zu 6 Monate, die Therapie mit Memantinen zur Stabilisierung der Alltagsfunktion (AlexanderBenson et al., 2013; Tan, Yu et al., 2014).

Nicht-pharmakologische Ansätze sind insbesondere der Einsatz von Ergo- und Physiotherapie, die Behandlung der kardiovaskulären Erkrankungen sowie der Therapie 
einer häufig begleitenden Depression. Ziel ist ein möglichst langer Erhalt der Eigenständigkeit und die Verbesserung der Lebensqualität (Froelich, 2010).

Experimentelle Therapieansätze fokussieren sich v.a. auf das $A \beta$ als zentralen Angriffspunkt, da die Erkrankung mit der Amyloid-Pathologie zu beginnen scheint (Bateman, Xiong et al., 2012; Jack and Holtzman, 2013). Bei den passiven Immunisierungen werden zumeist humanisierte monoklonale Antikörper oder Immunglobuline eingesetzt. In Tierexperimenten führten aktive und passive Immunisierungen zu einer verringerten Ausprägung der neuritischen Plaques mit teilweise verbesserter kognitiver Leistungsfähigkeit. 1999 erfolgte erstmals eine aktive Immunisierung in einem transgenen Mausmodell (Schenk, Barbour et al., 1999). Erste klinische Studien mit aktiver Immunisierung wurden aufgrund schwerwiegender unerwünschter Ereignisse, wie etwa Meningoenzephalitiden (Delrieu, Ousset et al., 2012a; Delrieu, Ousset et al., 2012b) abgebrochen. Klinische Studien mit humanisierten monoklonalen Antikörpern wurden aufgrund fehlender Wirksamkeit ebenfalls beendet. Bei Bapineuzumab und Solenezumab handelt es sich um humanisierte monoklonale Antikörper, die lösliches $A \beta$ und teilweise auch die aggregierte Form des $A \beta$ (Bapineuzuma) erkennen können. Die im Mausmodell gezeigte Verbesserung der Gedächtnisfunktion konnte in Phase III Studien nicht gezeigt werden. Mögliche Erklärungen sind eine zu spät begonnene Therapie und die Unzureichenheit $A \beta$ als alleinige Zielsubstanz zu verwenden (Doody, Thomas et al., 2014; Salloway, Sperling et al., 2014).

\subsection{Aggregationsinhibitoren}

Gegenstand aktueller Forschungen ist die Suche nach Wirkstoffen zur Therapie des M. Alzheimer durch Inhibierung der toxischen Aggregation von A $\beta$ (Bieschke, 2013). Verschiedene Farbstoffe wurden untersucht. Der erste beschriebene Wirkstoff, Kongorot (Azofarbstoff), hemmte in hohen Dosierungen in vitro die Amyloidformation, wirkte in den benötigten Konzentrationen jedoch toxisch (Feng, Toyama et al., 2008). Weitere Hemmstoffe wie Thioflavin $T$ und Methylenblau (Phenothiazin) folgten (Alavez, Vantipalli et al., 2011; Bieschke, 2013; McGovern, Caselli et al., 2002; Necula, Kayed et al., 2007; Wischik, Edwards et al., 1996). Bei den Antioxidantien handelt es sich vor allem um polyzyklische Polyphenole wie Curcumin, Resveratrol, Dopamin und Catechin (Ladiwala, Lin et al., 2010; Mazzulli, Mishizen et al., 2006).

Epi-Gallocatechine-3-Gallat (EGCG) hemmt die A $\beta$ - und $\alpha$-Synuclein-Aggregation duch Bindung und Stabilisierung des nativen ungefalteten Proteins ( $\alpha$-Synuclein) bzw. durch Förderung der Bildung von unstrukturierten, nicht toxischen Oligomeren (Bieschke, Russ et al., 2010). 
ECGC kann darüber hinaus bereits geformte Amyloid Fibrillen aus $A \beta$ und $\alpha$-Synuclein in kleinere, nicht-toxische amorphe Proteinaggregate umwandeln (Bieschke, Russ et al., 2010). ECGC inhibiert zudem die Aggregation von Huntingtin (Ehrnhoefer, Duennwald et al., 2006), Transthyretin (Ferreira, Cardoso et al., 2009), Lysozym (He, Xing et al., 2009) und PrionProtein-Sc (Rambold, Miesbauer et al., 2008). Bei EGCG handelt es sich nicht um einen reinen Aggregationsinhibitor. EGCG wirkt zudem als Antioxidans (Mandel, Amit et al., 2008) und erhöht die Spaltung des APP in nicht-amyloidogene-Peptide, indem es die aSekretaseaktivität erhöht (Fernandez, Rezai-Zadeh et al., 2010). Problematisch ist die geringe Blut-Hirn-Schranken-Penetration (10-20\%) von EGCG (Mereles and Hunstein, 2011; Singh, Shankar et al., 2011; Singh, Arseneault et al., 2008).

\subsection{Oligomermodulatoren}

In den Experimenten wurden verschiedene Modulatoren verwendet (Wagner, Ryazanov et al., 2013).

Diese waren im Rahmen eines Screens bezüglich einer aggregationshemmenden Wirkung bei Prion-Proteinen identifiziert worden (Abb. 3, Seite 10). Hierbei hatte sich die Schiff-Base N-Benzylidene-Benzohydrazaide (NBB) als Leitstruktur herauskristallisiert. Aufgrund des schnellen Metabolismus in vivo waren weitere Modifizierungen erfolgt. Es waren 150 DPP Derivate synthetisiert worden, deren Wirksamkeit mittels SIFT und in der Zellkultur im antiprion-assay getestet wurde. Die 38 wirksamsten Wirkstoffe waren anschließend in vivo im Mausmodell getestet worden.

Dabei hatte anle138b die stärkste Aktivität gegen das Aggregationsverhalten im Prion- und im a-Synuclein Modell gezeigt. 




Abb. 3: Zusammenfassende Darstellung der experimentellen Strategie zur Identifizierung potentieller Aggregationsinhibitoren.

[Abb. modifiziert nach (Wagner, Ryazanov et al. 2013), Seite 797]

Anle138b hatte dabei eine strukturabhängige Bindung zu den Aggreaten aufgewiesen und die Oligomerbildung in vivo und in vitro für das Prion-Protein Scrapie $\left(\mathrm{PrP}^{\mathrm{Sc}}\right)$ sowie für das a-Synuclein gehemmt. Darüber hinaus war eine verminderte neuronale Degeneration, ein verlängertes Überleben, eine Reduzierung motorischer Defizite, ein annähernd normales Körpergewicht sowie eine verzögerte Erkrankungsprogression festgestellt worden. Die orale Verabreichung der Wirkstoffe hatte mit 50\% area under the curve (AUC) eine hohe orale Bioverfügbarkeit aufgewiesen, die mit einer intraperitonealen Applikation vergleichbar war. Es war auch bei Langzeitbehandlungen ( $>1$ Jahr) keine Toxizität von anle138b in therapeutischen Dosen gefunden worden. Die Gabe höherer Dosierungen hatte bei proportional steigenden zentralen und peripheren Konzentrationen keine Sättigung der Clearance ergeben. Hierbei waren zentral höhere Konzentrationen als peripher erreicht worden, was Hinweise auf eine gute Blut-Hirn-Schranken Penetration ergeben hat. In den Gehirnextrakten, unter Zuhilfenahme von Hochleistungsflüssigkeitschromatographie (HPLC) und der Massenspektroskopie, waren keine Metabolite des anle138b detektiert worden.

Hieraus hatte sich ergeben, dass es sich bei anle138b um den aktiven Modulator gehandelt hat. In der Studie war gezeigt worden, dass die Prion-Protein- $\left(\operatorname{PrP}^{C}\right)$ und die $\alpha$-Synuclein 
Expression durch anle138b unbeeinträchtigt waren. Hieraus resultiert, dass anle138b direkt in den toxischen pathway von $\operatorname{PrP}^{C}$ und $\alpha$-Synuclein eingegriffen und deren Neurotoxizität reduziert hatte. Dabei hatte anle138b direkt die Amplifizierung des $\operatorname{PrP}^{\mathrm{Sc}}$ geblockt. In der Sucrose-Gradienten-Zentrifugation war eine Reduktion hochmolekularer Substanzen mit einer Verschiebung des Gradienten in Richtung niedermolekularer Oligomere erkennbar.

Physiologische Fibrillenbildung wie z.B. von Aktin war durch anle138b nicht beeinflusst worden. Insgesamt hatte sich anle138b auch nach Auftreten erster klinischer Symptome (z.B. motorische Defizite) noch als effektiv erwiesen. Dabei war der Wirkstoff 0, 80 und 120 Tage nach der Infektion verabreicht worden. Klinisch hatte sich ein verlängertes Überleben sowie ein stabilerer Körpergewichtsverlauf gezeigt. Immunhistochemisch und im Dotblot war eine verminderte $\mathrm{PrP}^{\mathrm{Sc}}$ Akkumulierung, histologisch eine Reduktion des neuronalen Zelltodes erkennbar.

Die Effektivität des Wirkstoffs bei fortgeschrittener Erkrankung erweist sich als nützlich, da bei Diagnosestellung klinische Symptome zumeist schon vorhanden sind. Bisher existieren keine Daten zur Wirksamkeit der Wirkstoffe auf $A \beta$. Aufgrund der Effekte auf $\alpha$-Synculcein und auf PrP wird jedoch eine Wirksamkeit vermutet.

\subsection{Drosophila melanogaster als Tiermodell für neurodegenerative Erkrankungen}

Für die Experimente wurde das Tiermodell Drosophila melanogaster verwendet, welches 1830 erstmalig von Johann Wilhelm Meigen, einem deutschen Entomologen, beschrieben wurde und weltweit zu den am besten erforschsten Tiermodellen zählt. Mit zunehmender Kenntnis über die Anatomie und Physiologie sowie der Sequenzierung des Genoms (AdamsCelniker et al., 2000) wurde sie zum Versuchstier der klassischen Genetik.

Eine Vielzahl von Genen und Signaltransduktionskaskaden stimmen zwischen dem Menschen und der Taufliege überein (Yoshihara, Ensminger et al., 2001), sodass sich neue Dimensionen zur Erforschung grundlegender Mechanismen von neurodegenerativer Erkrankungen zeigten. Das ganze Genom mit mehr als 14000 Genen ist bei Drosophila melanogaster auf vier Chromosomenpaaren organisiert, von denen der Großteil auf 3 Chromosomen lokalisiert ist. Fast 75\% der krankheitsrelevanten Gene im Menschen haben funktionelle Orthologe in Drosophila melanogaster (Lloyd and Taylor, 2010; Reiter, Potocki et al., 2001). In vielen Bereichen der Zellbiologie wie z.B der Genexpression, neuronaler Plastizität, Zelltod und dem Membrantransport zeigen sich Ähnlichkeiten zwischen Drosophila melanogaster und dem Menschen (Sang and Jackson, 2005). 
Die adulte Fliege enthält zahlreiche Strukturen, die menschlichen Organen (Herz, Lunge, Niere, Gastrointestinaltrakt und Reproduktionsorgane) ähneln. Das Nervensystem umfasst mehr als 100.000 Neurone, die komplexe Funktionen wie z.B Lernen und Gedächtnis, zirkadiane Rhythmik und Verhalten steuern (Greenspan, 2004). Die Blut-Hirn-Schranke wird durch subperineurinale Glia, einer Untergruppe Oberflächen assoziierter Gliazellen gebildet und schützt darüber das Nervensystem vor der kaliumreichen Hämolymphe (Schwabe, Bainton et al., 2005). Die Durchlässigkeit der Blut-Hirn-Schranke ähnelt der des Menschen (Stork, Engelen et al., 2008), wodurch die Effekte von ZNS-wirksamen-Medikamenten auf Drosophila melanogaster erklärbar sind. In Drosophila melanogster finden sich gleiche Neurotransmitter-Systeme (Acetylcholin, GABA, Dopamin, Glutamat) wie im menschlichen Genom (Greenspan, 2004).

Verschiedene Substanzen, die an die dopaminergen, nikotinergen und glutaergen Rezeptoren ansetzen, bewirkten nach Applikation die erwarteten Verhaltensänderungen und Symptome (Andretic, Kim et al., 2008; Bainton, Tsai et al., 2000; McClung and Hirsh, 1998; Nichols, Ronesi et al., 2002; Rothenfluh and Heberlein, 2002; Wolf and Heberlein, 2003).

Zahlreiche Drosophilamodelle mit Ausbildung eines deutlichen Phänotyps stehen zur Analyse komplexer Prozesse des ZNS zur Verfügung. Ein weiterer entscheidender Vorteil besteht in der hohen Nachkommenzahl bei nur geringem Kostenaufwand und gleichzeitiger kurzer temperaturabhängiger Generationsfolge.

\subsubsection{Alzheimer-Modelle im transgenen Fliegenmodell}

Ursächlich für eine Vielzahl neurodegenerativer Erkrankungen wie M. Alzheimer, Tauopathien und M. Parkinson sind fehlgefaltete aggregierende Proteine (Soto, 2003). Das homologe Drosophila-Gen des humanen APP, Drosophila-amyloid-precursor-like protein (dAPPL), enthält keine $A \beta$-Domäne und spaltet das humane APP nicht am N-Terminus, sondern am C-Terminus (Luo, Tully et al., 1992).

Die Komponenten des humanen y-Sekretase-Komplexes (siehe Abb.4, Seite 14) finden sich vollständig im Genom von Drosophila melanogaster (Periz and Fortini, 2004; Takasugi, Tomita et al., 2003). In dreifach (APP, BACE und Presenilin) transgen veränderten Fliegen konnte die amyloidogene Prozessierung des humanen APPs nachgewiesen werden und war von altersabhängiger Neurodegeneration und verringerter Lebensspanne gekennzeichnet (Greeve, Kretzschmar et al., 2004). Die klinische Symptomatik der $A \beta_{40}$ und $A \beta_{42}$ Produktion in den Gehirnen der Drosophila melanogster äußerte sich in einer verminderten Synapsenplastizität, Kurzzeitgedächtnisstörungen, motorischen Defiziten und in einer verkürzten Lebensspanne (lijima, Liu et al., 2004; Yagi, Tomita et al., 2000). 
Bei den in der vorliegenden Arbeit verwendeten Modellen war das $A \beta_{1-42}$-Peptid an ein Sekretionssignal gekoppelt, was eine Freisetzung des Peptids in den Extrazellulärraum gewährleistete (Crowther, Kinghorn et al., 2005). Immunhistochemisch konnte im Verlauf eine extra- und intrazelluläre $A \beta$-Akkumulierung, allerdings ohne Fibrillenbildung, nachgewiesen werden. Histologisch zeigte sich außerdem eine gendosisabhängige Ausbildung eines Augenphänotyps mit ausgeprägter Vakuolenbildung, Atrophie der Photorezeptorzellen und rauer Augenoberfläche. Klinisch imponierten zudem eine verkürzte Lebensdauer sowie eine verminderte lokomotorische Aktivität. Dabei zeigten Linien mit $A \beta_{1}$. 40-Expression eine deutlich verminderte Tendenz zur Aggregation mit nur geringer Symptomausprägung im Vergleich zu Linien mit $A \beta_{1-42}$-Expression.

Im Verhältnis zu Linien mit einfach inseriertem $A \beta_{1-42}$ waren Linien mit doppelt inseriertem $A \beta_{1-42}$ deutlich schwerer von der klinischen Symptomatik mit motorischer Dysfunktion und vermindertem Überleben betroffen (Crowther, Kinghorn et al., 2005).

Die zudem generierte arctic mutante AßGlu22Gly zeichnet sich durch eine deutlich aggressivere Verlaufsform der klinischen Symptomatik mit frühzeitigem Beginn aus (Crowther, Kinghorn et al., 2005). 


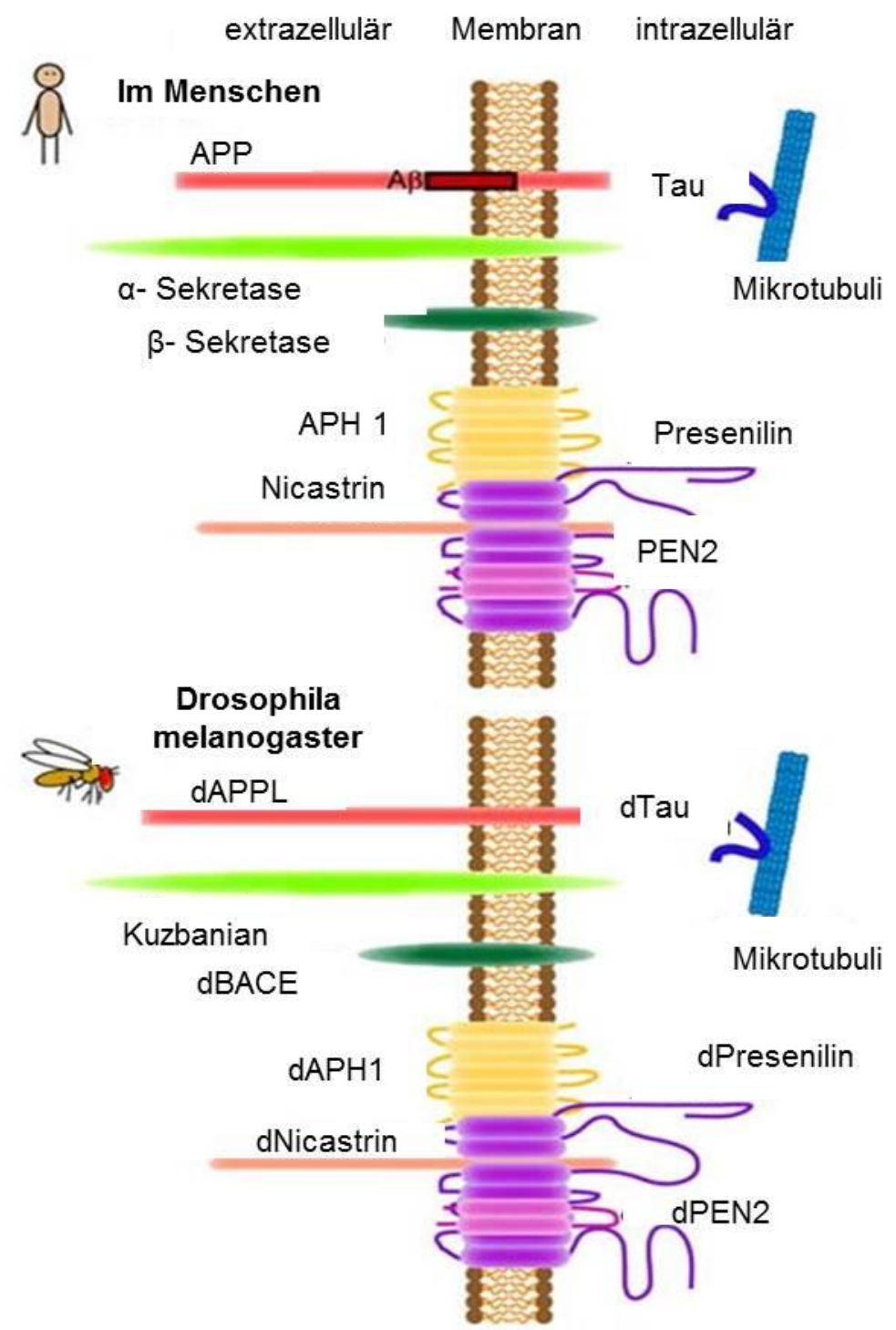

Abb. 4: Schematische Darstellung der beteiligten Komponenten bei der Alzheimer-Erkrankung am Beispiel des Menschen und Drosophila melanogaster.

[Abb. modifiziert nach (lijima, Liu et al. 2004), Seite 24] 


\subsection{Ziel der Arbeit}

Aufgrund der weltweiten demographischen Entwicklung mit insbesondere in den Industrieländern zunehmend steigendem Lebensalter und der damit verbundenen steigenden Anzahl neurodegenerativer Erkrankungen besteht eine Notwendigkeit zur Entwicklung neurer Therapiekonzepte zur Behandlung der Demenzerkrankungen.

Im Mittelpunkt steht hierbei das bessere Verständnis der Alzheimer-Erkrankung, welche prozentual die häufigste Ursache neurodegenerativer Erkrankungen im höheren Lebensalter darstellt. Ein möglicher Therapieansatz ist die Inhibierung toxischer Amyloid- $\beta$-Aggregate, die gemäß der Amyloid-Hypothese eine kausale Rolle bei der Entstehung der neuronalen Dysfunktion und Neurodegeneration im Rahmen der Alzheimer-Krankheit einnehmen.

Ziel dieser Arbeit ist die Untersuchung der Wirksamkeit verschiedener synthetischer Diphenyl-Pyrazol Derivate in transgenen Alzheimerfliegenmodellen auf das zentrale und periphere Nervensystem in vivo. Die beschriebenen Wirkstoffe zeigten in vitro eine Reduktion der Aggregation von $\alpha$-Synuclein und Prionproteinen bei unveränderter Expression auf Proteinebene. Der genaue Mechanismus ist jedoch noch nicht abschließend geklärt. Ebenso war nicht bekannt, ob die Substanzen auch die Aggregation von Tau oder $A \beta$ beeinflussen und welche dieser Substanzen die höchste Effektivität in vivo haben.

Zur Testung einer möglichen Wirkung in vivo wurden die Wirkstoffe in transgenen Alzheimerfliegenmodellen untersucht. Vorteile gegenüber einer Testung im Mausmodell sind kurze Generationszeiten, eine kostengünstige Aufzucht sowie eine geringere Arbeitsintensivität. Ziel war die Identifizierung der wirksamsten Substanzen, um deren Wirksamkeit anschliessend im Mausmodell zu testen. Idealerweise sollten diese anschließend in die (prä)klinische Testung gebracht werden. 


\section{Material und Methoden}

\subsection{Material}

\subsubsection{Chemikalien und Verbrauchsgüter}

\subsubsection{Chemikalien}

Guanidinhydrochlorid $(\mathrm{GnHCl})\left(\mathrm{CH}_{5} \mathrm{~N}_{3} \cdot \mathrm{HCl}\right)$

Hepes $\left(\mathrm{C}_{8} \mathrm{H}_{18} \mathrm{~N}_{2} \mathrm{O}_{4} \mathrm{~S}\right)$

Protease inhibitor cocktail

Ethylendiamintetraessigsäure $\left[\mathrm{C}_{10} \mathrm{H}_{16} \mathrm{~N}_{2} \mathrm{O}_{8}\right]$

Saccharose $\left[\mathrm{C}_{12} \mathrm{H}_{22} \mathrm{O}_{11}\right]$

Tris base $\left[\mathrm{C}_{4} \mathrm{H}_{11} \mathrm{NO}_{3}\right]$

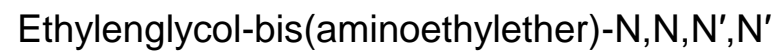

-tetraessigsäure (EGTA), $\left[\mathrm{C}_{14} \mathrm{H}_{24} \mathrm{~N}_{2} \mathrm{O}_{10}\right]$

Diethanolamin, (DEA) $\left[\mathrm{C}_{4} \mathrm{H}_{11} \mathrm{NO}_{29}\right]$

Natriumcholridlösung [ $\mathrm{NaCl}]$

Ameisensäure Lösung $\left[\mathrm{CH}_{2} \mathrm{O}_{2}\right]$

Dinatriumhydrogenphosphat $\left[\mathrm{Na}_{2} \mathrm{HPO}_{4}\right]$

Natriumacid [ $\left.\mathrm{NaN}_{3}\right]$

Dimethylsulfoxid $\left[\mathrm{C}_{2} \mathrm{H}_{6} \mathrm{OS}\right]$

Flüssigstickstoff $\left[\mathrm{LN}_{2}\right]$

\subsection{Puffer und Lösungen}

GnHCl-Extraktionspuffer

Gewebehomogenisierungspuffer

Diethylacetat-Puffer
Carl Roth $\circledast \mathrm{GmbH}$, Karlsruhe

AppliChem ${ }^{\circledR} \mathrm{GmbH}$, Darmstadt

Sigma-Aldrich ${ }^{\circledR}$ Corporation, St-Louis

AppliChem®, Darmstadt

Merck KGaA, Darmstadt

Sigma-Aldrich ${ }^{\circledR}$ Corporation, St. Louis

AppliChem ${ }^{\circledR} \mathrm{GmbH}$, Darmstadt

AppliChem®, Darmstadt

AppliChem®, Darmstadt

AppliChem®, Darmstadt

Carl Roth $\circledast \mathrm{GmbH}$, Karlsruhe

Carl Roth ${ } \mathrm{GmbH}$, Karlsruhe

AppliChem®, Darmstadt

AIR LIQUIDE®, Düsseldorf

M Guanidinium $\mathrm{HCl}, 50 \mathrm{mM}$ Hepes

pH 7.3, protease inhibitor cocktail

(Sigma, P8340), 5 mM EDTA

(250 mM Saccharose, $20 \mathrm{mM}$ Tris base, 1 mM EDTA, 1 mM EGTA, protease inhibitor cocktail (Sigma))

$0.4 \% \mathrm{DEA}, 100 \mathrm{mM} \mathrm{NaCl}$ and protease inhibitor cocktail 
Ameisensäure-Neutralisationpuffer

$1 \mathrm{M}$ Tris base, $0.5 \mathrm{M} \mathrm{Na}_{2} \mathrm{HPO}_{4}$,

$0.05 \% \mathrm{NaN}_{3}$

Nachfolgende, verwendete Wirkstoffe wurden im Max-Planck-Institut für biophysikalische Chemie in Göttingen synthetisiert.

3-(1,3-Benzodioxol-5-yl)-5-(3-bromophenyl)-1H-pyrazole anle138b

3-(3-Bromophenyl)-5-(3, 4-dihydroxyphenyl)-1H-pyrazole anle138c

3-(3 5-Dibromophenyl)-5-(3, 4, 5-trihydroxyphenyl)-1H-pyrazole hydrobromide anle145c

3-(3-Bromophenyl)-5-[4-(dimethylamino) phenyl]-1 H-pyrazole anle253b

5-(3,4-Dihydroxyphenyl)-3-(4-hydroxyphenyl) isoxazole sery 85

3-(3,4-Dihydroxyphenyl)-5-(3-fluorophenyl)-1 H-pyrazole sery 118

3-(1,3-Benzodioxol-5-yl)-5-(3-chlorophenyl)-1H-pyrazole sery313b

3-(1,3-benzodioxol-5-yl)-5-(3-bromophenyl)-1-methyl-1H-pyrazole sery335b

3-(1,3-Benzodioxol-5-yl)-5-(3-hydroxyphenyl)-1H-pyrazole sery392b

\subsubsection{Verbrauchsgüter}

Latexfreie Handschuhe

Pipettenspitzen $(1000 \mu \mathrm{l}, 200 \mu \mathrm{l}, 10 \mu \mathrm{l})$

Polypropylene Conical Tube $50 \mathrm{ml}$

Eppendorfer Tubes® $1,5 \mathrm{ml}$

Cellstar Tubes $15 \mathrm{ml}$

Plexiglasgefässe mit

Standardnährmedium und Stopfen

Bäckerhefe
Hartmann AG, Heidenheim

Starlab® GmbH, Hamburg

Becton Dickinson $\AA \mathrm{GmbH}$, Heidelberg

Eppendorf AG, Hamburg

Greiner Bio-One®GmbH, Frickenhausen

Max-Planck-Institut für biophysikalische

Chemie, Göttingen

kommerzielle Bäckerhefe

\subsubsection{Geräte}

Stereomikroskop W10x120

Fluoreszenzmikroskop PI 10x123 Discovery V8

Heraeus Multifuge X1R

Ultrazentrifuge Optima TM MAX-XP

Precellys 24

Reagenzglasschüttler, Vortex Genie2
Motic, Wetzlar

Carl Zeiss $\mathrm{GmbH}{ }^{\circledR}$, Jena

Thermo Fisher Scientific Massachusetts

Beckman Coulter, Krefeld

Bertin Technologies, peqlab

Biotechnologie $\mathrm{GmbH} \circledast$

Scientific industries, New York 
HI 2211 pH/ORP Meter

Messwaage (Kern FTB und Kern AEJ)

Pipetten (Eppendorf Research plus)

Comfort freezer

Ultraschallbad

Thermostatschrank

$\mathrm{CO}_{2}$ Betäubungsplatte

Wasserbad

Thermocycler Trio
Hanna instruments $\mathrm{GmbH}$, Kehl am Rhein Kern\&Sohn GmbH, Balingen

Eppendorf AG, Hamburg

Liebherr International AG, Bulle

Sonorex super; Bandelin $\mathrm{GmbH}$, Berlin

Aqualytic $\circledast \mathrm{GmbH}$, Dortmund

Sonderanfertigung Gunther Tietsch

Gesellschaft für Labortechnik $\AA G m b H$,

Burgwedel

Biometra® $\mathrm{GmbH}$, Göttingen

\subsubsection{Fliegenlinien}

\subsubsection{Gal4-Treiberlinien}

$w\left[{ }^{1118}\right] ; P\{w[+m C]=G A L 4-e l a v \cdot L\} 2 / C y O$

BL 8765

$w\left[{ }^{1118}\right] ; P\{w[+m C]=t u b P-G A L 80[T S][t s]\} 2 / T M 2$

BL 7017

$w\left[{ }^{1118}\right] ; P\{r y[+t 7.2]=n e o F R T\} 42 D P\{w[+m C]=M a e-G M R . E P\} h b s[E P] / C y O$

BL 27617

$w\left[{ }^{1118}\right] ; P\{w[+m W \cdot h s]=G a w B\} e l a v[C 155]$

BL 458

\subsubsection{UAS-spezifische Drosophila-Linien}

Nachfolgende Linien (a-d) wurden von D. Crowther zur Verfügung gestellt (Crowther, Kinghorn et al., 2005): Die Herstellung der Linien (a-c) erfolgte durch Einbringen des $A \beta_{1-42}$-Peptids (DAEFRHDSGYEVHHQKLVFFAEDVGSNKGAIIGLMVGGVVIA) in den Gal4pUAS Expressionsvektor.

\subsection{A $A$-Linien}

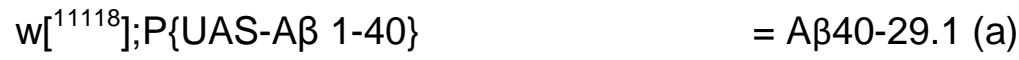

$$
\begin{aligned}
& \mathrm{W}\left[{ }^{11118]} ; \mathrm{P}\{\mathrm{U} A \mathrm{~S}-\mathrm{A} \beta \mathrm{1} \text { 1-42 }\} \quad=A \beta 42 \text {-alz3 }(\mathrm{b})\right. \\
& w\left[{ }^{11118}\right] ; P\{U A S-A \beta 1-42\} ; P\{U A S A \beta 1-42\}=\operatorname{alz3;alz8~(c)~} \\
& w\left[{ }^{11118}\right] ; \text { P }\{\text { UAS-Arctic A } 1 \text { 1-42 (Glu22Gly) }\}=\operatorname{arc2e}(d)
\end{aligned}
$$


Die nachfolgende Linie (e) wurde von M.Konsolaki zur Verfügung gestellt. Die Herstellung erfolgte durch Einfügen der $A \beta_{42}$-Sequenz in den augenspezifischen Expressionvektor pGMR (Brand and Perrimon, 1993; Finelli, Kelkar et al., 2004; Hay, Wolff et al., 1994)

$\mathrm{w}\left[{ }^{11118}\right] P\{$ UAS-APP.Aß42\}H29.3 = A $\quad=A 42-H 29.3(\mathrm{e})$

\subsection{Kontrolllinien}

$w\left[{ }^{1118}\right] ; P\{w[+m C]=U A S-l a c Z . N Z\} 20 b$

w[1118]P\{UAS-mCD8::GFP.L\}LL5 


\subsection{Methoden}

\subsubsection{Zucht- und Haltebedingungen von Drosophila melanogaster}

Die Haltung und Zucht von Drosophila melanogaster erfolgte auf einem Nährmedium in Glasröhrchen. Dabei sind konstante Bedingungen hinsichtlich Temperatur, Luftfeuchtigkeit und Tag/Nacht-Rhythmus von hoher Bedeutung. Um dies zu gewährleisten, erfolgte die Haltung und Zucht von Drosophila melanogaster bei einer konstanten Temperatur von $29^{\circ} \mathrm{C}$, einer Luftfeuchtigkeit von 60\% und einem Tag/Nacht-Rhythmus von 12 Stunden (h) unter Verwendung eines Inkubators.

Um eine bakterielle Kontaminierung so gering wie möglich zu halten, wurden die Fliegen ca. alle 3 Tage auf frisches Nährmedium gesetzt (Greenspan, 2004).

Für die Verkreuzung der Fliegen wurden jeweils die Jungfrauen der Treiberlinie mit den Männchen der transgenen Linie in einem Verhältnis von 3:1 verkreuzt.

Nach zwei- bis dreitägiger Eiablage wurden die adulten Tiere aus dem Zuchtgefäß entfernt. Abhängig von der umgebenden Temperatur benötigt Drosophila melanogaster für die Entwicklung vom Ei bis zur adulten Fliege etwa 9-21 Tage. Für die Versuche wurden jeweils die Männchen der F1-Generation verwendet.

\subsubsection{Nährmedium}

Zur Herstellung des Nährmediums mit einem Gesamtvolumen von 8 I wurden 4 I deionisiertes Wasser mit $64 \mathrm{~g}$ Fadenagar vermengt und über Nacht zum Quellen stehen gelassen. Im Anschluss erfolgte das Aufkochen, bis der Agar vollständig gelöst war. Das Gemisch wurde mit $640 \mathrm{~g}$ Maismehl, $80 \mathrm{~g}$ Sojamehl, $200 \mathrm{~g}$ Bierhefe und $2 \mathrm{I}$ deionisiertem Wasser versetzt. Anschließend erfolgte die Zugabe von $640 \mathrm{~g}$ Malz, $175 \mathrm{~g}$ Rübensirup und $1 \mathrm{I}$ deionisiertem Wasser. Der Brei wurde 30 min gekocht und im Anschluss auf $55-60{ }^{\circ} \mathrm{C}$ abgekühlt. Nach dem Abkühlen wurden die Konservierunsstoffe Nipagin (12 g) sowie Propionsäure $(75 \mathrm{ml})$ hinzugefügt. Das noch flüssige Futter wurde in verschieden große Plexiröhrchen gefüllt, mit Folie abgedeckt und bis zur Verwendung bei $4^{\circ} \mathrm{C}$ gelagert. 


\subsubsection{Genexpression mittels UAS-Gal4-System}

In den Versuchen wurde das gängige UAS-Gal4-System verwendet (siehe Abb. 5). Dabei bedient man sich der Methode, Genaktivität mit Hilfe notwendiger Transkriptionsfaktoren (Gal4,Gal80[ts]) zu steuern. Bei Gal4 handelt es sich um ein aus 881 Aminosäuren bestehendes Protein, welches erstmals in Hefe gefunden wurde und die Genexpression in spezifischen Geweben regulieren kann (Laughon, Driscoll et al., 1984; Laughon and Gesteland, 1984).

Mittels p-Element induzierter Keimbahnmutation ist die Einbringung des hefespezifischen Tranksriptionsfaktores unter Promotor-Kontrolle möglich. Das zu untersuchende Gen wird mittels Fusionierung des Enhancer-Elementes UAS (upstream activating sequence) ebenfalls über ein p-Transposon in die Keimbahn eingefügt. Die Genaktivierung erfolgt nach Verkreuzung der Stämme in der F1-Generation. Dabei bindet das Protein GAL4 spezifisch an die UAS, wodurch ein downstream gelegenes Zielgen aktiviert wird, beispielsweise das grün-fluoreszierende-Protein (GFP). Im Anschluss erfolgt die Proteinbiosynthese über die Ribonucleinsäure (RNA)-Polymerase II mit gewebespezifscher Exprimierung (Brand and Perrimon, 1993).
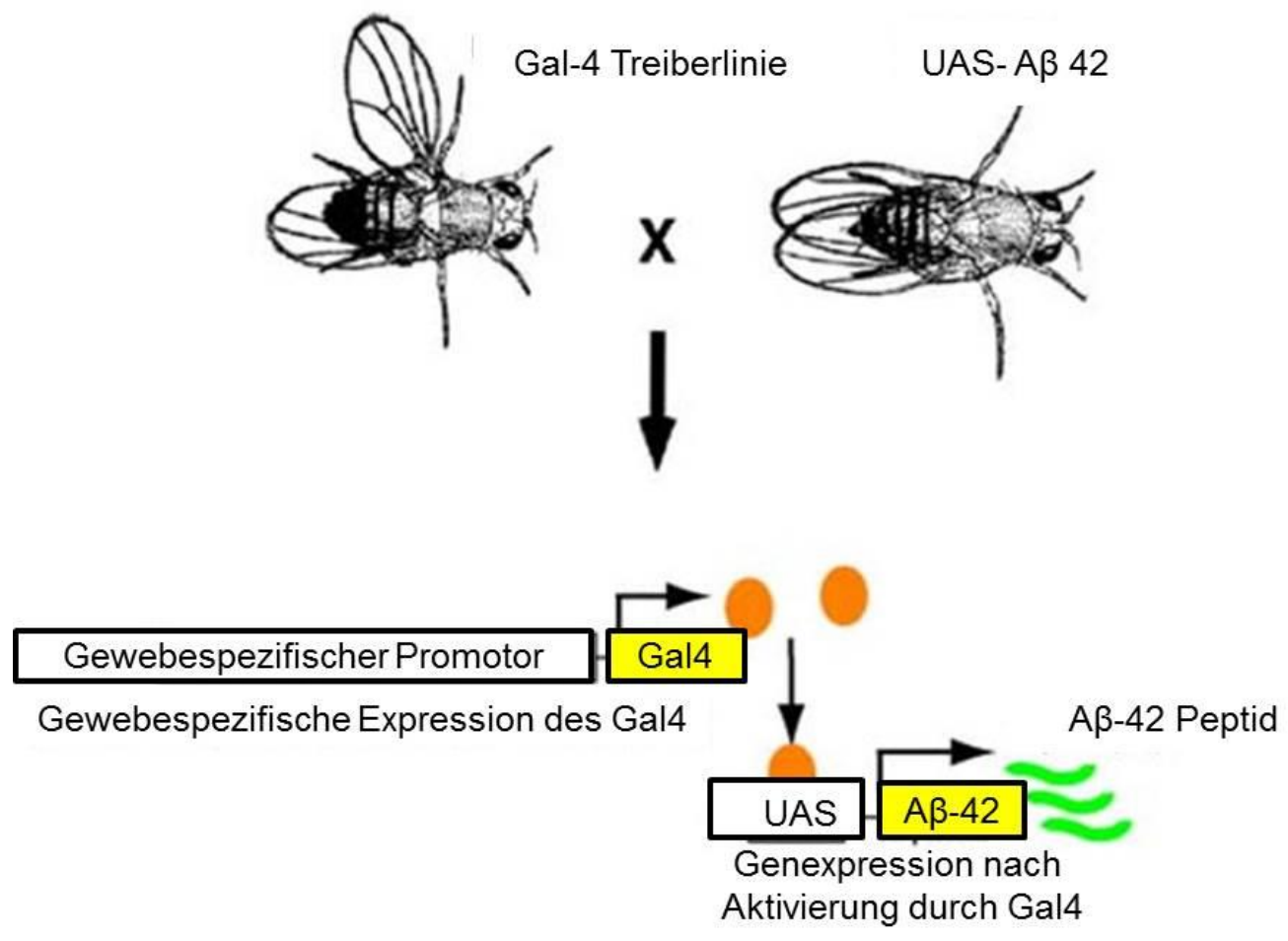

Abb. 5: Schematische Darstellung der Funktionsweise des UAS-Gal4-Systems am Beispiel des $A \beta_{42}$-Peptids.

Die Treiberlinie (Fliege links im Bild) exprimiert den Transkriptionsfaktor Gal4. Nach Verkreuzung mit einer UAS-Linie (Fliege rechts im Bild), welche die Zielsequenz enhält, wird die Sequenz in einem spezifischen Gewebe exprimiert

[Abb. modifiziert nach (lijima-Ando and lijima, 2010), Seite25] 


\subsubsection{Erstellung doppelt homozygoter Treiberlinien}

Zur Herstellung der temperaturabhängigen Treiberlinie, welche für die Überlebenstestung verwendet wurde, wurde das nachfolgende Kreuzungsschema verwendet (siehe Abb. 6). Dabei führt die Erhöhung der Temperatur zur Dissoziation des Repressors, sodass eine Expression von abeta möglich wird.

w[ $\left.{ }^{1118}\right]$; Gal4-elav/CyO; TM2/TM6 $\quad x \quad$ w[ $\left.{ }^{[118}\right]$; Sp/CyO; tubGal80[ts]/TM2

$$
\text { w[ } \left.{ }^{1118}\right] \text {; Gal4-elav/(CyO);tubGal80[ts]/(TM6) }
$$

Abb. 6: Verkreuzungsschema der temperaturabhängigen Treiberlinie elavGal4;tubGal80[ts]

\subsubsection{Herstellung der Aggregationsmodulatoren}

Die verwendeten Wirkstoffe (siehe Tab. 1, Seite 23) wurden von der AG Griesinger (MaxPlanck Institut für biophysikalische Chemie) zur Verfügung gestellt (Wagner, Ryazanov et al., 2013). Die Modulatoren wurden als Pulver in Dimethylsulfoxid (DMSO) gelöst und anschließend $180 \mu \mathrm{l}$ der Lösung zu $6 \mathrm{~g}$ Bäckerhefe gegeben (Endkonzentration $250 \mu \mathrm{M}$ ).

Die chemische Struktur der einzelnen Wirkstoffe ist im Anhang dargestellt, die zugehörigen Molekulargewichte sind in Tab. 1 aufgelistet. Die F1-Generation wurde ab dem 1. Tag des Schlüpfens mit den Wirkstoffen behandelt. Dazu wurden $4 \mathrm{~g}$ des Gemisches in ein Röhrchen mit ca. 40 Fliegen gegeben. Nach jeweils zwei Tagen wurden die Fliegen in ein neues Röhrchen mit frisch angesetztem Medium umgesetzt und das Experiment insgesamt dreimal wiederholt. Pro Durchgang wurden pro Linie 300 Jungfrauen mit 100 männlichen Fliegen verkreuzt und 120 Fliegen der F1-Generation für einen Wirkstoff, aufgeteilt auf vier Röhrchen, verwendet. 
Tab. 1: Darstellung der verwendeten Modulatoren und deren Molekulargewicht

\begin{tabular}{l|l}
\hline \hline \multicolumn{1}{c|}{ Wirkstoff } & Molekulargewicht [g/mol] \\
\hline \hline Anle 138b & 343 \\
Anle 138c & 331 \\
Anle 145c & 507 \\
Anle 253b & 342,2 \\
Sery 85 & 270 \\
Sery 118 & 269 \\
Sery 313b & 280,3 \\
Sery 335b & 298,7 \\
Sery 392b & 357 \\
\hline \hline
\end{tabular}

\subsubsection{Bestimmung der Überlebensdauer}

Zur Bestimmung der Überlebensdauer wurde ein longevity assay mit einer temperaturabhängigen Gal4-Linie (elavGal4;tubGal80[ts]) verwendet.

Bei einer Umgebungstemperatur von $18^{\circ} \mathrm{C}$ verhindert das aktivierte Gal80[ts] die Bindung des Gal4 am UAS, sodass das nachgeschaltete Gen nicht exprimiert werden kann. Bei einer Umgebungstemperatur von $29^{\circ} \mathrm{C}$ kann Gal80[ts] nicht mehr binden, sodass Gal4 am UAS haftet und das Gen exprimiert wird. Auf diese Weise besteht die Möglichkeit von außen Einfluss auf den Beginn der Expression zu nehmen.

Zur Bestimmung der Überlebenszeit der Fliegen wurden, nach erfolgter Verkreuzung der Treiberlinie (elavGal4;tubGal80[ts]) mit den transgenen Linien, die Männchen nach dem Schlüpfen abgesammelt und in ein Zuchtgefäß gegeben. In einem Zuchtröhrchen mit einem Volumen von $30 \mathrm{ml}$ wurden zwischen 25 bis 35 Fliegen gehalten. Um das Überleben bzw. das Sterben der Fliegen beurteilen zu können, wurden die Röhrchen täglich zur selben Zeit begutachtet und die verstorbenen Tiere gezählt. Unter Berücksichtigung des Zustands des Nährmediums wurden die Tiere nach 2 bis 3 Tagen auf frisches Futter gesetzt.

\subsection{6 $A \beta_{42}$-Überexpression in retinalen Ganglienzellen}

In der vorliegenden Arbeit dient die Testung der Darstellung von Proteinablagerungen in den Facettenaugen mit teilweiser Vakuolenbildung und Rückbildung des Augenfarbstoffes. Für die Untersuchung wurde die Gal4-Treiberlinie GMR/CyO, die eine spezifische Exprimierung in den Photorezeptorzellen gewährleistet, verwendet (Freeman, 1996; Song, Guan et al., 2000). Die Jungfrauen der Treiberlinie wurden mit den jeweiligen männlichen transgenen Fliegen verkreuzt und der Augenphänotyp nach einem Tag sowie nach sieben Tagen unter dem Lichtmikroskop begutachtet. 
Dafür wurden die Fliegen zunächst mit $\mathrm{CO}_{2}$ (Kohlendioxid) narkotisiert, auf einem Wachsbett fixiert und die Bildaufnahmen der Augen unter mikroskopischer Betrachtung durchgeführt. Das Schockgefrieren bei $-80^{\circ} \mathrm{C}$ zur Darstellung des Augenphänotyps als Alternativmethode konnte aufgrund diverser Artefaktbildungen in den Facettenaugen nicht verwendet werden.

\subsubsection{Präparation von löslichem, unlöslichem und Gesamt-A $\beta_{42}$}

Die Präparation des Gesamt-, löslichen und unlöslichen- $A \beta_{42}$ erfolgte in modifizierter Form nach (Rogers, Luber-Narod et al., 1988). Die hierzu verwendeten Fliegen wurden zunächst in Stickstoff schockgefroren und anschließend die Fliegenköpfe durch Vortexen von den Fliegenkörpern getrennt.

Zur Bestimmung des Gesamt-A $\beta_{42}$ wurden fünf Fliegenköpfe in $500 \mu \mathrm{l}$ GHCl-Puffer (5 M Guanidinium $\mathrm{HCl}, 50$ mM Hepes, protease inhibitor cocktail (Sigma, P8340) und 5 mM EDTA $\mathrm{pH} 7.3)$ zunächst im Precelly 24 homogenisiert und anschließend bei $21,000 \mathrm{~g}$ für $5 \mathrm{~min}$ bei $4{ }^{\circ} \mathrm{C}$ in einer Ultrazentrifuge zentrifugiert. Die im Überstand enthaltene $A \beta_{42}$-Menge wurde als Gesamt- $A \beta_{42}$ bezeichnet.

Zur Isolierung der löslichen $A \beta_{42}$-Fraktion wurden 50 Fliegenköpfe in $400 \mu$ l Gewebehomogenisierungspuffer ( $250 \mathrm{mM}$ Sucrose, $20 \mathrm{mM}$ Tris base, $1 \mathrm{mM}$ EDTA, $1 \mathrm{mM}$ EGTA, protease inhibitor cocktail (Sigma)) homogenisiert. Nach Zugabe von $400 \mu$ l Diethylacetat (Netzeva, Dearden et al.)-Puffer (0.4\% DEA, $100 \mathrm{mM} \mathrm{NaCl}$, protease inhibitor cocktail) wurden die Proben bei $135,000 \mathrm{~g}$ für eine Stunde bei $4{ }^{\circ} \mathrm{C}$ in der Ultrazentrifuge zentrifugiert. Der daraus gewonnene Überstand stellte die lösliche $A \beta_{42}$-Fraktion dar.

Das Pellet wurde in $500 \mu$ leiskalter 70 \%iger Ameisensäure resuspendiert und anschließend im Ultraschallbad behandelt (viermal 15 sek bei 100\%). Darauf folgte ein weiterer Zentrifugationsschritt für $1 \mathrm{~h}$ bei $4{ }^{\circ} \mathrm{C} .50 \mu \mathrm{l}$ des Überstandes wurden mit $5 \mu$ l Neutralisationspuffer $(1 \mathrm{M}$ Tris base, $0.5 \mathrm{M} \mathrm{Na}_{2} \mathrm{HPO}_{4}, 0.05 \% \mathrm{NaN}_{3}$ ) verdünnt und bildeten die unlösliche $A \beta_{42}$-Fraktion. 


\subsubsection{Quantifizierung von $A \beta_{42}$}

Die Quantifizierung der $A \beta_{42}$-Konzentrationen erfolgte mittels ElektrochemilumineszenzAssays (Meso Scale Discovery) und wurde vom Hertie Institut für klinische Hirnforschung, Abteilung Zellbiologie Neurologischer Erkrankungen, in Tübingen durchgeführt.

Der Assay ist zur Detektion von $\mathrm{A}_{42}$ im CSF, in Zelllysaten sowie in humanen Gewebehomogenisaten etabliert. Hierbei werden die Proben auf eine Elektroden-besetzte Platte gebracht, welche zuvor mit einem anti- $A \beta_{42}-A k$ beschichtet wurde. Nach Zugabe eines SULFO-TAG ${ }^{\mathrm{TM}}$-markierten Aks erfolgt durch das Anlegen einer Spannung eine ReduktionsOxiations-Reaktion und Emission von Licht bei $620 \mathrm{~nm}$ (Abb. 7).



Abb. 7: Schematische Darstellung des MSD human $A \beta_{42}$ ELISA

(Abb. modifiziert nach Handbuch; MSD® MULTI-SPOT Assay System)

\subsubsection{Statistik}

Die statistische Auswertung erfolgte unter Verwendung von IBM SPSS Statistics 16. 


\section{Ergebnisse}

In der vorliegenden Arbeit wurde ein In-vivo-Screen mit verschiedenen Aggregationsinhibitoren durchgeführt, um die wirksamste Substanz zur Hemmung der $A \beta$-Aggregation zu testen. Dazu wurden zunächst verschiedene Fliegenlinien, in denen humanes $A \beta$ panneuronal überexprimiert wird, bezüglich ihrer Lebensdauer (Iongevity assay) im Vergleich zu Kontrolllinien (CD8eGFP und lacz) untersucht, um Linien mit einem robusten Phänotyp zu identifizieren. Anschließend wurde das relative Überleben der transgenen Linien im Vergleich zu den Kontrollen mit und ohne Inhibitoren gestestet. Für die beiden wirksamsten Inhibitoren wurde im Anschluss eine Quantifizierung des löslichen und unlöslichen $A \beta_{42}$ durchgeführt.

\subsection{Auswahl eines geeigneten Screening-Tests}

\subsection{Auswahl der $\mathrm{A} \beta$-Linien}

$\mathrm{Zu}$ Beginn der Arbeit wurden mehrere Fliegenlinien, die humanes $A \beta_{42}$ exprimieren, bezüglich ihres Phänotyps untersucht (Crowther, Kinghorn et al., 2005; Finelli, Kelkar et al., 2004). Hierfür wurden diese mit der panneuronalen Treiberlinie elavC155 gekreuzt und die Männchen der F1-Generation bzgl. ihrer Überlebenswahrscheinlichkeit bei unterschiedlichen Temperaturen untersucht. Von den untersuchten transgenen Fliegenlinien zeigten elavC155/arc2e und elavC155/alz3;alz8 unter einer konstanten Temperatur von $29^{\circ} \mathrm{C}$ den stärksten Phänotyp (Abb. 8 und Tab. 2, Seite 27), sodass diese Linien im weiteren Verlauf der Experimente verwendet wurden. Bei alz3;alz8 handelt es sich um eine transgene Linie, die humanes $A \beta_{42}$ mit einem Sekretionssignal exprimiert und somit für die AlzheimerPathologie relevant ist. Die Verkreuzung der transgen veränderten Linien mit einer Gal4Treiberlinie führt zu einer Überexpression von $A \beta_{42}$. Als Überexpressionskontrolle wurde lacz verwendet. 


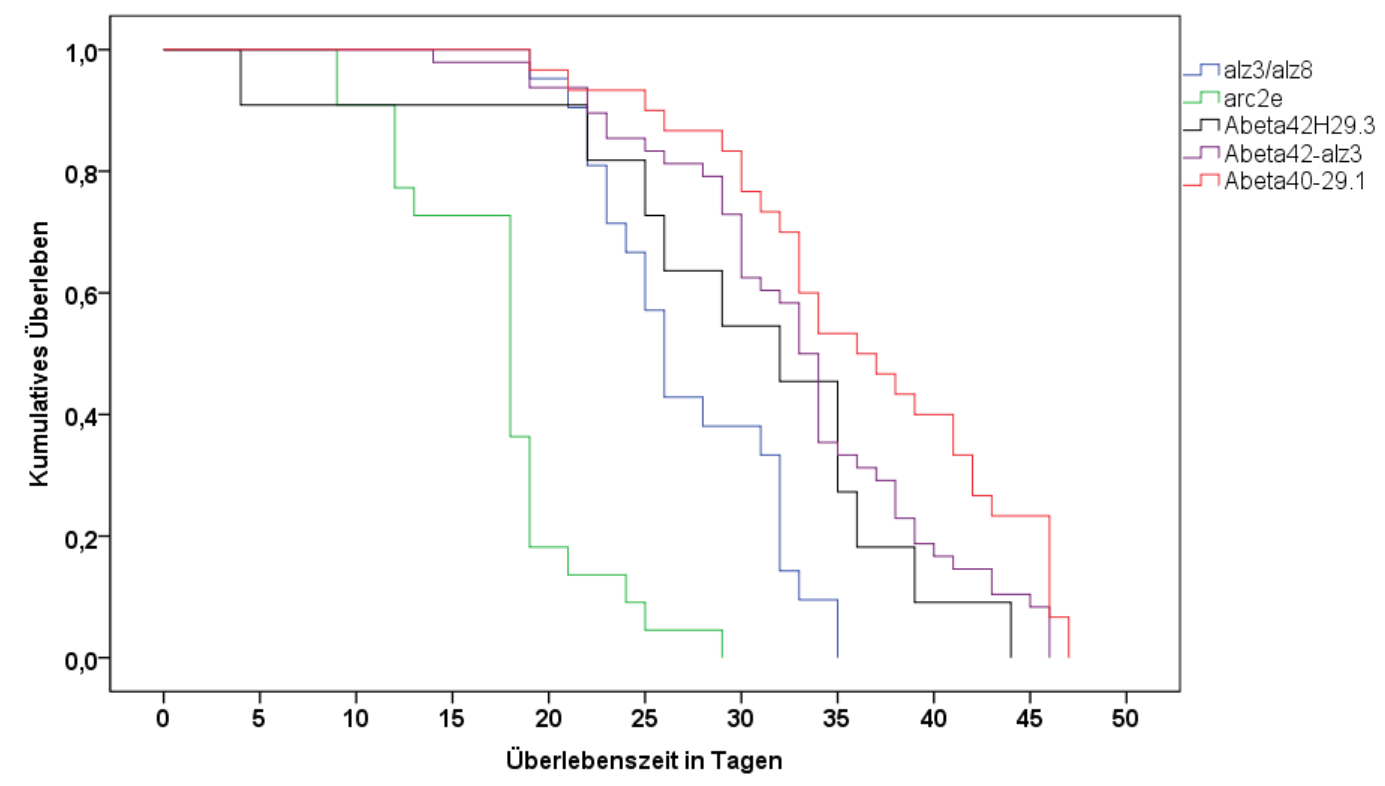

Abb. 8: Überlebensdauer der transgenen $A \beta$-Linien unter elavC155

Betrachtet wurden die Nachkommen aus der Verkreuzung der transgenen A $\beta$-Linien unter Verwendung von elavC155 (elav). Es zeigte sich ein vermindertes Überleben der transgenen, doppelt inserierten Linien elavC155/alz3;alz8 $(n=21)$ und der transgenen Alzheimermutante elavC155/arc2e $(n=22)$ gegenüber den einfach inserierten $A \beta$-Linien elavC155/A $\beta_{42} H 29.3(n=11)$ und elavC155/A $\beta_{42^{-}}$ alz3 (48) sowie gegenüber der Kontrolle elavC155/A $\beta_{40}-29.1(n=30)$.

Tab. 2: Darstellung der mittleren Überlebenswahrscheinlichkeit der transgenen $A \beta$-Linien unter elavC155

\begin{tabular}{|l|r|r|r|r|}
\hline \multirow{2}{*}{ Genotyp } & \multicolumn{4}{|c|}{ Mittelwert } \\
\cline { 2 - 5 } & & & \multicolumn{2}{|c|}{$95 \%$-Konfidenzintervall } \\
\cline { 4 - 6 } & & & & \\
& & & & \\
elavC155/alz3;alz8 & 27,238 & 1,071 & 25,139 & 29,337 \\
\hline elavC155/arc2e & 17,545 & 1,050 & 15,487 & 19,604 \\
\hline elavC155; Abeta42H29.3 & 29,727 & 3,231 & 23,395 & 36,060 \\
\hline elavC155/Abeta42-alz3 & 33,063 & 1,103 & 30,900 & 35,225 \\
\hline elavC155/Abeta40-29.1 & 36,433 & 1,460 & 33,573 & 39,294 \\
\hline
\end{tabular}




\subsection{Kontrolle der Expression mit der Treiberline elavGal4;tubGal80[ts]}

In den Experimenten für die Überlebensanalyse wurde die temperaturabhängige Gal4-Treiberlinie, elavGal4;tubGal80[ts] verwendet. Die Nutzung dieser Linie ermöglicht unter $18^{\circ} \mathrm{C}$ eine nahezu vollständige Suppression des nachgeschalteten Gens (Suster, Seugnet et al., 2004). Um die Expression bei $29^{\circ} \mathrm{C}$ visuell beurteilen zu können, wurde elavGal4;tubGal80[ts] UAS-Linie CD8eGFP, als Kontrolle getestet.

Dabei wurde die Fluoreszenz im Larvenstadium und in der adulten Fliege der F1-Generation mittels Fluoreszenzmikroskop beurteilt. In Tab. 3 sind die verschiedenen Temperaturbedingungen dargestellt. Unter $18^{\circ} \mathrm{C}$ ließ sich kein GFP-Signal detektieren.

Unter $25^{\circ} \mathrm{C}$ leuchtete ein Teil der Fliegen mit dem Genotyp elavGal4/CD8eGFP;tubGal80[ts] in der F1-Generation. Eine maximales GFP-Signal ließ sich unter dem Fluoreszenzmikroskop bei $29^{\circ} \mathrm{C}$ feststellen.

Tab. 3: Darstellung der untersuchten Temperaturbedingungen während der Verkreuzung und im adulten Stadium

\begin{tabular}{|c|c|c|c|}
\hline \hline $\begin{array}{c}\text { Temperatur } \\
\text { während der } \\
\text { Verkreuzung } \\
\text { der Fliegen }\end{array}$ & $\begin{array}{c}\text { Temperatur } \\
\text { nach dem } \\
\text { Schlüpfen der } \\
\text { Fliegen }\end{array}$ & $\begin{array}{c}\text { GFP-Fluoreszenz in } \\
\text { elavGal4;tubGal80[ts]/ } \\
\text { CD8eGFP }\end{array}$ & $\begin{array}{c}\text { Ausbildung eines Phänotyps in } \\
\text { den Versuchstieren mit } \\
\text { Ueberexpression des humanen } \\
\text { A } \text {-Peptids }\end{array}$ \\
\hline \hline $18^{\circ} \mathrm{C}$ & $18^{\circ} \mathrm{C}$ & Nein & Nein \\
$18^{\circ} \mathrm{C}$ & $25^{\circ} \mathrm{C}$ & Nein & Nein \\
$18^{\circ} \mathrm{C}$ & $29^{\circ} \mathrm{C}$ & n.d. Schlüpfen ja & Gering \\
$25^{\circ} \mathrm{C}$ & $18^{\circ} \mathrm{C}$ & Nein & Nein \\
$25^{\circ} \mathrm{C}$ & $25^{\circ} \mathrm{C}$ & Nein & Nein \\
$25^{\circ} \mathrm{C}$ & $29^{\circ} \mathrm{C}$ & n.d.Schlüpfen ja & Gering \\
$29^{\circ} \mathrm{C}$ & $18^{\circ} \mathrm{C}$ & n.d. Schlüpfen ja & Gering \\
$29^{\circ} \mathrm{C}$ & $25^{\circ} \mathrm{C}$ & n.d. Schlüpfen ja & Gering \\
$29^{\circ} \mathrm{C}$ & $29^{\circ} \mathrm{C}$ & Ja & Ja \\
\hline \hline
\end{tabular}

Bei den Nachkommen der Fliegen mit überexprimiertem humanem $A \beta_{42}$ (elavGal4/alz3;tubGal80[ts]/alz8, elavGal4;arc2e;tubGal80[ts]) zeigte sich ein ausgeprägter Phänotyp in Bezug auf das Überleben bei einer konstanten Temperatur von $29^{\circ} \mathrm{C}$ unter Verwendung der Treiberlinie elavGal4;tubGal80[ts].

Unter den anderen Temperaturbedingungen konnte kein eindeutiger Phänotyp dargestellt werden, sodass für die nachfolgenden Experimente konstante Verhältnisse unter $29^{\circ} \mathrm{C}$ geschaffen wurden. 


\subsection{Analyse der Überlebensdauer von $A \beta_{42}$-exprimierenden Fliegen}

\subsubsection{Analyse der Überlebensdauer ohne Zugabe von Wirkstoffen}

Um die Wirksamkeit der verschiedenen Modulatoren in vivo testen zu können, wurde das Überleben der $A \beta_{42}$-exprimierenden Fliegenlinien und lacz-exprimierenden Kontrollen ohne und mit Zusatz der Modulatoren untersucht. Als Referenz dienten dabei die mit DMSO behandelten Fliegen bei einer konstanten Umgebungstemperatur von $29^{\circ} \mathrm{C}$. Es erfolgten tägliche Kontrollen der Röhrchen, um das Überleben der Fliegen zu dokumentieren.

Wie in Abb. 9 (Seite 29) und Tabelle 4 (Seite 30) dargestellt, betrug das mittlere Überleben der Kontrolle elavGal4;tubGal80[ts],lacz 39,09 Tage, das der Fliegen mit dem Genotyp elavGal4/alz3;tubGal80[ts]/alz8 19,98 Tage und das der Fliegen mit dem Genotyp elavGal4/arc2e;tubGal80[ts] 13,14 Tage.

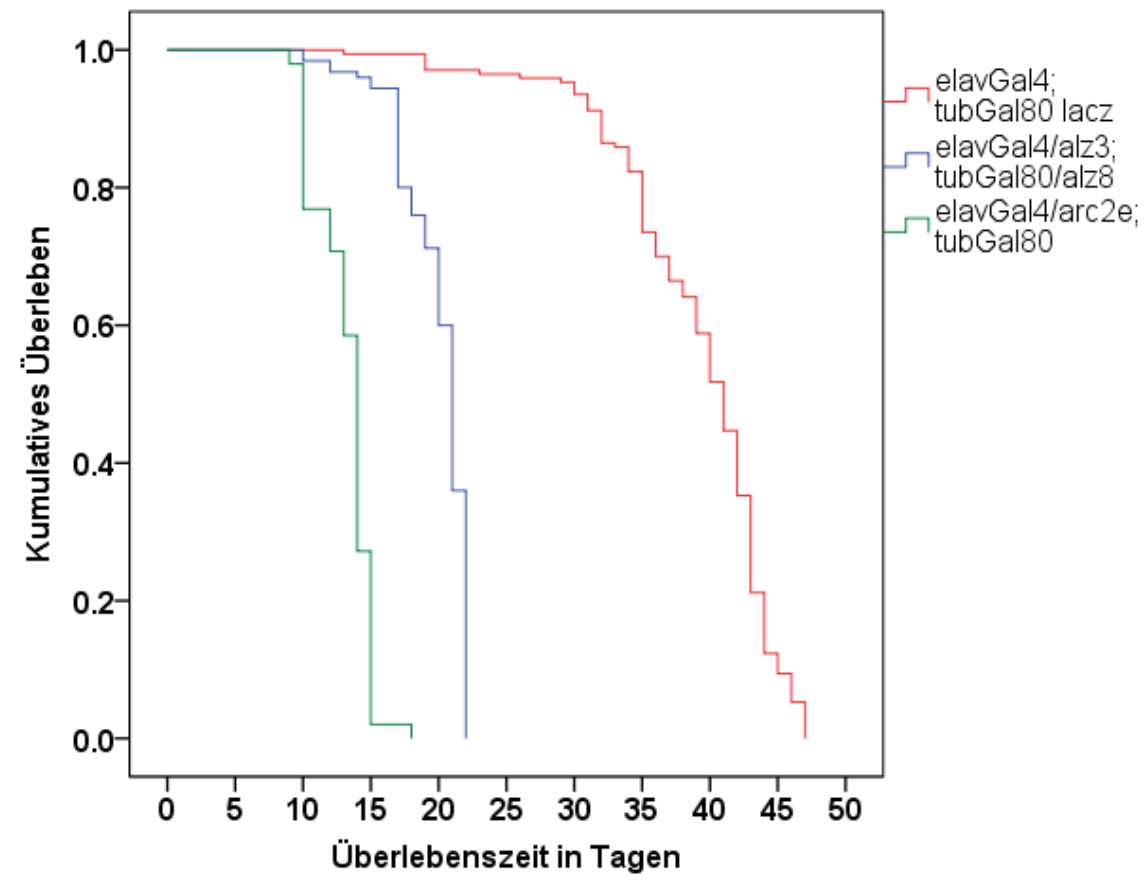

Abb. 9: Überlebensdauer der Versuchstiere

Prozentuale Überlebensdauer von elavGal4;tubGal80[ts]lacz, elavGal4/alz3;tubGal80[ts]/alz8 und elavGal4/arc2e;tubGal80[ts] bei $29^{\circ} \mathrm{C}$ ohne Zugabe von Modulatoren, gemessen in Tagen. Die mittlere Überlebenszeit betrug für elavGal4;tubGal80[ts]lacz $(n=170) \quad 39,09$ Tage, für elavGal4/alz3;tubGal80[ts]/alz8 ( $n=125) \quad 19,98$ Tage und für elavGal4/arc2e;tubGal80[ts] $(n=147)$ 13,14 Tage. 
Tab. 4: Mittelwerte für die Überlebenszeit der Fliegen unter Verwendung der Treiberlinie elavGal4;tubGal80[ts]

Tabellarische Aufzeichnung der Mittelwerte für die Überlebenszeit der F1-Generationen von elavGal4;tubGal80[ts] lacz, elavGal4/alz3;tubGal80[ts]/alz8 und elavGal4/arc2e;tubGal80[ts] ohne Verwendung von Wirkstoffen.

\begin{tabular}{|l|r|r|r|r|}
\hline \multirow{2}{*}{ Genotyp } & \multicolumn{4}{|c|}{ Mittelwert } \\
\cline { 2 - 5 } & & & \multicolumn{2}{|c|}{ 95\%-Konfidenzintervall } \\
\cline { 4 - 6 } & Schätzer & Standardfehler & Untere Grenze & Obere Grenze \\
\hline elavGal4;tubGal80 lacz & 39,094 &, 467 & 38,179 & 40,009 \\
\hline elavGal4/alz3;tubGal80/alz8 & 19,984 &, 229 & 19,535 & 20,433 \\
\hline elavGal4/arc2e;tubGal80 & 13,143 &, 167 & 12,815 & 13,471 \\
\hline
\end{tabular}

\subsubsection{Analyse der Überlebensdauer unter Zugabe von Wirkstoffen}

Im longevity assay wurden neun Modulatoren getestet (Wagner, Ryazanov et al., 2013). Die Wirkstoffe wurden in DMSO mit einer Konzentration von $10 \mathrm{mM}$ gelöst und DMSO alleine als Negativkontrolle verwendet. Unter einer konstanten Temperatur von $29^{\circ} \mathrm{C}$ erfolgte die Verkreuzung der Treiberlinie elavGal4;tubGal80[ts] mit den Linien $\mathrm{w}^{1118 ;}$ arc2e, $\mathrm{w}^{1118}$;alz3;alz8 und $\mathrm{w}^{1118}$;lacz. Für die Testung wurden die männlichen Fliegen aus der F1-Generation verwendet. Die Zugabe der in Hefe gelösten Wirkstoffe erfolgte alle 2 Tage ab dem Zeitpunkt des Schlüpfens.

Wie in den Abb. 10 und Abb. 11 (Seite 31) dargestellt, zeigte sich bei den Fliegen mit dem Genotyp elavGal4;tubGal80[ts] lacz innerhalb der ersten 25 Lebenstage unabhängig vom verwendeten Wirkstoff ein hohe Überlebensrate der F1-Generation. Die mittlere Überlebensdauer lag für anle138b $(n=142)$ bei 32,93 Tagen, für anle138c $(n=161)$ bei 32,35 Tagen und für DMSO $(n=145)$ bei 31,18 Tagen. Die Wirkstoffe sery85 $(n=135)$, sery118 $(n=145)$, sery335b $(n=143)$, anle138b, anle138c und anle253b $(n=143)$ zeigten ein nicht signifikant verlängertes Überleben gegenüber DMSO. Sery392b $(n=136)$ sery313b $(n=157)$ und anle145c ( $n=151)$ zeigten ein signifikant verlängertes Überleben gegenüber DMSO. Das insgesamt signifikant verminderte Überleben der mit DMSO oder mit in DMSO gelösten Wirkstoffen behandelten F1-Generation im Vergleich zu unbehandelten Nachkommen erklärt sich durch die Toxizität des DMSO.

In den Tabellen 5 und 6 (Seite 32) sind zudem die mittleren Überlebenswahrscheinlichkeiten mit den dazugehörigen Signifikanzwerten für elavGal4;tubGal80[ts] lacz dargestellt. 


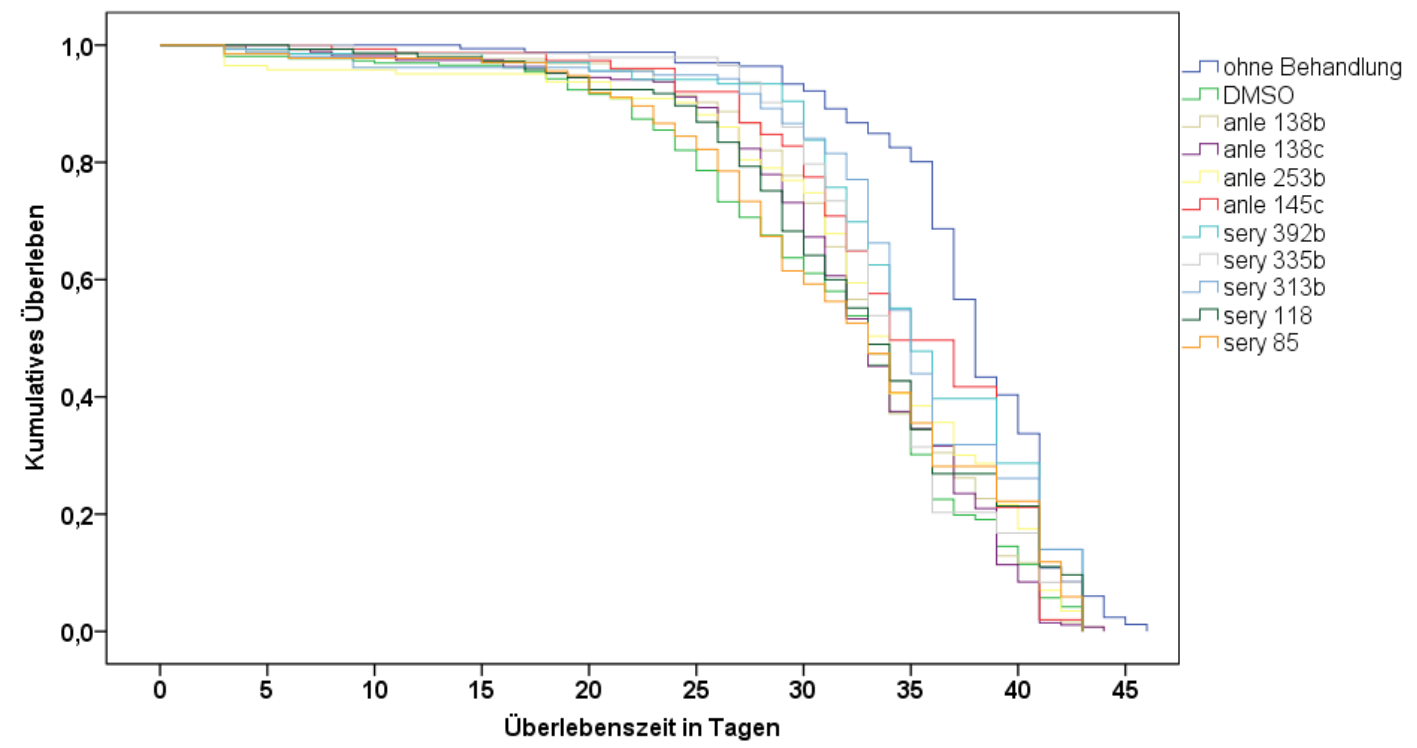

Abb.10: Überlebensdauer der Kontrolle elavGal4;tubGal80[ts] lacz unter Wirkstoffzugabe Prozentuale Überlebensdauer der Versuchstiere ( $n=1628)$ mit dem Genotyp elavGal4;tubGal80[ts], lacz unter Verwendung verschiedener Modulatoren und DMSO als Negativkontrolle, gemessen in Tagen bei $29^{\circ} \mathrm{C}$. Das mittlere Überleben lag zwischen 31,18 und 37,54 Tagen.

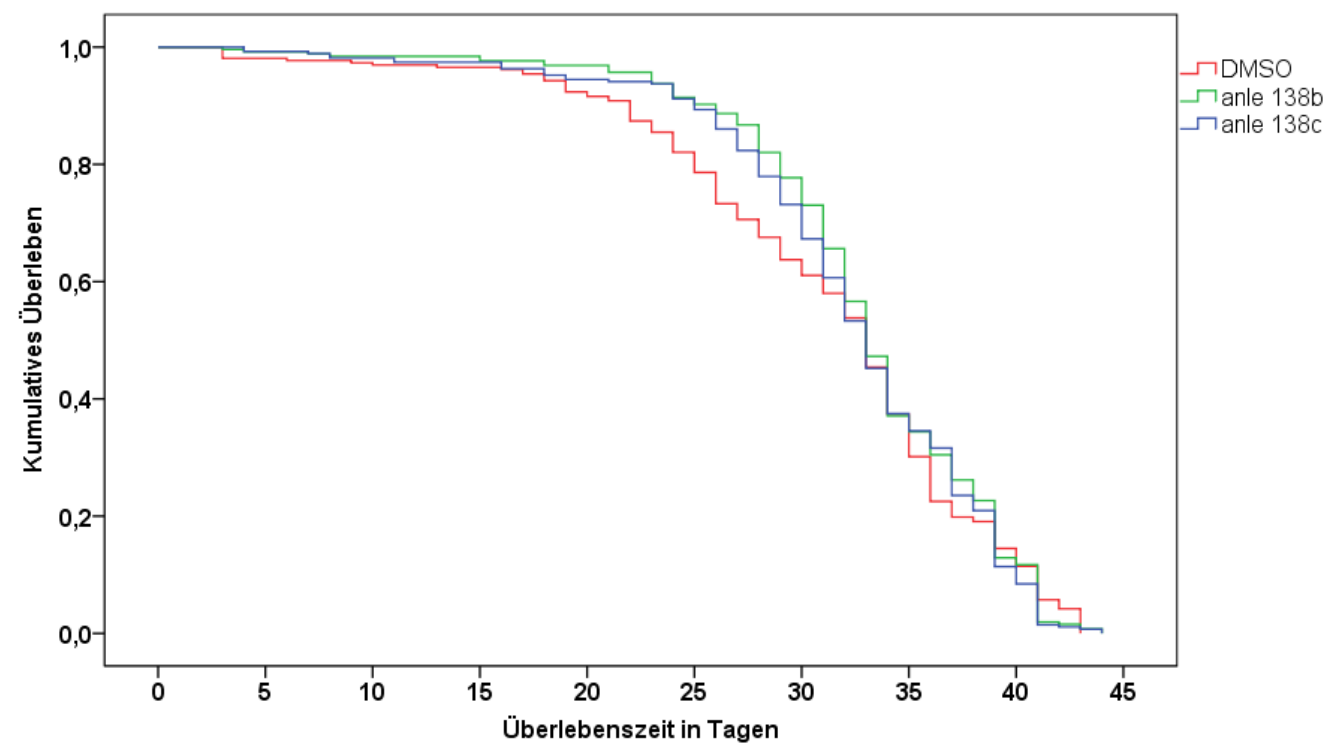

Abb. 11: Überlebensdauer der Kontrolle elavGal4;tubGal80[ts] lacz unter Zugabe von anle138, anle138c und DMSO

Zur besseren Darstellung der Ergebniss wurden die Kurven mit den Werten für anle138b, anle138c und DMSO der Abb.10 entnommen und gesondert dargestellt. Prozentuale Überlebensdauer der Versuchstiere mit dem Genotyp elavGal4;tubGal80[ts], lacz unter Verwendung der Modulatoren anle138b und 138c sowie der Negativkontrolle DMSO, gemessen in Tagen bei $29^{\circ} \mathrm{C}$. Das mittlere Überleben unter DMSO lag hier bei 31,18 Tagen, unter anle138b bei 32,93 Tagen und unter anle138c bei 32,35 Tagen. 
Tab. 5: Mittelwerte für die Überlebenszeit des Genotyps elavGal4;tubGal80[ts],lacz Tabellarische Aufzeichnung der Mittelwerte für die Überlebenszeit der F1-Generation der Linie elavGal4;tubGal80[ts] lacz mit und ohne Verwendung verschiedener Wirkstoffe.

\begin{tabular}{|ll|r|r|r|r|}
\hline \multirow{2}{*}{} & & \multicolumn{3}{|c|}{ Mittelwert } \\
\cline { 3 - 6 } & & & & & \multicolumn{2}{|c|}{$95 \%$-Konfidenzintervall } \\
\cline { 5 - 6 } & & & & & \\
Genotyp & & & & & \\
\hline elavGal4;tub & Ohne Behandlung & & & \\
Gal80lacz & DMSO & 39,094 & 467 & 38,179 & 40,010 \\
& anle 138b & 31,179 &, 497 & 30,205 & 32,154 \\
& anle 138c & 32,930 &, 401 & 32,143 & 33,717 \\
& anle 253b & 32,349 &, 415 & 31,536 & 33,162 \\
& anle 145c & 32,636 &, 716 & 31,232 & 34,040 \\
& sery 392b & 34,490 &, 515 & 33,481 & 35,499 \\
& sery 335b & 35,074 &, 590 & 33,917 & 36,230 \\
& sery 313b & 33,958 &, 452 & 33,072 & 34,845 \\
& sery 118 & 34,656 &, 587 & 33,505 & 35,807 \\
& sery 85 & 32,690 &, 616 & 31,483 & 33,897 \\
& Gesamt & 32,022 &, 701 & 30,648 & 33,397 \\
& & 33,385 &, 162 & 33,067 & 33,703 \\
\hline
\end{tabular}

Tab. 6: Mittlere Überlebenswahrscheinlichkeit im paarweisen Vergleich unter Zugabe von Modulatoren

Tabellarische Darstellung der Signifikanztestung im paarweisen Vergleich in Bezug auf die mittlere Überlebenswahrscheinlichkeit der F1-Generationen der Linie elavGal4;tubGal80[ts],lacz.

\begin{tabular}{|c|c|c|c|c|c|c|c|c|c|c|c|c|}
\hline & & Ohne Behandlung & DMSO & anle $138 \mathrm{~b}$ & anle $138 \mathrm{c}$ & anle 253b & anle $145 \mathrm{c}$ & sery $392 b$ & sery $335 b$ & sery $313 b$ & sery 118 & sery 85 \\
\hline elavGal; & ohne Behandlung & & 000 &, 000 & ,000 & 000 & ,000 & 017 & ,000 & 001 & ,000 & ,000 \\
\hline tubGal80 & DMSO & ,000 & & ,327 & ,794 & ,070 & ,001 & 000 & ,025 & ,000 & ,032 & ,112 \\
\hline \multirow[t]{9}{*}{ lacz } & anle 138b & ,000 & ,327 & & ,353 & ,173 & ,003 & 000 & ,154 & 000 & ,158 & ,284 \\
\hline & anle 138c & 000 & ,794 & ,353 & & 031 & ,000 & 000 & ,042 & ,000 & ,038 & ,082 \\
\hline & anle 253b & ,000 & ,070 & ,173 & ,031 & & ,258 & ,003 & ,666 & ,005 & ,664 & ,984 \\
\hline & anle 145c & ,000 & 001 & 003 & 000 & ,258 & & 060 & ,259 & , 138 &, 421 & ,329 \\
\hline & sery $392 b$ & 017 & 000 & 000 & 000 & 003 & ,060 & & 011 & ,804 & 013 & ,003 \\
\hline & sery $335 b$ &, 000 & ,025 &, 154 & 042 & 666 & ,259 & 011 & & 015 & ,785 & ,430 \\
\hline & sery $313 b$ & 001 & 000 & 000 &, 000 & 005 & , 138 & 804 & 015 & &, 019 & ,005 \\
\hline & sery 118 & 000 & ,032 & , 158 & ,038 & ,664 & ,421 & 013 & ,785 & 019 & & ,560 \\
\hline & sery 85 &, 000 &, 112 & ,284 & 082 & ,984 &, 329 & 003 &, 430 & 005 & ,560 & \\
\hline
\end{tabular}

Wie die Abb. 12 und Abb. 13 (Seite 33) zeigen, imponierte bei den Fliegen mit dem Genotyp elavGal4/alz3;tubGal80[ts]/alz8 in den ersten 15 Tagen, unabhängig vom verwendeten Wirkstoff, ein $>90 \%$ Überleben der F1-Generation. Unter Verwendung der Modulatoren sery85 ( $n=95)$, sery335b $(n=103)$ und anle138c $(n=141)$ kam es zu einem vorzeitigen, jedoch nicht signifikanten Versterben der Versuchtstiere im Vergleich zu denen, die DMSO $(n=94)$ erhalten hatten. Unter anle138b $(n=141)$ anle145c $(n=131)$, sery392b $(n=90)$ und sery313b $(n=101)$ zeigte sich ein signifikant längeres Überleben gegenüber DMSO. Sery118 $(n=89)$ zeigte ein nicht signifikant verlängertes Überleben gegenüber DMSO. 
In den Tabellen 7 und 8 (Seite 34) sind zudem die mittleren Überlebenswahrscheinlichkeiten mit den dazugehörigen Signifikanzwerten für elavGal4/alz3;tubGal80[ts]/alz8 dargestellt.



Abb. 12: Überlebensdauer von elavGal4/alz3;tubGal80[ts]/alz8 unter Wirkstoffzugabe Prozentuale Überlebensdauer der Versuchstiere $(n=1219)$ mit dem Genotyp elavGal4/alz3;tubGal80 [ts]/alz8 unter Verwendung verschiedener Modulatoren und DMSO als Negativkontrolle, gemessen in Tagen bei $29^{\circ} \mathrm{C}$. Das mittlere Überleben betrug zwischen 19,92 und 23,34 Tagen.

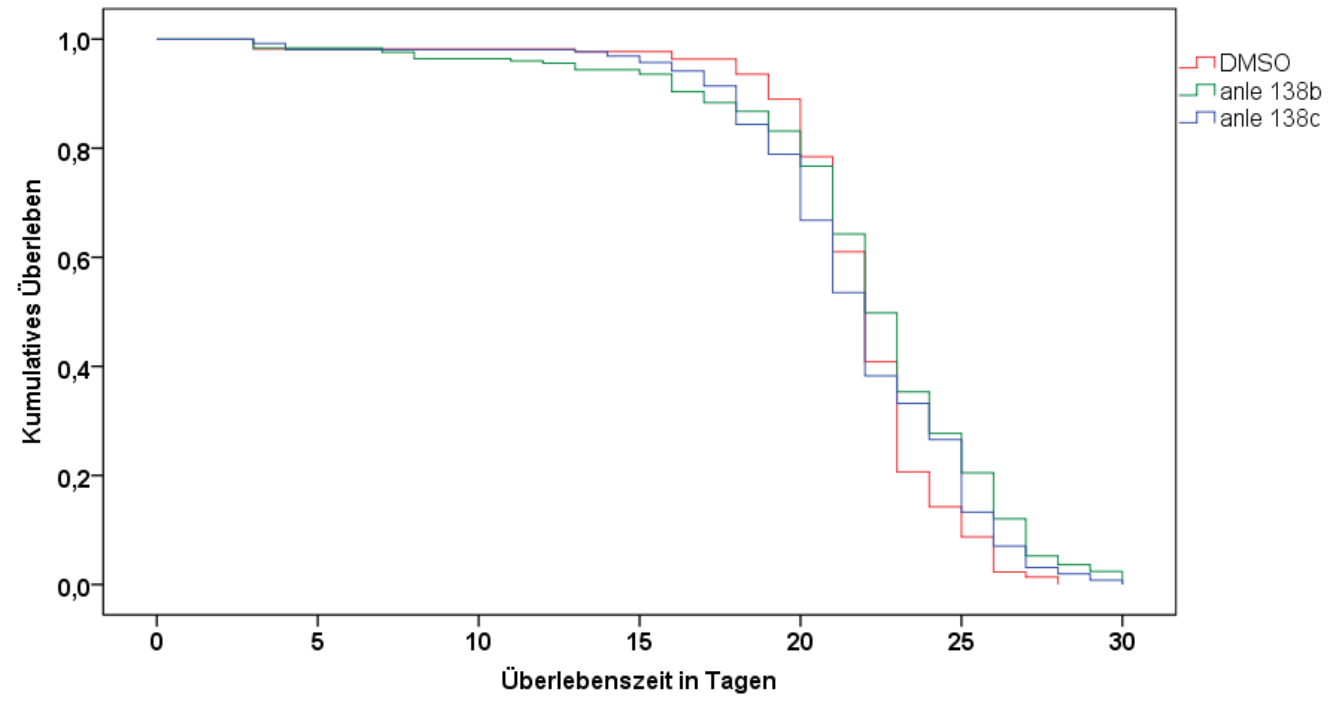

Abb. 13: Überlebensdauer von elavGal4/alz3;tubGal80[ts]/alz8 unter Zugabe von anle138b, anle138c und DMSO

Zur besseren Darstellung der Ergebnisse wurden die Kurven mit den Werten für anle138b, anle138c und DMSO der Abb.12 entnommen und gesondert dargestellt. Prozentuale Überlebensdauer der Versuchstiere mit dem Genotyp elavGal4/alz3;tubGal80[ts]/alz8 unter Verwendung der Modulatoren anle138b und 138c sowie der Negativkontrolle DMSO, gemessen in Tagen bei $29^{\circ} \mathrm{C}$. Die mittlere Überlebenswahrscheinlichkeit unter DMSO betrug 21,78 Tage, unter anle138b 22,0 Tage und unter anle138c 21,65 Tage. 
Tab. 7: Mittelwerte für die Überlebenszeit des Genotyps elavGal4/alz3;tubGal80[ts]/alz8

Tabellarische Aufzeichnung der Mittelwerte für die Überlebenszeit der F1-Generation der Linie elavGal4/alz3;tubGal80[ts]/alz8 mit und ohne Verwendung verschiedener Wirkstoffe.

\begin{tabular}{|c|c|c|c|c|c|}
\hline \multirow[b]{3}{*}{ Genotyp } & & \multicolumn{4}{|c|}{ Mittelwert } \\
\hline & & \multirow[b]{2}{*}{ Schätzer } & \multirow[b]{2}{*}{ Standardfehler } & \multicolumn{2}{|c|}{ 95\%-Konfidenzintervall } \\
\hline & & & & Untere Grenze & Obere Grenze \\
\hline \multirow{12}{*}{$\begin{array}{l}\text { elavGal4/ } \\
\text { alz3;tub } \\
\text { Gal80/alz8 }\end{array}$} & Ohne Behandlung & 19,920 & 244 & 19,442 & 20,398 \\
\hline & DMSO & 21,775 & ,231 & 21,322 & 22,228 \\
\hline & anle $138 b$ & 22,004 & 296 & 21,424 & 22,584 \\
\hline & anle $138 \mathrm{c}$ & 21,652 & 253 & 21,156 & 22,149 \\
\hline & anle $253 b$ & 22,121 & ,411 & 21,315 & 22,927 \\
\hline & anle $145 c$ & 23,359 & 286 & 22,798 & 23,920 \\
\hline & sery $392 b$ & 22,294 & ,473 & 21,368 & 23,221 \\
\hline & sery $335 b$ & 21,163 & ,473 & 20,236 & 22,090 \\
\hline & sery $313 b$ & 21,844 &, 511 & 20,843 & 22,845 \\
\hline & sery 118 & 21,786 &, 535 & 20,738 & 22,833 \\
\hline & sery 85 & 21,578 & ,464 & 20,668 & 22,487 \\
\hline & Gesamt & 21,788 & 107 & 21,578 & 21,998 \\
\hline
\end{tabular}

Tab. 8: Mittlere Überlebenswahrscheinlichkeit im paarweisen Vergleich unter Zugabe von Modulatoren

Tabellarische Darstellung der Signifikanztestung im paarweisen Vergleich in Bezug auf die mittlere Überlebenswahrscheinlichkeit der F1-Generationen der Linie elavGal4/alz3;tubGal80[ts]/alz8.

\begin{tabular}{|c|c|c|c|c|c|c|c|c|c|c|c|c|}
\hline & & Ohne Behandlung & DMSO & anle 138b & anle 138c & anle $253 b$ & anle $145 \mathrm{c}$ & sery $392 b$ & sery $335 b$ & sery $313 b$ & sery 118 & sery 85 \\
\hline elavGal4/ & Ohne Behandlung & & 000 & 000 &, 000 &, 000 & 000 & 000 & 000 & , 000 &, 000 &, 000 \\
\hline alz3; & DMSO & ,000 & & 001 & ,252 & ,001 & ,000 & ,001 & ,939 & ,015 & ,009 & ,090 \\
\hline tubGal80/ & anle 138b & 000 & 001 & & ,027 & ,923 & ,043 & 960 & ,007 & 671 & ,680 & ,290 \\
\hline \multirow[t]{8}{*}{ alz8 } & anle 138c & 000 & ,252 & 027 & & 069 & 000 & , 132 & ,313 & ,213 & ,257 & ,635 \\
\hline & anle 253b & ,000 & 001 & ,923 & 069 & & ,067 & ,929 & ,004 & ,639 & ,716 & ,306 \\
\hline & anle 145c & 000 & ,000 & 043 & 000 & 067 & & 057 & ,000 & 041 & 045 & ,010 \\
\hline & sery $392 b$ & ,000 & 001 & ,960 & , 132 & ,929 & ,057 & & ,004 & ,641 & ,798 & ,337 \\
\hline & sery $335 b$ & ,000 & ,939 & 007 &, 313 & 004 & 000 & ,004 & & 043 & 025 & ,153 \\
\hline & sery $313 b$ & ,000 & ,015 & ,671 & ,213 & ,639 & ,041 & ,641 & 043 & & ,992 & ,446 \\
\hline & sery 118 & 000 & 009 & ,680 & ,257 & ,716 & ,045 & ,798 & ,025 & ,992 & & ,527 \\
\hline & sery 85 & .000 & 090 & 290 & .635 & .306 & .010 & .337 &, 153 & .446 & .527 & \\
\hline
\end{tabular}

In den Abb. 14 und Abb. 15 (Seite 35) ist die Überlebensdauer der F1-Generation mit dem Genotyp elavGal4/arc2e;tubGal80[ts] unter Applikation von unterschiedlichen Wirkstoffen dargestellt. Unter sery392b $(n=149)$, sery335b $(n=165)$ und sery313b $(n=153)$ zeigte sich ein nicht signifikant verkürztes Überleben gegenüber der mit DMSO behandelten Fliegen. Die mittlere Überlebenswahrscheinlichkeit der mit sery85 $(n=163)$ behandelten Fliegen war signifikant vermindert gegenüber dem Überleben der Fliegen, welche mit DMSO $(n=156)$ behandelt wurden. Unter Verwendung von sery118 $(n=148)$, anle253b $(n=149)$, anle145c $(n=147)$, anle138b $(n=156)$ und anle138c $(n=155)$ zeigte sich jeweils ein signifikant verlängertes Überleben gegenüber der Verwendung von DMSO. 
In den Tabellen 9 und 10 (Seite 36) sind zudem die mittleren Überlebenswahrscheinlichkeiten mit den dazugehörigen Signifikanzwerten für die F1-Generation mit dem Genotyp elavGal4/arc2e;tubGal80[ts] dargestellt.

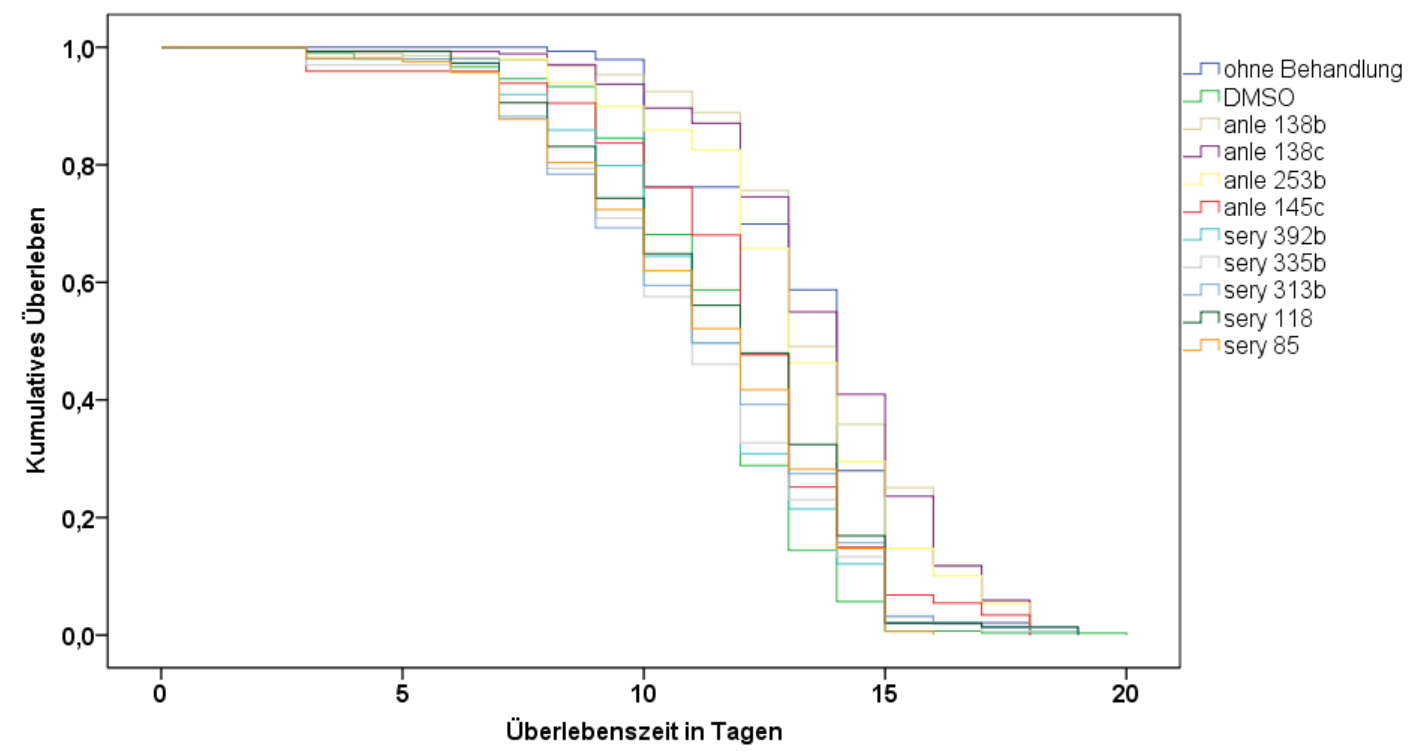

Abb. 14: Überlebensdauer von elavGal4/arc2e;tubGal80[ts] unter Wirkstoffzugabe

Prozentuale Überlebensdauer der Versuchstiere $(n=1688)$ mit dem Genotyp elavGal4/arc2e;tubGal80 [ts] unter Verwendung verschiedener Modulatoren und DMSO als Negativkontrolle, gemessen in Tagen bei $29^{\circ} \mathrm{C}$. Das mittlere Überleben betrug 11,04 bis 13,75 Tage.

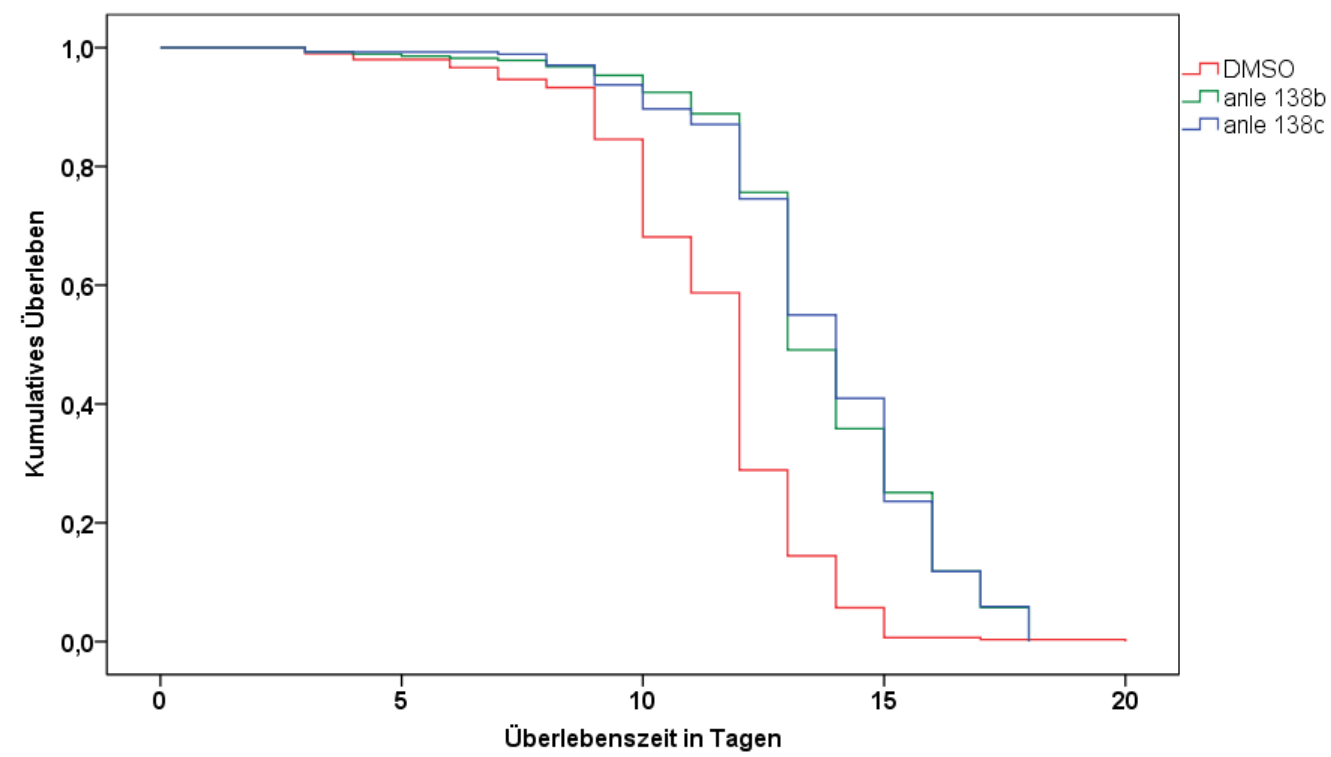

Abb. 15: Überlebensdauer von elavGal4/arc2e;tubGal80[ts] unter Wirkstoffzugabe

Zur besseren Darstellung der Ergebniss wurden die Kurven mit den Werten für anle138b, anle138c und DMSO der Abb.14 entnommen und gesondert dargestellt. Prozentuale Überlebensdauer der Versuchstiere mit dem Genotyp elavGal4/arc2e;tubGal80[ts] unter Verwendung der Wirkstoffe anle138b und 138c sowie der Negativkontrolle DMSO, gemessen in Tagen bei $29^{\circ} \mathrm{C}$. Die mittlere Überlebenswahrscheinlichkeit unter DMSO betrug 11,42 Tage, unter anle138b und anle138c 13,70 bzw.13,75 Tage. 
Tab. 9: Mittelwerte für die Überlebenszeit des Genotyps elavGal4/arc2e;tubGal80[ts] Tabellarische Aufzeichnung der Mittelwerte für die Überlebenszeit der F1-Generation der Linie elavGal4/arc2e;tubGal80[ts] mit und ohne Verwendung verschiedener Wirkstoffe.



Tab. 10: Mittlere Überlebenswahrscheinlichkeit im paarweisen Vergleich unter Zugabe von Modulatoren

Tabellarische Darstellung der Signifikanztestung im paarweisen Vergleich in Bezug auf die mittlere Überlebenswahrscheinlichkeit der F1-Generationen der Linie elavGal4/arc2e;tubGal80[ts].

\begin{tabular}{|c|c|c|c|c|c|c|c|c|c|c|c|c|}
\hline & & Ohne Behandlung & DMSO & anle $138 \mathrm{~b}$ & anle $138 \mathrm{c}$ & anle $253 b$ & anle $145 \mathrm{c}$ & sery $392 b$ & sery $335 b$ & sery $313 b$ & sery 118 & sery 85 \\
\hline elavGal4/ & ohne Behandlung & &, 000 & ,003 & 001 & ,638 &, 000 & 000 & 000 & 000 & 000 & 000 \\
\hline arc2e; & DMSO &, 000 & &, 000 &, 000 &, 000 &, 000 &, 594 & 808 & 159 & ,003 & ,093 \\
\hline \multirow[t]{9}{*}{ tubGal80 } & anle 138b & ,003 & ,000 & & ,765 & ,082 & ,000 & ,000 & ,000 & ,000 & ,000 & ,000 \\
\hline & anle 138c & 001 & 000 & ,765 & & 043 & 000 & ,000 & ,000 &, 000 & 000 & ,000 \\
\hline & anle 253b & ,638 & 000 & ,082 & ,043 & & ,000 & ,000 & 000 & ,000 & ,000 & ,000 \\
\hline & anle 145c &, 000 & ,000 &, 000 & 000 &, 000 & & 021 & ,010 & ,141 & ,743 & ,075 \\
\hline & sery $392 b$ & ,000 & ,594 & ,000 & ,000 &, 000 & ,021 & & ,727 & ,591 & ,101 & ,622 \\
\hline & sery 335b & 000 & 808 & ,000 & 000 &, 000 &, 010 &, 727 & &, 423 &, 070 & ,521 \\
\hline & sery $313 b$ & ,000 & ,159 & ,000 & ,000 & ,000 & ,141 & ,591 & ,423 & & ,346 & 856 \\
\hline & sery 118 & 000 & ,003 & 000 & 000 & 000 & ,743 & ,101 & 070 & 346 & & ,265 \\
\hline & sery 85 & .000 & .093 & .000 & .000 & .000 & .075 & .622 & .521 & .856 & 265 & \\
\hline
\end{tabular}

Zusammenfassend zeigte sich bei den Fliegen mit dem Genotyp elavGal4;tubGal80[ts] lacz unter Verwendung von sery392b, sery313b und anle145c ein signifikant verlängertes Überleben gegenüber DMSO sowie ein nicht signifikantes verlängertes Überleben unter Verwendung von anle138b und anle138c.

Bei den Fliegen mit dem Genotyp elavGal4/alz3;tubGal80[ts]/alz8 konnte ein signifikant verlängertes Überleben unter Applikation von anle138b, anle145c, sery392b und sery313b nachgewiesen werden. Das initial gezeigte signifikant verlängerte Überleben unter anle138c konnte im Verlauf nicht reproduziert werden. Die Modulatoren anle138b, anle138c, anle145c, 
anle253b und sery118 zeigten ein signifikant verlängertes Überleben bei Fliegen mit dem Genotyp elavGal4/arc2e;tubGal80[ts].

\subsection{Einfluss der getesteten Wirkstoffe auf lösliches und unlösliches- $\mathrm{A} \boldsymbol{\beta}_{42}$}

Die Linien $w^{1118}$;alz3;alz8, $w^{1118}$;arc2e sowie die Kontrolle $w^{1118}$;lacz wurden für die Quantifizierung von löslichem und unlöslichem $A \beta_{42}$ mit der Treiberlinie elavGal4;tubGal80[ts] verkreuzt. Die Wirkstoffgabe erfolgte gemäß dem Protokoll für den longevity assay. Nach Erreichen der mittleren Überlebenswahrscheinlichkeit wurden die Fliegen dekaptiert und die Proteinmenge bestimmt. In den Abb. 16 und Abb. 17 (Seite 38) sind die absoluten Mengen von unlöslichem und löslichem $A \beta_{42}$ in pikogramm (pg) dargestellt. Unter DMSO-Gabe zeigte sich eine leicht erhöhte lösliche $A \beta_{42}$-Menge gegenüber anle138b und anle138c und eine verminderte Menge von unlöslichem $A \beta_{42}$ in den Fliegen mit dem Genotyp elavGal4/alz3;tubGal80[ts]/alz8.

In den Versuchstieren mit dem Genotyp elavGal4/arc2e;tubGal80[ts] konnte unter Zugabe von DMSO im Verhältnis zu anle138b und anle138c eine erhöhte Menge von unlöslichem $A \beta_{42}$ und eine verminderte Menge von löslichem $A \beta_{42}$ festgestellt werden. In den Fliegen mit dem Genotyp elavGal4;tubGal80[ts],lacz erfolgte ebenfalls eine Quantifizierung von löslichem und unlöslichem $A \beta_{42}$. Die Werte waren jedoch, wie erwartet, unterhalb der Nachweisgrenze. 


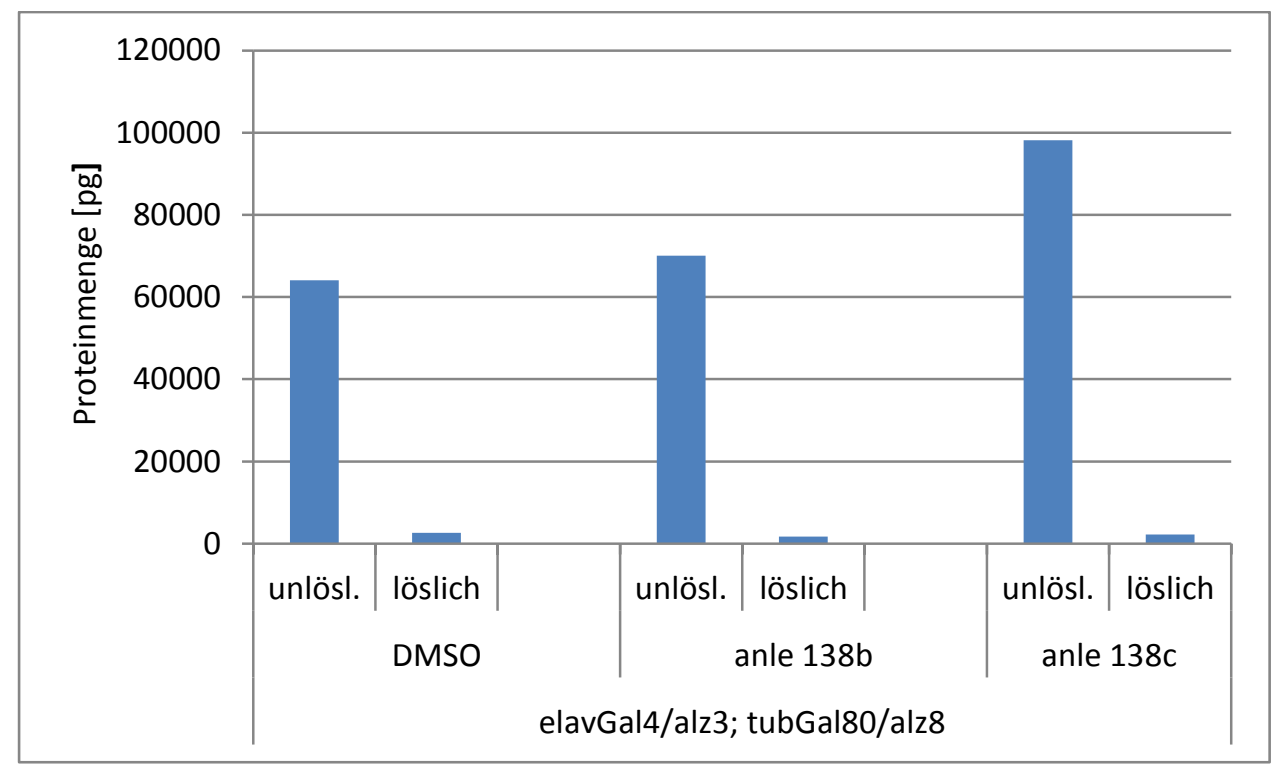

Abb. 16: Darstellung der $A \beta_{42}$-Proteinmenge am Bsp. des Genotyps elavGal4/alz3;tubGal80[ts] /alz8

Quantifizierung der Anteile von unlöslichem und löslichem $A \beta_{42}$ aus den Fliegengehirnen von elavGal4/alz3;tubGal80[ts]/alz8 im Alter von 22 Tagen. Unter Zugabe von DMSO $64080 \mathrm{pg}$ unlösliches $A \beta_{42}$ und $2610 \mathrm{pg}$ lösliches $A \beta_{42}$, unter anle138b $70020 \mathrm{pg}$ unlösliches $A \beta_{42}$ und $1710 \mathrm{pg}$ lösliches $A \beta_{42}$ und unter anle138c 98100 pg unlösliches und 2190 pg lösliches $A \beta_{42}$.

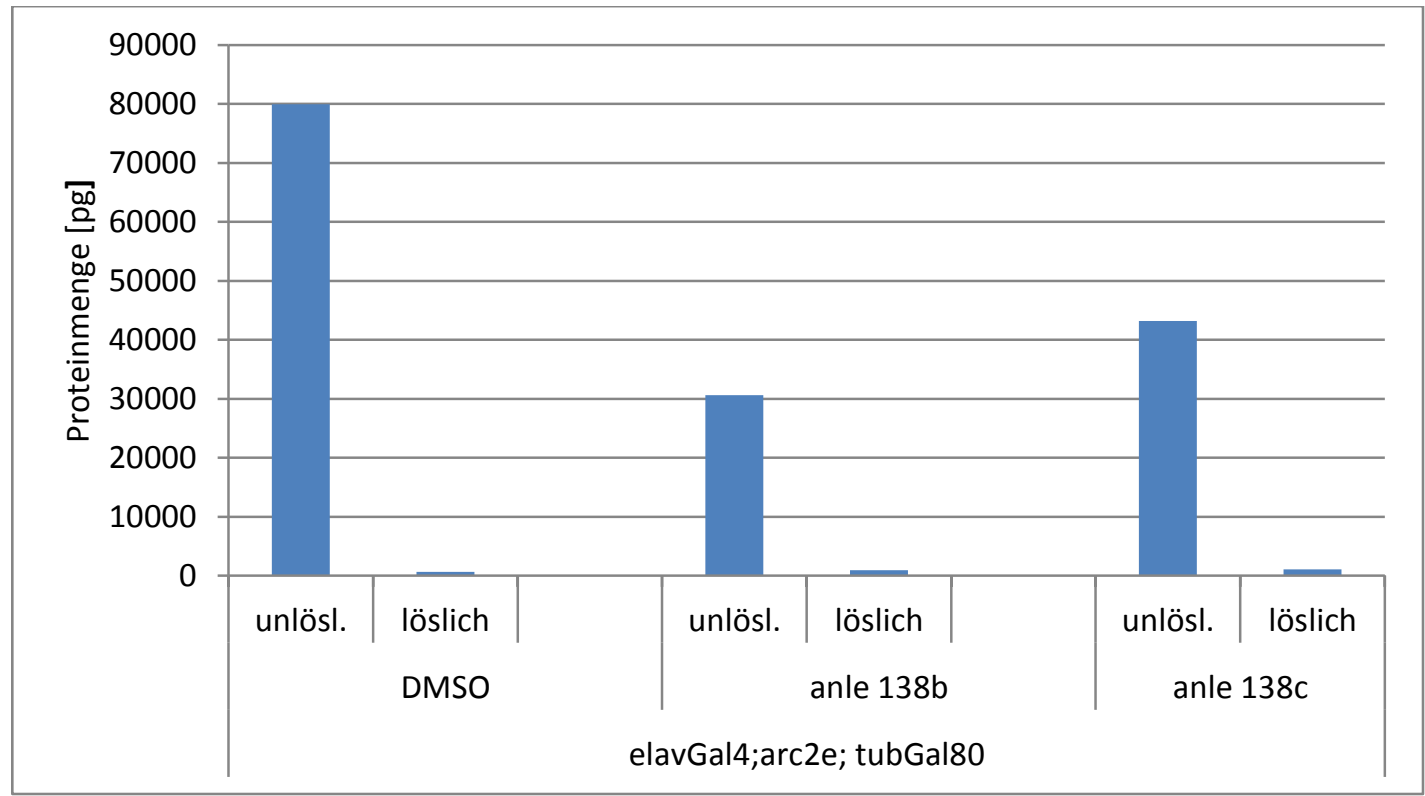

Abb. 17: Darstellung der $A \beta_{42}$-Proteinmenge am Bsp. des Genotyps elavGal4/arc2e;tubGal80[ts] Quantifizierung der Anteile von unlöslichem und löslichem $A \beta_{42}$ aus den Fliegengehirnen von elavGal4/arc2e;tubGal80[ts] im Alter von 12 Tagen. Unter Zugabe von DMSO 79920 pg unlösliches $A \beta_{42}$ und $675 \mathrm{pg}$ lösliches $A \beta_{42}$, unter anle138b $30600 \mathrm{pg}$ unlösliches $A \beta_{42}, 900$ pg lösliches $A \beta_{42}$ und unter anle138c $43200 \mathrm{pg}$ unlösliches und $1100 \mathrm{pg}$ lösliches $A \beta_{42}$. 
In der Betrachtung des Verhältnisses von unlöslichem $A \beta_{42}$ zum Gesamt-A $\beta_{42}$ (Abb. 18) zeigten sich beim Genotyp elavGal4/arc2e;tubGal80[ts] Werte von 0,99 (DMSO), 0,97 (anle138b) und 0,97 (anle138c), sowie in der Linie elavGal4/alz3;tubGal80[ts]/alz8 Werte von 0,96 für DMSO, 0,98 für anle138b und 0,98 für anle138c



\section{Abb. 18: Darstellung des Verhältnisses von unlöslichem zum Gesamt- $A \beta_{42}$}

Verhältnis von unlöslichem $A \beta_{42}$ zum Gesamt- $A \beta_{42}$ am Bsp. von elavGal4/arc2e;tubGal80[ts] und elavGal4/alz3;tubGal80[ts]/alz8. Bezug von unlöslichem zu Gesamt-A $\beta_{42}$ in der familiären transgenen Linie unter Zugabe von DMSO 0,99, unter Zugabe von anle138b 0,97 und unter Zugabe von anle138c 0,97. Bezug von unlöslichem zum Gesamt- $A \beta_{42}$ bei den Fliegen mit dem Genotyp elavGal4/alz3;tubGal80[ts]/alz8 unter Zugabe von DMSO 0,96, unter Zugabe von anle138b 0,98 und unter Zugabe von anle138c 0,98.

Bei den Fliegen mit dem Genotyp elavGal4/alz3;tubGal80[ts]/alz8 zeigten sich verminderte absolute Werte des unlöslichen $A \beta$ unter Verwendung von DMSO gegenüber anle138b und anle138c. Bei den Fliegen mit dem Genotyp elavGal4/arc2e,tubGal80[ts] zeigten sich hingegen erhöhte Werte des unlöslichen $A \beta$ und leicht verminderte Werte des löslichen $A \beta$ unter Applikation von DMSO gegenüber anle138b und anle138c. Die Ergebnisse weisen auf eine mögliche Verlagerung des Gleichgewichts von unlöslich zu löslich hin, wobei keine Replikation des Experiments erfolgte und die Daten deshalb nur von sehr begrenzter Aussagekraft sind. Eine Wiederholung des Experiments müsste außerdem zu einem früheren Zeitpunkt stattfinden, da zum gewählten Zeitpunkt eine nahezu vollständige Aggregation von $A \beta$ stattgefunden hatte.

Aus dem Experiment lässt sich unter Berücksichtigung der Einschränkung durch die fehlende Wiederholung schlussfolgern, dass die Aggregationsinhibitoren nicht die Ablagerung von unlöslichem $A \beta$ per se inhibieren, was passend zur eingangs erwähnten Möglichkeit einer Stabilisierung von off pathway Oligomeren wäre. 


\subsection{Photorezeptorspezifische Expression von $A \beta_{42}$}

Im weiteren Verlauf wurde die lokale Expression des $A \beta_{42}$ in den Photorezeptoren von Drosophila melanogaster untersucht. Das optische System gehört zum peripheren Nervensystem, wobei das Komplexauge aus ca. 800 Ommatidien besteht (Ready, 1989; Treisman, 2013) von denen jede eine funktionelle Einheit der Retina darstellt. Eintretende Veränderungen, beispielsweise neuronale Schädigungen, können nach außen sichtbar gemacht werden.

\subsubsection{Physiologischer Augenphänotyp}

Zunächst wurden die Komplexaugen der Linien $w^{1118}$,arc2e/arc2e, CD8eGFP und GMR/CyO ohne Verwendung der Treiberlinie einen Tag nach dem Schlüpfen untersucht.

In den Abb. 19 A-C waren keine strukturellen Defizite im Bereich der Facettenaugen erkennbar. Es fanden sich bei den o.g Linien bei einer konstanten Temperatur von $29{ }^{\circ} \mathrm{C}$ eine homogene Verteilung des Augenfarbstoffes sowie eine physiologische Anordnung der Ommatidien.
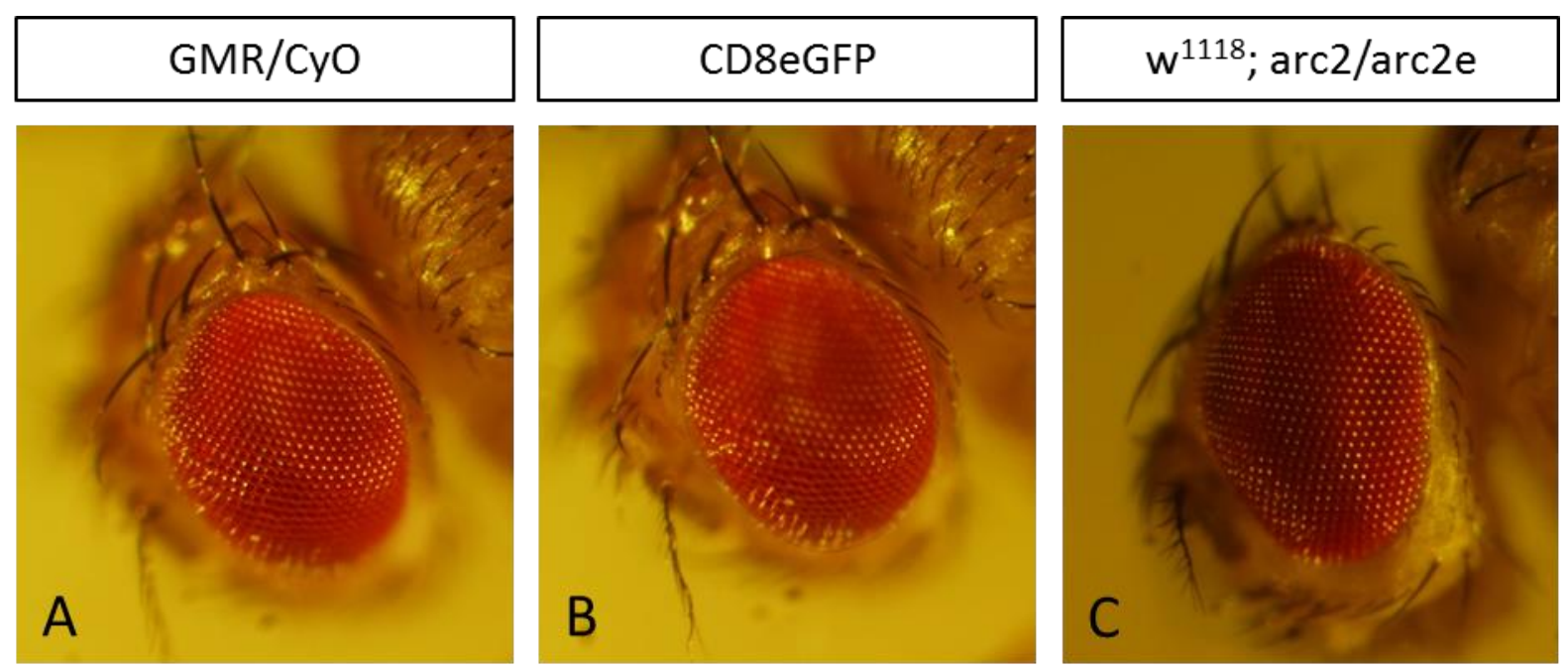

Abb. 19: Darstellung des physiologischen Augenphänotyps verschiedener Fliegenlinien

A: Adulte Fliege $(\mathrm{GMR} / \mathrm{CyO})$ im Alter von einem Tag mit homogener Verteilung des Augenfarbstoffes und der Facettenaugen.

B: Darstellung einer adulten Fliege (CD8eGFP) im Alter von einem Tag mit homogener Verteilung des Augenfarbstoffes und physiologischer Anordung der Ommatidien.

C: Adulte Fliege $\left(\mathrm{w}^{1118}\right.$;acr2e/arc2e) mit homogner Verteilung der Facettenaugen und des Augenfarbstoffes im Alter von einem Tag 


\subsubsection{Pathologischer Augenphänotyp}

\subsubsection{Augenphänotyp von GMR/arc2e unter Verwendung der Wirkstoffe anle138b und anle138c sowie der Negativkontrolle DMSO}

In der F1-Generation der Linie GMR/arc2e zeigten sich bereits ein Tag nach dem Schlüpfen (Abb. 20) beginnende pathologische Erscheinungen mit Vakuolenbildung und inhomogener Verteilung des Augenfarbstoffes. Mit zunehmendem Alter (Tag 7) nahmen die pathologischen Veränderungen auch unter Applikation der Wirkstoffe anle138b und anle138c sowie unter der Negativkontrolle DMSO weiter zu.


Abb. 20: Augenphänotyp mit dem Genotyp GMR/arc2e unter $29^{\circ} \mathrm{C}$
A: Adulte Fliege (GMR/arc2e) im Alter von einem Tag mit Zeichen einer Vakuolisierung.
B: Adulte Fliege (GMR/arc2e) im Alter von 7 Tagen mit ausgeprägter Vakuolisierung und zum Teil fehlendem Augenfarbstoff unter anle138b.
C: Adulte Fliege (GMR/arc2e) im Alter von 7 Tagen mit ausgeprägter Vakuolisierung und zum Teil fehlendem Augenfarbstoff unter anle138c.
D: Adulte Fliege (GMR/arc2e) im Alter von 7 Tagen mit ausgeprägter Vakuolisierung und zum Teil fehlendem Augenfarbstoff unter DMSO 


\subsubsection{Augenphänotyp der Kontrolle GMR/CyO unter Verwendung der Wirkstoffe anle138b und anle138c sowie der Negativkontrolle DMSO.}

In der F1-Generation der Linie GMR/CyO zeigte sich ein Tag nach dem Schlüpfen (Abb. $21 \mathrm{~A}$ ) ein physiologischer Augenphänotyp ohne strukturelle pathologische Erscheinungen. Mit zunehmendem Alter (Tag 7) nahmen die pathologischen Veränderungen unter gleichzeitiger Applikation der Wirkstoffe anle138b und anle138c sowie unter der Negativkontrolle DMSO zu (Abb. 21 B-D).
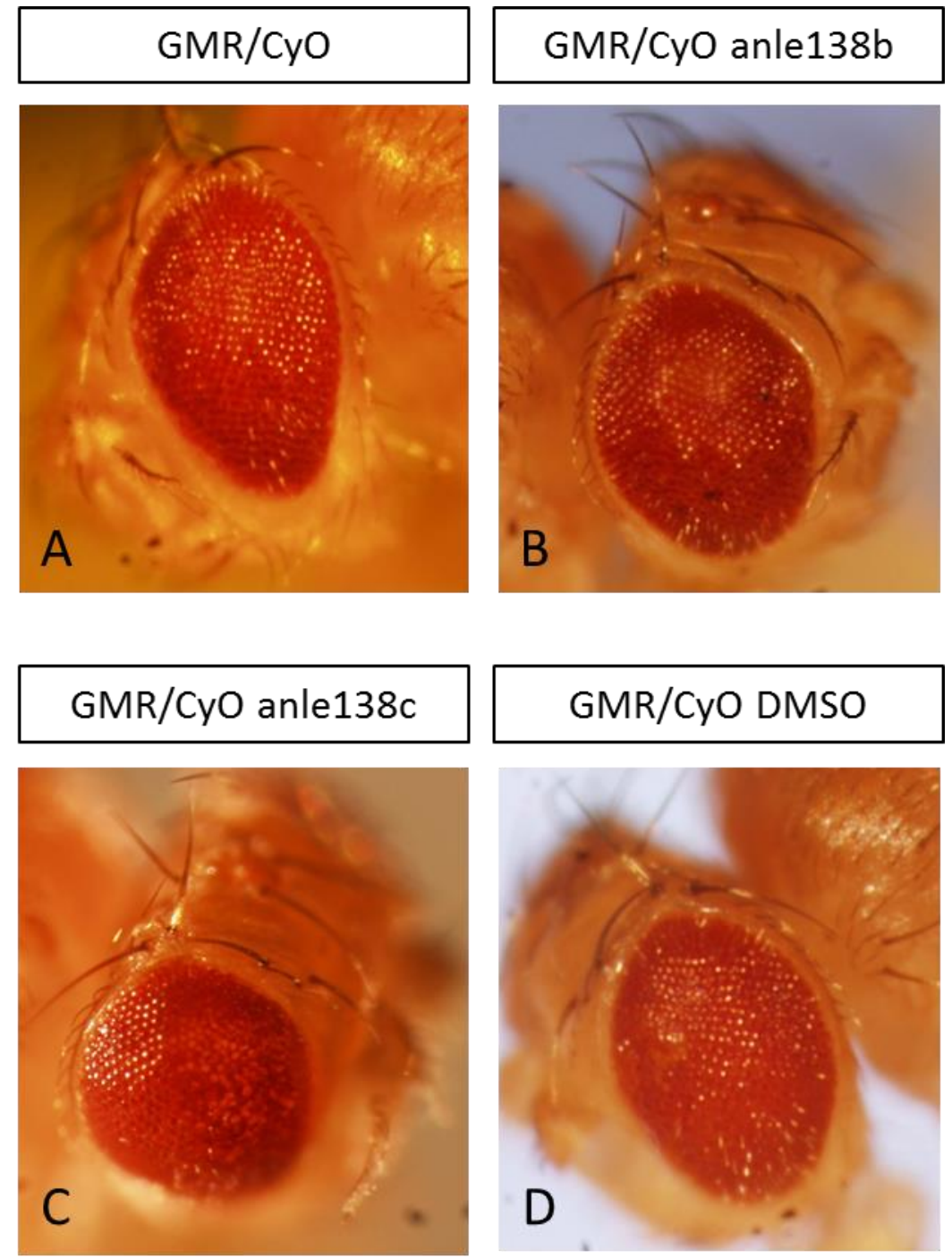

Abb. 21: Augenphänotyp der Fliegenlinie GMR/CyO unter $29^{\circ} \mathrm{C}$

A: Homogene Verteilung der Facettenaugen und des Augenfarbstoffes im Alter von einem Tag

B: Adultes Fliegenauge der Kontrolllinie im Alter von 7 Tagen, unter Applikation von anle138b mit Zeichen einer Vakuolisierung sowie eine verminderte Augenfarbstoffkonzentration insbesondere im zentralen Augenbereich.

C: Adultes Fliegenauge der Kontrollinie im Alter von 7 Tagen unter Applikation von anle138c mit Vakuolisierung und teilweiser Aufhebung des Augenfarbstoffes

D: Adultes Fliegenauge der Kontrollinie im Alter von 7 Tagen unter Applikation von DMSO mit Zeichen einer Vakuolisierung und teilweisen Aufhebung des Augenfarbstoffes 


\subsubsection{Augenphänotyp der Kontrolle elav GMR/eGFP unter Verwendung der Wirkstoffe anle138b und anle138c sowie der Negativkontrolle DMSO.}

In der F1-Generation der Linie GMR/eGFP waren bereits ein Tag nach dem Schlüpfen

(Abb. 22 A) Vakuolen erkennbar. Mit zunehmendem Alter und unter Applikation der Wirkstoffe anle138b und anle138c sowie unter der Negativkontrolle DMSO nahm die Vakuolenbildung weiter zu. Parallel war eine inhomogene Augenfarbstoffverteilung zu erkennen (Abb. 22 B-D).
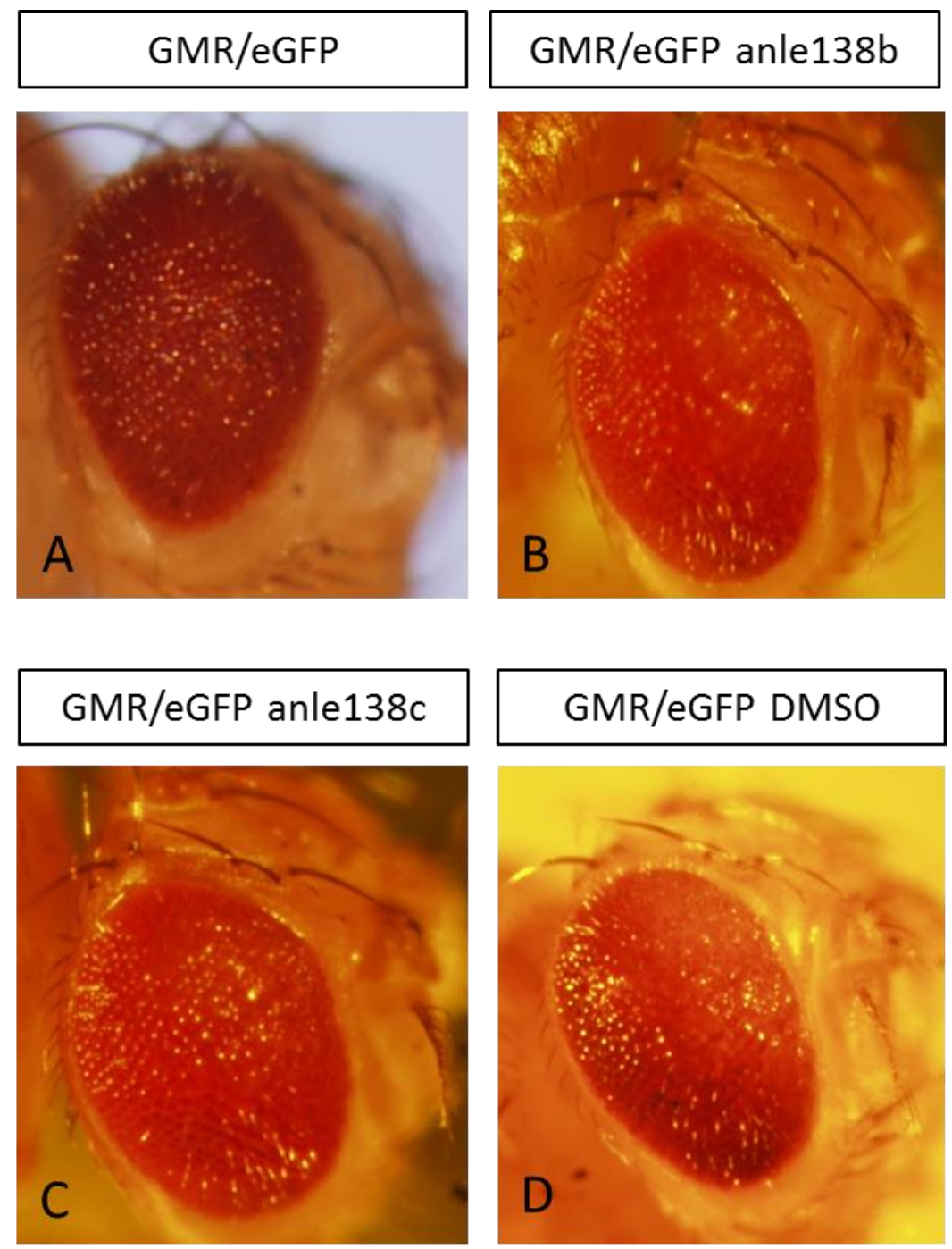

Abb. 22: Augenphänotyp des Genotyps GMR/CD8eGFP(eGFP) unter $29^{\circ} \mathrm{C}$

A: Weitestgehend homogene Verteilung der Facettenaugen und des Augenfarbstoffes einer Fliege mit dem Genotyp GMR/eGFP im Alter von einem Tag. Leichte Schädigungen vor allem im unteren Randbereich des Auges erkennbar

B: Adultes Fliegenauge der Kontrolle GMR/eGFP im Alter von 7 Tagen, unter Applikation von anle138b. Insbesondere im zentralen Bereich des Auges deutliche Vakuolisierung.

C: Adultes Fliegenauge der Kontrolle GMR/eGFP im Alter von 7 Tagen, unter Applikation von anle138c. Vakuolenbildung vor allem im seitlichen Abschnitt des Auges.

D: Adultes Fliegenauge der Kontrolle GMR/eGFP im Alter von 7 Tagen unter Applikation von DMSO mit teilweise Aufhebung des Augenfarbstoffes und Vakuolenbildung. 


\section{Diskussion}

M. Alzheimer zählt zu den häufigsten neurodegenerativen Erkankungen im höheren Lebensalter. Aufgrund des demographischen Wandels mit steigendem Lebensalter nehmen die Inzidenz und Prävalenz der erkrankten Personen stetig zu. Aus diesem Grund ist es notwendig, die molekularbiologischen Grundlagen der Erkrankung zu verstehen und neue Wirkstoffe zur Therapie des M. Alzheimer zu entwicklen. In Studien konnte gezeigt werden, dass das Entfernen bereits bestehender A $\beta$-Plaques keinen Einfluss auf das kognitive Defizit hat. Vielmehr ist die Verhinderung der Bildung toxisch wirkender Oligomere in den Vordergrund der Forschung gerückt.

Die Arbeit beschäftigt sich mit der Testung potentieller Aggregations-Modulatoren auf die A $\beta$-Toxizität im Tiermodell Drosophila melanogaster.

\subsection{Auswahlverfahren verschiedener Mutanten}

Zur Erforschung der Pathogenese der Alzheimer-Erkrankung wurden verschiedene transgene Fliegenmodelle hergestellt (Crowther, Kinghorn et al., 2005; Finelli, Kelkar et al., 2004; Wittmann, Wszolek et al., 2001). Unter Verwendung unterschiedlicher Gal4Treiberlinien konnten verkürzte Lebenserwartungen, motorische Defizite sowie Veränderungen der Augen dargestellt werden. In dieser Arbeit zeigten sich unter $29^{\circ} \mathrm{C}$ ein deutlich vermindeter Überlebensphänotyp, motorische Defizite sowie ein Augenphänotyp für die F1-Generation der Alzheimermutante $w^{1118}$;arc2e sowie für die doppelt transgen veränderte Fliegenlinie $\mathrm{w}^{1118}$;alz3;alz8.

Für die Tiere des Genotyps elavGal4/alz3;tubGal80[ts]/alz8 zeigte sich im Mittel ein 52,05\% längeres Überleben im Vergleich zur Alzheimermutante elavGal4/arc2e;tubGal80[ts].

Im Gegensatz zu den publizierten Ergebnissen (Crowther, Kinghorn et al., 2005; Finelli, Kelkar et al., 2004), konnten bei den Linien mit einfach inseriertem $A \beta_{42}$-Peptid unabhängig von der Temperatur nur geringe Unterschiede zu den Kontrollen in Bezug auf das Überleben und die motorischen Fähigkeiten nachgewiesen werden. Die Expression des $A \beta_{42}$ zur Ausbildung eines Phänotyps fällt hier möglicherweise zu gering aus. Ursächlich hierfür könnte die Verwendung einer anderen Treiberlinie, als die im Paper beschriebene Linie (elavC155) sein. Zudem schwanken die absoluten Überlebenszeiten auch bei den Kontrolllinien, was auf einen anfälligen assay bei nur schwacher Phänotypausprägung hinweist. Eine weitere Ursache könnte eine eventuelle Kontamination der nicht gebalancten Fliegenlinie sein. 


\subsection{Einfluss der Wirkstoffe auf das Überleben und Aggregationsverhalten der transgen veränderten Fliegen}

\subsubsection{Auswirkungen der Wirkstoffe auf das Überleben der Fliegen}

Für die Testung der verschiedenen Oligomermodulatoren wurden die im Vorfeld untersuchten transgenen Linien $\mathrm{w}^{1118}$;arc2e, $\mathrm{w}^{1118}$ alz3;alz8 sowie die temperaturabhängige Treiberlinie elavGal4;tubGal80[ts] verwendet. Als Kontrolle diente die Linie $w^{1118}$;lacz.

\subsubsection{Auswirkungen der Wirkstoffe auf Fliegen mit dem Genotyp elavGal4/tubGal80[ts],lacz}

Unter Anwendung der Wirkstoffe konnte kein signifikanter Überlebensvor- oder nachteil für Kontrollfliegen des Genotyps elavGal4;tubGal80[ts] lacz gegenüber der Negativkontrolle DMSO festgestellt werden (Tab. 11 und Tab. 12 im Anhang).

Die mittlere Überlebenszeit ohne Zugabe von DMSO fiel um 10,28 bis 20,24 \% höher aus, verglichen zu den Fliegen, die mit DMSO bzw. mit in DMSO gelösten Wirkstoffen behandelt wurden.

Die Ursache hierfür ist am ehesten die bereits in der Literatur beschriebene Toxizität des DMSO, insbesondere bei Konzentrationen über 0,3\% (Nazir, Mukhopadhyay et al., 2003). Unter Zugabe der sery-Modulatoren war in den Versuchstieren mit $A \beta_{42}$-Expression sowie teilweise in der Kontrolle ein signifikant vermindertes Überleben gegenüber DMSO zu sehen. Dies deutet auf einen zum DMSO additiv toxisch wirkenden Effekt der Modulatoren auf die Fliegenlinien hin.

\subsubsection{Auswirkung der Wirkstoffe im arctic - und im sporadischen Fliegenmodell}

In den durchgeführten Messungen zeigte sich eine signifikant erhöhte Überlebensdauer (Tab. 11 und Tab. 12 im Anhang) der $A \beta_{42}$-exprimierenden Fliegen unter Applikation unterschiedlicher Wirkstoffe gegenüber DMSO. Unter anle138b zeigte sich bei den Fliegen mit dem Genotyp elavGal4/arc2e;tubGal80[ts] eine Verlängerung der mittleren Überlebenswahrscheinlichkeit um 19,96 \% und unter anle138c um 20,4 \% gegenüber den mit DMSO behandelten Kontrollfliegen. 
Die stärksten positiven Effekte auf die mittlere Überlebenswahrscheinlichkeit im Modell elavGal4/alz3;tubGal80[ts]/alz8 zeigten die Modulatoren sery392b (5,23 \% höhere mittlere Überlebenswahrscheinlichkeit, $p=0,001)$ und anle145c $(7,25 \%$ höhere mittlere Überlebenswahrscheinlichkeit, $p=0,00)$.

\subsubsection{Quantifizierung von Iöslichem, unlöslichem und Gesamt-A $\beta_{42}$-Protein}

Mittels msd assay erfolgte die Quantifizierung von löslichem und unlöslichem $A \beta_{42}$ aus Proteinextrakten von Fliegengehirnen.

Für die Versuchstiere des Genotyps elavGal4;tubGal80[ts],lacz lag die $A \beta_{42}$-Proteinmenge, wie erwartet, unterhalb des messbaren Bereichs.

Die Auswertung zeigt, dass zum Messzeitpunkt nahezu alles $A \beta$ bereits aggregiert vorliegt. Möglicherweise könnten Messungen zu einem früheren Zeitpunkt Effekte von anle138b und anle138c zeigen, die mit voranschreitender Zeit verloren gehen. Eine Unterscheidung zwischen toxischen und nichttoxischen Oligomeren ist mit dieser Methode ebenfalls nicht möglich, so dass nicht klar ist, ob das Fehlen einer Reduktion der unlöslichen Aggregate mit einem fehlenden Wirkeffekt der anle-Substanzen gleichzusetzen ist. Zudem konnte das Experiment aus Zeitgründen auch nur einmal durchgeführt werden, so dass die Aussagekraft insgesamt sehr eingeschränkt ist.

\subsection{Lokale Expression von $A \beta_{42}$ im Auge von Drosophila melanogaster}

Um einen direkten Einfluss der Modulatoren auf die Struktur und Funktion von Neuronen zu testen, wurde $A \beta_{42}$ im Auge der Fliegen exprimiert. Durch den direkten Zugang zum Auge und somit zu den Photorezeptorzellen können etwaige Veränderungen direkt sichtbar werden.

Unter Verwendung der Treiberlinie zeigte sich in der F1-Generation der verkreuzten Fliegen bereits am 1. Tag nach dem Schlüpfen eine beginnende Vakuolenbildung bei den Fliegen mit dem Genotyp GMR/arc2e sowie leichte Veränderungen bei der Kontrolle GMR/CD8eGFP. Aufgrund des frühen Auftretens der Veränderungen ergeben sich Hinweise

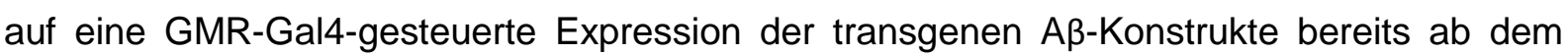
Embryonalstadium. Bei der Kontrolllinie (GMR/CyO) waren nach dem Schlüpfen keine Veränderungen in den Augen zu sehen. 
Im weiteren Verlauf zeigte sich auch unter Applikation der Wirkstoffe und der Negativkontrolle DMSO eine deutliche Zunahme der Fehlbildungen in den Augen der Fliegen mit $A \beta_{42}$-Expression. Die Ergebnisse korrelieren mit experimentellen Beobachtungen (Finelli, Kelkar et al., 2004), in denen die Degeneration der Facettenaugen mit steigendem Lebensalter bei $A \beta_{42}$ Expression zunehmend waren. Dabei zeigten sich Fehler in der Organisation der Facettenaugen, eine Verkleinerung des Auges insgesamt sowie eine verminderte Anzahl der interommatidialen Borsten. Die Schwere der Ausprägung korrelierte zusätzlich mit einer gesteigerten Insertionsrate des A $\beta$-Peptids (Crowther, Kinghorn et al., 2005) und ist am ehesten durch den progredienten Zelltod bedingt (Freeman, 1996; Kramer and Staveley, 2003).

Ähnliche Schädigungen zeigten sich auch im Versuch bei den behandelten Kontrollen nach 7 Tagen. Ursächlich hierfür könnte die Toxizität des DMSO sein, in dem die Wirkstoffe gelöst sind. Diese Vermutungen decken sich mit Beobachtungen von Nazir et al., wonach die Grenze der Toxizität des DMSO bei einer Konzentration von 0,3\% liegt. Darüber hinausgehende Konzentrationen wirken zytotoxisch und behindern die Entwicklung sowie die Reproduktionsfähigkeit der Fliegen (Nazir, Mukhopadhyay et al., 2003).

Die in den Experimenten verwendeten DMSO-Konzentrationen in den Wirkstoffen lagen bei $3 \%$, sodass eine Interpretation des äußeren Erscheinungsbildes unter diesen Umständen nicht möglich ist.

$\mathrm{Da} A \beta_{42}$ bereits seit dem Embryonalstadium exprimiert wurde, ist von irreversiblen Schädigungen des visuellen Systems durch das $A \beta_{42}$-Peptid bei den Fliegen mit dem Genotyp GMR/arc2e sowie durch Bildung von Peroxiden bei der Entstehung des Fluorophors bei der Linie GMR/CD8GFP während der Entwicklungsphasen auszugehen. Der progrediente Zelltod in der Treiberlinie GMR/CyO ist wahrscheinlich durch die Zytotoxizität des DMSO bedingt, das Fortschreiten der Schäden in den anderen Fliegen darüber hinaus auf eine kontinuierliche Expression der Proteine beziehungsweise auf die kontinuierliche Bildung der Peroxide zurückzuführen. Zum besseren Verständnis der pathologischen Veränderungen sollte eine Optimierung der einflussnehmenden Faktoren erfolgen. Mittels einer über Gal80[ts] steuerbaren Gal4GMR-Treiberlinie bestünde beispielsweise die Möglichkeit, dass $A \beta_{42}$ erst im adulten Stadium exprimiert wird und somit die irreversiblen Schädigungen vor dem Schlüpfen verhindert werden können. Infolgedessen wären mögliche Therapieeffekte besser zu interpretieren. Eine Besserung des Augenphänotyps ist unter diesen Bedingungen auch bei möglicher positiven Wirkung der Modulatoren auf die Amyloidproduktion nicht zu erwarten. 


\subsection{Mögliche Anwendung für die Klinik}

Die Herstellung antidementiv wirkender Medikamente steht neben der molekularbiologischen Grundlagenforschung im Focus der Alzheimerforschung.

Die im Fliegenmodell wirksamen Oligomermodulatoren anle138b und anle138c zeigten ein signifikant verlängertes Überleben, insbesondere für die arctic-Mutante im Fliegenmodell, sodass diese ein zukünftiger Ansatzpunkt zur Etablierung medikamentöser Therapien sein könnte. Bereits nach dem Schlüpfen der $A \beta$-Mutanten und somit vor Beginn der Therapie konnten leichte motorische Defizite im longevity assay beobachtet werden, die als Folgen der bereits in der Entwicklungsphase stattfindenden Expression des $A \beta$ zu interpretieren sind. Trotz beginnender klinischer Symptomatik erwiesen sich anle138b und anle138c als effektive Modulatoren, die einen Überlebensvorteil bewirkten. Dies erweist sich als nützlich, da Patienten zumeist erst mit einer verzögerten Latenz nach dem Auftreten der kognitiven Defizite den Arzt aufsuchen und die Diagnose gestellt wird. Die aktuell verfügbaren Antidementiva wirken oftmals nur unzureichend, insbesondere im fortgeschrittenen Demenzstadium.

Im nächsten Schritt sollten die Oligomermodulatoren im transgenen Alzheimer-Mausmodell getestet werden um die Wirksamkeit zu kontrollieren. Die Blut-Hirn-Schranke der Drosophila besteht, anders als beim Menschen, aus Oberflächen-assoziierten-Gliazellen (Schwabe, Bainton et al., 2005). Anle138b wurde bereits im $\alpha$-Syn- und im Creutzfeld-JakobMausmodell mit aussichtsreichen Ergebnissen getestet. Es zeigten sich ausreichende Plasmaspiegel und eine gute Blut-Hirn-Schrankenpenetration (Wagner, Ryazanov et al., 2013).

Eine Überprüfung der ZNS-Wirksamkeit und des Plasmaspiegels in Bezug auf anle138c wurden hingegen bisher nicht durchgeführt. Aufgrund der deutlichen Toxizität des DMSO, in dem die Wirkstoffe gelöst sind, sollte darüber hinaus nach weniger toxischen Lösungsmitteln gesucht werden.

Weiterhin stellt sich die Frage, ob bereits gebildete Fibrillen durch die Wirkstoffe moduliert werden können oder unwirksam werden.

Da eine Wirksamkeit des anle138b in vitro und in vivo in verschiedenen neurodegenerativen Krankheitsmodellen mit Proteinfehlfaltungen wie der Creutzfeld-Jakob-Erkrankung (PrionProtein-Scrapie), dem M. Parkinson ( $\alpha$-Synuclein) (Wagner, Ryazanov et al., 2013) und dem M. Alzheimer $(A \beta)$ gezeigt wurde, lässt sich ein gemeinsamer Mechanismus vermuten. Die Wirkweise der Oligomermodulatoren scheint dabei unabhängig von der Aminosäuresequenz der Peptide zu sein. Aufbauend auf den dargelegten Ergebissen sind die Modulatoren anle138b und anle138c positiv im Mausmodell getestet worden. 


\section{Zusammenfassung und Ausblick}

In der vorliegenden Arbeit "In-vivo-Screen verschiedener Aggregationsmodulatoren in transgenen Drosophila melanogaster Alzheimermodellen“ wurden die Aggregationsmodulatoren in verschiedenen Systemen der Drosophila melanogaster untersucht. Ziel der Arbeit war die Untersuchung der Wirksamkeit der synthetischen Diphenyl-Pyrazol-Derivate im Alzheimermodell in vivo, bei vorbeschriebener erfolgreicher Effektivität in vitro sowie in vivo im Creutzfeld-Jakob- und im Parkinsonmodell, um im nächsten Schritt eine Testung im Mausmodell durchführen zu können.

$\mathrm{Zu}$ Beginn der Arbeit erfolgte ein ausführliches Screeningverfahren zur Identifizierung geeigenter transgener Alzheimermodelle $\left(w\left[{ }^{11118}\right] ; P\{U A S-A \beta 1-42\} ; P\{U A S-A \beta 1-42\}\right.$ und $w\left[{ }^{11118}\right] ; P\left\{U A S-A r c t i c A \beta 1-42\right.$ (Glu22Gly)\}), Kontroll- $\left(w\left[{ }^{1118}\right] ; P\{w[+m C]=U A S-l a c Z . N Z\} 20 b\right.$ und $w[1118] P\{U A S-m C D 8: G F P . L\} L L 5)$ und Treiberlinien ( $w\left[{ }^{1118}\right] ; P\{w[+m C]=G A L 4-e l a v . L\} 2 / C y O$, $w\left[{ }^{1118}\right] ; P\{w[+m C]=t u b P-G A L 80[t s]\} 2 / T M 2, w\left[{ }^{1118}\right] ; P\{r y[+t 7.2]=n e o F R T\} 42 D P\{w[+m C]=M a e-$ GMR.EP\}hbs[EP]/CyO,w[1118]; P\{w[+mW.hs]=GawB\}VGlut[OK371]), die zur Ausbildung eines starken Phänotyps führten.

Unter Verwendung dieser charackteristischen Treiberlinien konnte die Expression von A $\beta$ gewebespezifisch gesteuert werden. Mittels der panneuronalen, temperaturabhängigen Treiberlinie elavGal4;tubGal80[ts] wurde ein longevity assay durchgeführt. Unter den neun getesteten Modulatoren zeigte sich in den transgenen Alzheimerfliegenmodellen unter Applikation von anle138b und bei den Fliegen mit dem Genotyp elavGal4/arc2e;tubGal80 zudem auch unter anle138c, ein signifikant verlängertes Überleben im Vergleich zur Negativkontrolle DMSO. In der anschließend durchgeführten Quantifizierung mittels Elektrochemilumineszenz-Assay zeigte sich im Modell elavGal4/arc2e;tubGal80 unter Applikation von anle138b und anle138c eine Verminderung des unlöslichen $A \beta$ bei unverändertem Gesamtprotein. Im Modell elavGal4/alz3;tubGal80/alz8 konnte ein ähnlicher Effekt nicht nachgewiesen werden.

Der zweite Teil der Arbeit beschäftigte sich mit der ausschliesslichen Expression in den Photorezeptoren der Drosophila melanogaster. Nach dem Schlüpfen zeigten sich in den Alzheimermodellen bereits teilweise leichte Veränderungen im Bereich der Ommatidien. Unter Verwendung der Aggregationsmodulatoren und der Negativkontrolle DMSO verstärkten sich die Veränderungen zunehmend und traten auch bei der Kontrollfliegenlinie auf, sodass von einem starken toxischen Effekt des DMSO ausgegangen werden muss.

Das gewählte System ist nur bedingt zur objektiven Testung geeignet. Bei einer erneuten Testung sollte es durch einen geeigneteren Assay ersetzt werden. 
In dieser Arbeit wurde gezeigt, dass die orale Gabe von anle138b und anle138c die verkürzte Lebensspanne in einem $A \beta$-Überexpressions-Modell der Alzheimer-Erkrankung in Drosophila verlängern kann. Parallel zur vorliegenden Arbeit wurden beide Substanzen in einem Alzheimer-Mausmodell (APPPS1delta9) nach Auftreten der ersten Plaque-Pathologie getestet. Dort konnte anle138b die beeinträchtigte Gedächtnisfunktion wiederherstellen. Als möglicher Wirkmechanismus konnte in vitro gezeigt werden, dass anle138b die Bildung von Poren in Lipidmembranen inhibiert. Ein Effekt auf die Oligomerisierung von $A \beta$ konnte auf Rasterkraftmikroskopieebene nicht gesehen werden. Dafür fanden sich weitere in vitro Hinweise für die Stabilisierung von off-pathway Oligomeren, die mit einer verminderten Hydrophobizität einhergingen.

Idealerweise sollten im nächsten Schritt präklinische Testungen erfolgen, um notwendige Therapiekonzepte zu etablieren. 


\section{Literaturverzeichnis}

1. Adams, M.D., Celniker, S.E., Holt, R.A., Evans, C.A., Gocayne, J.D., Amanatides, P.G., Scherer, S.E., Li, P.W., Hoskins, R.A., Galle, R.F., et al. (2000). The genome sequence of Drosophila melanogaster. Science. 287, 2185-2195.

2. Alavez, S., Vantipalli, M.C., Zucker, D.J., Klang, I.M., and Lithgow, G.J. (2011). Amyloid-binding compounds maintain protein homeostasis during ageing and extend lifespan. Nature. $\underline{472}, 226-229$.

3. Alexander, S.P., Benson, H.E., Faccenda, E., Pawson, A.J., Sharman, J.L., McGrath, J.C., Catterall, W.A., Spedding, M., Peters, J.A., Harmar, A.J., et al. (2013). The Concise Guide to PHARMACOLOGY 2013/14: overview. Br J Pharmacol. 170, 1449-1458.

4. Alzheimer, A. (1907). Über eine eigenartige Erkrankung der Hirnrinde. Allgemeine Zeitschrift für Psychiatrie. 146-148.

5. Amieva, H., Le Goff, M., Millet, X., Orgogozo, J.M., Peres, K., Barberger-Gateau, P., Jacqmin-Gadda, H., and Dartigues, J.F. (2008). Prodromal Alzheimer's disease:

Successive emergence of the clinical symptoms. Annals of Neurology. 64, 492-498.

6. Anand, R., Gill, K.D., and Mahdi, A.A. (2014). Therapeutics of Alzheimer's disease: Past, present and future. Neuropharmacology. $76 \mathrm{Pt} \mathrm{A}, 27-50$.

7. Andretic, R., Kim, Y.C., Jones, F.S., Han, K.A., and Greenspan, R.J. (2008). Drosophila D1 dopamine receptor mediates caffeine-induced arousal. Proc Natl Acad Sci U S A. $\underline{105}, 20392-20397$.

8. Bainton, R.J., Tsai, L.T., Singh, C.M., Moore, M.S., Neckameyer, W.S., and Heberlein, U. (2000). Dopamine modulates acute responses to cocaine, nicotine and ethanol in Drosophila. Cur Biol. 10, 187-194.

9. Barnes, D.E., and Yaffe, K. (2011). The projected effect of risk factor reduction on Alzheimer's disease prevalence. Lancet Neurol. 10, 819-828.

10. Bateman, R.J., Xiong, C., Benzinger, T.L., Fagan, A.M., Goate, A., Fox, N.C., Marcus, D.S., Cairns, N.J., Xie, X., Blazey, T.M., et al. (2012). Clinical and biomarker changes in dominantly inherited Alzheimer's disease. N Engl J Med. 367, 795-804.

11. Benilova, I., Karran, E., and De Strooper, B. (2012). The toxic Abeta oligomer and Alzheimer's disease: an emperor in need of clothes. Nat Neurosci. 15, 349-357.

12. Bieschke, J. (2013). Natural compounds may open new routes to treatment of amyloid diseases. Neurotherapeutics. 10 , 429-439.

13. Bieschke, J., Russ, J., Friedrich, R.P., Ehrnhoefer, D.E., Wobst, H., Neugebauer, K., and Wanker, E.E. (2010). EGCG remodels mature alpha-synuclein and amyloid-beta fibrils and reduces cellular toxicity. Proc Natl Acad Sci U S A. 107, 7710-7715.

14. Bird, T.D. (2008). Genetic aspects of Alzheimer disease. Genet Med. 10, 231-239.

15. Brand, A.H., and Perrimon, N. (1993). Targeted gene expression as a means of altering cell fates and generating dominant phenotypes. Development. 118, 401-415.

16. Butterfield, D.A., Reed, T., Newman, S.F., and Sultana, R. (2007). Roles of amyloid beta-peptide-associated oxidative stress and brain protein modifications in the pathogenesis of Alzheimer's disease and mild cognitive impairment. Free Radic Biol Med. 43, 658-677.

17. Canevari, L., Clark, J.B., and Bates, T.E. (1999). beta-Amyloid fragment 25-35 selectively decreases complex IV activity in isolated mitochondria. FEBS Lett. 457, 131134.

18. Citron, M., Diehl, T.S., Gordon, G., Biere, A.L., Seubert, P., and Selkoe, D.J. (1996). Evidence that the 42- and 40-amino acid forms of amyloid beta protein are generated from the beta-amyloid precursor protein by different protease activities. Proc Natl Acad Sci U S A. 93, 13170-13175. 
19. Crowther, D.C., Kinghorn, K.J., Miranda, E., Page, R., Curry, J.A., Duthie, F.A., Gubb, D.C., and Lomas, D.A. (2005). Intraneuronal Abeta, non-amyloid aggregates and neurodegeneration in a Drosophila model of Alzheimer's disease. Neuroscience. 132, 123-135.

20. Danysz, W., Parsons, C.G., Mobius, H.J., Stoffler, A., and Quack, G. (2000). Neuroprotective and symptomatological action of memantine relevant for Alzheimer's disease--a unified glutamatergic hypothesis on the mechanism of action. Neurotox Res. $\underline{2}$, $85-97$.

21. De Jonghe, C., Esselens, C., Kumar-Singh, S., Craessaerts, K., Serneels, S., Checler, F., Annaert, W., Van Broeckhoven, C., and De Strooper, B. (2001). Pathogenic APP mutations near the gamma-secretase cleavage site differentially affect Abeta secretion and APP C-terminal fragment stability. Hum Mol Genet. 10, 1665-1671.

22. Delrieu, J., Ousset, P.J., Caillaud, C., and Vellas, B. (2012a). 'Clinical trials in Alzheimer's disease': immunotherapy approaches. J Neurochem. 120 Suppl 1, 186-193.

23. Delrieu, J., Ousset, P.J., and Vellas, B. (2012b). Gantenerumab for the treatment of Alzheimer's disease. Expert Opin Biol Ther. 12, 1077-1086.

24. Dickson, D.W. (1997). The pathogenesis of senile plaques. J Neuropathol Exp Neurol. 56, 321-339.

25. Doody, R.S., Thomas, R.G., Farlow, M., Iwatsubo, T., Vellas, B., Joffe, S., Kieburtz, K., Raman, R., Sun, X., Aisen, P.S., et al. (2014). Phase 3 trials of solanezumab for mild-tomoderate Alzheimer's disease. N Engl J Med. $\underline{370}$, 311-321.

26. Duara, R., Loewenstein, D.A., Potter, E., Appel, J., Greig, M.T., Urs, R., Shen, Q., Raj, A., Small, B., Barker, W., et al. (2008). Medial temporal lobe atrophy on MRI scans and the diagnosis of Alzheimer disease. Neurology. 71, 1986-1992.

27. Duyckaerts, C., Delatour, B., and Potier, M.C. (2009). Classification and basic pathology of Alzheimer disease. Acta Neuropathol. 118, 5-36.

28. Ehrnhoefer, D.E., Duennwald, M., Markovic, P., Wacker, J.L., Engemann, S., Roark, M., Legleiter, J., Marsh, J.L., Thompson, L.M., Lindquist, S., et al. (2006). Green tea (-)epigallocatechin-gallate modulates early events in huntingtin misfolding and reduces toxicity in Huntington's disease models. Hum Mol Genet. 15, 2743-2751.

29. Esler, W.P., and Wolfe, M.S. (2001). A portrait of Alzheimer secretases--new features and familiar faces. Science. 293, 1449-1454.

30. Feng, B.Y., Toyama, B.H., Wille, H., Colby, D.W., Collins, S.R., May, B.C., Prusiner, S.B., Weissman, J., and Shoichet, B.K. (2008). Small-molecule aggregates inhibit amyloid polymerization. Nat Chem Biol. 4, 197-199.

31. Fernandez, J.W., Rezai-Zadeh, K., Obregon, D., and Tan, J. (2010). EGCG functions through estrogen receptor-mediated activation of ADAM10 in the promotion of nonamyloidogenic processing of APP. FEBS Lett. 584, 4259-4267.

32. Ferreira, N., Cardoso, I., Domingues, M.R., Vitorino, R., Bastos, M., Bai, G., Saraiva, M.J., and Almeida, M.R. (2009). Binding of epigallocatechin-3-gallate to transthyretin modulates its amyloidogenicity. FEBS Lett. 583, 3569-3576.

33. Finelli, A., Kelkar, A., Song, H.J., Yang, H., and Konsolaki, M. (2004). A model for studying Alzheimer's Abeta42-induced toxicity in Drosophila melanogaster. Mol Cell Neurosc. 26, 365-375.

34. Forstl, H., and Kurz, A. (1999). Clinical features of Alzheimer's disease. Eur Arch Psychiatry Clin Neurosc. 249, 288-290.

35. Francis, R., McGrath, G., Zhang, J., Ruddy, D.A., Sym, M., Apfeld, J., Nicoll, M., Maxwell, M., Hai, B., Ellis, M.C., et al. (2002). aph-1 and pen-2 are required for Notch pathway signaling, gamma-secretase cleavage of betaAPP, and presenilin protein accumulation. Dev Cell. $\underline{3}$, 85-97. 
36. Freeman, M. (1996). Reiterative use of the EGF receptor triggers differentiation of all cell types in the Drosophila eye. Cell. $\underline{87}, 651-660$.

37. Froelich, L. (2010). S3-Leitlinie „Demenzen“. Der Nervenarzt (Springer Verlag).

38. Gandy, S. (2005). The role of cerebral amyloid beta accumulation in common forms of Alzheimer disease. J Clin Invest. 115, 1121-1129.

39. Giuffrida, M.L., Caraci, F., Pignataro, B., Cataldo, S., De Bona, P., Bruno, V., Molinaro, G., Pappalardo, G., Messina, A., Palmigiano, A., et al. (2009). Beta-amyloid monomers are neuroprotective. J Neurosci. 29, 10582-10587.

40. Glenner, G.G., and Wong, C.W. (1984). Alzheimer's disease: initial report of the purification and characterization of a novel cerebrovascular amyloid protein. Biochem Biophys Res Commun. 120, 885-890.

41. Goate, A., Chartier-Harlin, M.C., Mullan, M., Brown, J., Crawford, F., Fidani, L., Giuffra, L., Haynes, A., Irving, N., James, L., et al. (1991). Segregation of a missense mutation in the amyloid precursor protein gene with familial Alzheimer's disease. Nature. 349, 704-706.

42. Goedert, M., and Spillantini, M.G. (2006). A century of Alzheimer's disease. Science. $\underline{314}, 777-781$.

43. Goedert, M., Klug, A., and Crowther, R.A. (2006). Tau protein, the paired helical filament and Alzheimer's disease. J Alzheimers Dis. 9, 195-207.

44. Greenspan, R.J. (2004). Fly Pushing: The Theory and Practice of Drosophila Genetics.

45. Greeve, I., Kretzschmar, D., Tschape, J.A., Beyn, A., Brellinger, C., Schweizer, M., Nitsch, R.M., and Reifegerste, R. (2004). Age-dependent neurodegeneration and Alzheimer-amyloid plaque formation in transgenic Drosophila. J Neurosci. 24, 38993906.

46. Grundke-Iqbal, I., Iqbal, K., Quinlan, M., Tung, Y.C., Zaidi, M.S., and Wisniewski, H.M. (1986a). Microtubule-associated protein tau. A component of Alzheimer paired helical filaments. J Biol Chem. 261, 6084-6089.

47. Grundke-Iqbal, I., Iqbal, K., Tung, Y.C., Quinlan, M., Wisniewski, H.M., and Binder, L.I. (1986b). Abnormal phosphorylation of the microtubule-associated protein tau (tau) in Alzheimer cytoskeletal pathology. Proc Natl Acad Sci U S A. 루, 4913-4917.

48. Haass, C., and Selkoe, D.J. (2007). Soluble protein oligomers in neurodegeneration: lessons from the Alzheimer's amyloid beta-peptide. Nat Rev Mol Cell Biol. $\underline{8}, 101-$ 112.

49. Hardy, J. (1997). Amyloid, the presenilins and Alzheimer's disease. Trends Neurosci. 20, 154-159.

50. Hay, B.A., Wolff, T., and Rubin, G.M. (1994). Expression of baculovirus P35 prevents cell death in Drosophila. Development. 120, 2121-2129.

51. He, J., Xing, Y.F., Huang, B., Zhang, Y.Z., and Zeng, C.M. (2009). Tea catechins induce the conversion of preformed lysozyme amyloid fibrils to amorphous aggregates. J Agric Food Chem. 57, 11391-11396.

52. Hong, M., Zhukareva, V., Vogelsberg-Ragaglia, V., Wszolek, Z., Reed, L., Miller, B.I., Geschwind, D.H., Bird, T.D., McKeel, D., Goate, A., et al. (1998). Mutationspecific functional impairments in distinct tau isoforms of hereditary FTDP-17. Science. 282, 1914-1917.

53. Huang, Y., and Mucke, L. (2012). Alzheimer mechanisms and therapeutic strategies. Cell. $\underline{148}, 1204-1222$.

54. Iijima, K., Liu, H.P., Chiang, A.S., Hearn, S.A., Konsolaki, M., and Zhong, Y. (2004). Dissecting the pathological effects of human Abeta40 and Abeta42 in Drosophila: a potential model for Alzheimer's disease. Proc Natl Acad Sci U S A. 101, 6623-6628.

55. Iijima-Ando, K., and Iijima, K. (2010). Transgenic Drosophila models of Alzheimer's disease and tauopathies. Brain Struct Funct. 214, 245-262. 
56. Jack, C.R., and Holtzman, D.M. (2013). Biomarker Modeling of Alzheimer's Disease. Neuron. $\underline{80}, 1347-1358$.

57. Jahn, H. (2013). Memory loss in Alzheimer's disease. Dialogues Clin Neurosci. 15, 445-454.

58. Jarrett, J.T., Berger, E.P., and Lansbury, P.T., Jr. (1993). The carboxy terminus of the beta amyloid protein is critical for the seeding of amyloid formation: implications for the pathogenesis of Alzheimer's disease. Biochemistry. 32, 4693-4697.

59. Jiao, B., Tang, B., Liu, X., Xu, J., Wang, Y., Zhou, L., Zhang, F., Yan, X., Zhou, Y., and Shen, L. (2014). Mutational analysis in early-onset familial Alzheimer's disease in Mainland China. Neurobiol Aging. 35, 1957

60. Jucker, M., and Walker, L.C. (2013). Self-propagation of pathogenic protein aggregates in neurodegenerative diseases. Nature. 501, 45-51.

61. Kang, J., Lemaire, H.G., Unterbeck, A., Salbaum, J.M., Masters, C.L., Grzeschik, K.H., Multhaup, G., Beyreuther, K., and Muller-Hill, B. (1987). The precursor of Alzheimer's disease amyloid A4 protein resembles a cell-surface receptor. Nature. $\underline{325}$, 733-736.

62. Karch, C.M., and Goate, A.M. (2015). Alzheimer's disease risk genes and mechanisms of disease pathogenesis. Biol Psychiatry. 77, 43-51.

63. Kramer, J.M., and Staveley, B.E. (2003). GAL4 causes developmental defects and apoptosis when expressed in the developing eye of Drosophila melanogaster. Genet Mol Res. 2, 43-47.

64. Ladiwala, A.R., Lin, J.C., Bale, S.S., Marcelino-Cruz, A.M., Bhattacharya, M., Dordick, J.S., and Tessier, P.M. (2010). Resveratrol selectively remodels soluble oligomers and fibrils of amyloid Abeta into off-pathway conformers. J Biol Chem. 285, 24228-24237.

65. Lahiri, D.K., Farlow, M.R., Nurnberger, J.I., Jr., and Greig, N.H. (1997). Effects of cholinesterase inhibitors on the secretion of beta-amyloid precursor protein in cell cultures. Ann N Y Acad Sci. $\underline{826}, 416-421$.

66. Laughon, A., and Gesteland, R.F. (1984). Primary structure of the Saccharomyces cerevisiae GAL4 gene. Mol Cell Biol. 4, 260-267.

67. Laughon, A., Driscoll, R., Wills, N., and Gesteland, R.F. (1984). Identification of two proteins encoded by the Saccharomyces cerevisiae GAL4 gene. Mol Cell Biol. $\underline{4}, 268-$ 275.

68. Lee, Y., Back, J.H., Kim, J., Kim, S.H., Na, D.L., Cheong, H.K., Hong, C.H., and Kim, Y.G. (2010). Systematic review of health behavioral risks and cognitive health in older adults. Int Psychogeriatr. 22, 174-187.

69. Lesne, S., Koh, M.T., Kotilinek, L., Kayed, R., Glabe, C.G., Yang, A., Gallagher, M., and Ashe, K.H. (2006). A specific amyloid-beta protein assembly in the brain impairs memory. Nature. 440, 352-357.

70. Lin, H., Bhatia, R., and Lal, R. (2001). Amyloid beta protein forms ion channels: implications for Alzheimer's disease pathophysiology. FASEB J. 15, 2433-2444.

71. Lindsay, J., Laurin, D., Verreault, R., Hebert, R., Helliwell, B., Hill, G.B., and McDowell, I. (2002). Risk factors for Alzheimer's disease: a prospective analysis from the Canadian Study of Health and Aging. Am J Epidemiol. 156, 445-453.

72. Lloyd, T.E., and Taylor, J.P. (2010). Flightless flies: Drosophila models of neuromuscular disease. Ann N Y Acad Sci. 1184, e1-20.

73. Luo, L., Tully, T., and White, K. (1992). Human amyloid precursor protein ameliorates behavioral deficit of flies deleted for Appl gene. Neuron. $\underline{9}$, 595-605.

74. Mahley, R.W., Weisgraber, K.H., and Huang, Y. (2006). Apolipoprotein E4: a causative factor and therapeutic target in neuropathology, including Alzheimer's disease. Proc Natl Acad Sci U S A. 103, 5644-5651. 
75. Mandel, S.A., Amit, T., Kalfon, L., Reznichenko, L., Weinreb, O., and Youdim, M.B. (2008). Cell signaling pathways and iron chelation in the neurorestorative activity of green tea polyphenols: special reference to epigallocatechin gallate (EGCG). J Alzheimers Dis. 15, 211-222.

76. Mandelkow, E.M., and Mandelkow, E. (1998). Tau in Alzheimer's disease. Trends Cell Biol. $\underline{8}$, 425-427.

77. Mandelkow, E.M., and Mandelkow, E. (2012). Biochemistry and cell biology of tau protein in neurofibrillary degeneration. Cold Spring Harb Perspect Med. 2 , a006247.

78. Mandelkow, E., von Bergen, M., Biernat, J., and Mandelkow, E.M. (2007). Structural principles of tau and the paired helical filaments of Alzheimer's disease. Brain Pathol. $\underline{17}, 83-90$.

79. Mazzulli, J.R., Mishizen, A.J., Giasson, B.I., Lynch, D.R., Thomas, S.A., Nakashima, A., Nagatsu, T., Ota, A., and Ischiropoulos, H. (2006). Cytosolic catechols inhibit alpha-synuclein aggregation and facilitate the formation of intracellular soluble oligomeric intermediates. J Neurosci. 26, 10068-10078.

80. McClung, C., and Hirsh, J. (1998). Stereotypic behavioral responses to free-base cocaine and the development of behavioral sensitization in Drosophila. Curr Biol. $\underline{8}$, 109-112.

81. McGovern, S.L., Caselli, E., Grigorieff, N., and Shoichet, B.K. (2002). A common mechanism underlying promiscuous inhibitors from virtual and high-throughput screening. J Med Chem. 45, 1712-1722.

82. McKhann, G.M., Knopman, D.S., Chertkow, H., Hyman, B.T., Jack, C.R., Jr., Kawas, C.H., Klunk, W.E., Koroshetz, W.J., Manly, J.J., Mayeux, R., et al. (2011). The diagnosis of dementia due to Alzheimer's disease: recommendations from the National Institute on Aging-Alzheimer's Association workgroups on diagnostic guidelines for Alzheimer's disease. Alzheimers Dement. 7, 263-269.

83. McLean, C.A., Cherny, R.A., Fraser, F.W., Fuller, S.J., Smith, M.J., Beyreuther, K., Bush, A.I., and Masters, C.L. (1999). Soluble pool of Abeta amyloid as a determinant of severity of neurodegeneration in Alzheimer's disease. Ann Neurol. 46, 860-866.

84. Mereles, D., and Hunstein, W. (2011). Epigallocatechin-3-gallate (EGCG) for clinical trials: more pitfalls than promises? Int J Mol Sci. 12, 5592-5603.

85. Mills, J., and Reiner, P.B. (1999). Regulation of amyloid precursor protein cleavage. J Neurochem. $\underline{72}$, 443-460.

86. Muller, U.C., Pietrzik, C.U., and Deller, T. (2012). The physiological functions of the beta-amyloid precursor protein APP. Exp Brain Res. 217, 325-329.

87. Nazir, A., Mukhopadhyay, I., Saxena, D.K., and Chowdhuri, D.K. (2003). Evaluation of the No Observed Adverse Effect Level of Solvent Dimethyl Sulfoxide in Drosophila melanogaster. Toxicol Mech Methods. 13, 147-152.

88. Necula, M., Kayed, R., Milton, S., and Glabe, C.G. (2007). Small molecule inhibitors of aggregation indicate that amyloid beta oligomerization and fibrillization pathways are independent and distinct. J Biol Chem. 282, 10311-10324.

89. Nelson, P.T., Alafuzoff, I., Bigio, E.H., Bouras, C., Braak, H., Cairns, N.J., Castellani, R.J., Crain, B.J., Davies, P., Del Tredici, K., et al. (2012). Correlation of Alzheimer disease neuropathologic changes with cognitive status: a review of the literature. J Neuropathol Exp Neurol. 71, 362-381.

90. Netzeva, T.I., Dearden, J.C., Edwards, R., Worgan, A.D., and Cronin, M.T. (2004). QSAR analysis of the toxicity of aromatic compounds to Chlorella vulgaris in a novel short-term assay. J Chem Inf Comput Sci. 44, 258-265.

91. Neve, R.L., Harris, P., Kosik, K.S., Kurnit, D.M., and Donlon, T.A. (1986). Identification of cDNA clones for the human microtubule-associated protein tau and 
chromosomal localization of the genes for tau and microtubule-associated protein 2. Brain Res.387, 271-280.

92. Nichols, C.D., Ronesi, J., Pratt, W., and Sanders-Bush, E. (2002). Hallucinogens and Drosophila: linking serotonin receptor activation to behavior. Neuroscience. $\underline{115}$, 979984.

93. Nicolas, M., and Hassan, B.A. (2014). Amyloid precursor protein and neural development. Development. 141, 2543-2548.

94. Pardossi-Piquard, R., and Checler, F. (2012). The physiology of the beta-amyloid precursor protein intracellular domain AICD. J Neurochem. 120 Suppl 1, 109-124.

95. Periz, G., and Fortini, M.E. (2004). Functional reconstitution of gamma-secretase through coordinated expression of presenilin, nicastrin, Aph-1, and Pen-2. J Neurosci Res. 77, 309-322.

96. Puglielli, L., Tanzi, R.E., and Kovacs, D.M. (2003). Alzheimer's disease: the cholesterol connection. Nat Neurosci. $\underline{6}, 345-351$.

97. Qi-Takahara, Y., Morishima-Kawashima, M., Tanimura, Y., Dolios, G., Hirotani, N., Horikoshi, Y., Kametani, F., Maeda, M., Saido, T.C., Wang, R., et al. (2005). Longer forms of amyloid beta protein: implications for the mechanism of intramembrane cleavage by gamma-secretase. J Neurosci. 25, 436-445.

98. Rambold, A.S., Miesbauer, M., Olschewski, D., Seidel, R., Riemer, C., Smale, L., Brumm, L., Levy, M., Gazit, E., Oesterhelt, D., et al. (2008). Green tea extracts interfere with the stress-protective activity of PrP and the formation of PrP. J Neurochem. 107, 218-229.

99. Ramirez-Bermudez, J. (2012). Alzheimer's disease: critical notes on the history of a medical concept. Arch Med Res. 43, 595-599.

100. Ready, D.F. (1989). A multifaceted approach to neural development. Trends Neurosci. $\underline{12}, 102-110$.

101. Reiter, L.T., Potocki, L., Chien, S., Gribskov, M., and Bier, E. (2001). A systematic analysis of human disease-associated gene sequences in Drosophila melanogaster. Genome Res. 11, 1114-1125.

102. Rogawski, M.A., and Wenk, G.L. (2003). The neuropharmacological basis for the use of memantine in the treatment of Alzheimer's disease. CNS Drug Rev. 9, 275-308.

103. Rogers, J., Luber-Narod, J., Styren, S.D., and Civin, W.H. (1988). Expression of immune system-associated antigens by cells of the human central nervous system: relationship to the pathology of Alzheimer's disease. Neurobiol Aging. 9, 339-349.

104. Rosales-Corral, S., Tan, D.X., Reiter, R.J., Valdivia-Velazquez, M., Acosta-Martinez, J.P., and Ortiz, G.G. (2004). Kinetics of the neuroinflammation-oxidative stress correlation in rat brain following the injection of fibrillar amyloid-beta onto the hippocampus in vivo. J Neuroimmunol. 150, 20-28.

105. Rose, C., Peoc'h, K., Chasseigneaux, S., Paquet, C., Dumurgier, J., Bourasset, F., Calon, F., Laplanche, J.L., Hugon, J., and Allinquant, B. (2012). New highly sensitive rodent and human tests for soluble amyloid precursor protein alpha quantification: preclinical and clinical applications in Alzheimer's disease. BMC Neurosci. 13, 84.

106. Rosen, D.R., Martin-Morris, L., Luo, L.Q., and White, K. (1989). A Drosophila gene encoding a protein resembling the human beta-amyloid protein precursor. Proc Natl Acad Sci U S A. $\underline{86}, 2478-2482$.

107. Rothenfluh, A., and Heberlein, U. (2002). Drugs, flies, and videotape: the effects of ethanol and cocaine on Drosophila locomotion. Curr Opin Neurobiol. 12, 639-645.

108. Salloway, S., Sperling, R., Fox, N.C., Blennow, K., Klunk, W., Raskind, M., Sabbagh, M., Honig, L.S., Porsteinsson, A.P., Ferris, S., et al. (2014). Two phase 3 trials of bapineuzumab in mild-to-moderate Alzheimer's disease. New Engl J Med. $\underline{370}$, 322333. 
109. Salminen, A., Ojala, J., Suuronen, T., Kaarniranta, K., and Kauppinen, A. (2008). Amyloid-beta oligomers set fire to inflammasomes and induce Alzheimer's pathology. J Cell Mol Med. 12, 2255-2262.

110. Sang, T.K., and Jackson, G.R. (2005). Drosophila models of neurodegenerative disease. NeuroRx. 2, 438-446.

111. Savva, G.M., Stephan, B.C., and Alzheimer's Society Vascular Dementia Systematic Review, G. (2010). Epidemiological studies of the effect of stroke on incident dementia: a systematic review. Stroke. $\underline{41}$, e41-46.

112. Schenk, D., Barbour, R., Dunn, W., Gordon, G., Grajeda, H., Guido, T., Hu, K., Huang, J., Johnson-Wood, K., Khan, K., et al. (1999). Immunization with amyloidbeta attenuates Alzheimer-disease-like pathology in the PDAPP mouse. Nature. $\underline{400}$, 173-177.

113. Schwabe, T., Bainton, R.J., Fetter, R.D., Heberlein, U., and Gaul, U. (2005). GPCR signaling is required for blood-brain barrier formation in drosophila. Cell. 123 , 133144.

114. Selkoe, D.J. (2008). Soluble oligomers of the amyloid beta-protein impair synaptic plasticity and behavior. Behav Brain Res. 192, 106-113.

115. Shankar, G.M., Li, S., Mehta, T.H., Garcia-Munoz, A., Shepardson, N.E., Smith, I., Brett, F.M., Farrell, M.A., Rowan, M.J., Lemere, C.A., et al. (2008). Amyloid-beta protein dimers isolated directly from Alzheimer's brains impair synaptic plasticity and memory. Nat Med. 14, 837-842.

116. Shariati, S.A., Lau, P., Hassan, B.A., Muller, U., Dotti, C.G., De Strooper, B., and Gartner, A. (2013). APLP2 regulates neuronal stem cell differentiation during cortical development. J Cell Sci. 126, 1268-1277.

117. Sherrington, R., Rogaev, E.I., Liang, Y., Rogaeva, E.A., Levesque, G., Ikeda, M., Chi, H., Lin, C., Li, G., Holman, K., et al. (1995). Cloning of a gene bearing missense mutations in early-onset familial Alzheimer's disease. Nature. 375, 754-760.

118. Singh, B.N., Shankar, S., and Srivastava, R.K. (2011). Green tea catechin, epigallocatechin-3-gallate (EGCG): mechanisms, perspectives and clinical applications. Biochem Pharmacol. $\underline{82}$, 1807-1821.

119. Singh, M., Arseneault, M., Sanderson, T., Murthy, V., and Ramassamy, C. (2008). Challenges for research on polyphenols from foods in Alzheimer's disease: bioavailability, metabolism, and cellular and molecular mechanisms. J Agric Food Chem. 56, 4855-4873.

120. Smolarkiewicz, M., Skrzypczak, T., and Wojtaszek, P. (2013). The very many faces of presenilins and the gamma-secretase complex. Protoplasma. 250, 997-1011.

121. Song, Z., Guan, B., Bergman, A., Nicholson, D.W., Thornberry, N.A., Peterson, E.P., and Steller, H. (2000). Biochemical and genetic interactions between Drosophila caspases and the proapoptotic genes rpr, hid, and grim. Mol Cell Biol. 20, 2907-2914.

122. Soto, C. (2003). Unfolding the role of protein misfolding in neurodegenerative diseases. Nat Rev Neurosci. $\underline{4}, 49-60$.

123. Stork, T., Engelen, D., Krudewig, A., Silies, M., Bainton, R.J., and Klambt, C. (2008). Organization and function of the blood-brain barrier in Drosophila. J Neurosci. $\underline{28}$, 587-597.

124. Sundstrom, A., Nilsson, L.G., Cruts, M., Adolfsson, R., Van Broeckhoven, C., and Nyberg, L. (2007). Increased risk of dementia following mild head injury for carriers but not for non-carriers of the APOE epsilon4 allele. Int Psychogeriatr. 19, 159-165.

125. Suster, M.L., Seugnet, L., Bate, M., and Sokolowski, M.B. (2004). Refining GAL4driven transgene expression in Drosophila with a GAL80 enhancer-trap. Genesis. $\underline{39}$, 240-245. 
126. Takami, M., Nagashima, Y., Sano, Y., Ishihara, S., Morishima-Kawashima, M., Funamoto, S., and Ihara, Y. (2009). gamma-Secretase: successive tripeptide and tetrapeptide release from the transmembrane domain of beta-carboxyl terminal fragment. J Neurosci. 29, 13042-13052.

127. Takasugi, N., Tomita, T., Hayashi, I., Tsuruoka, M., Niimura, M., Takahashi, Y., Thinakaran, G., and Iwatsubo, T. (2003). The role of presenilin cofactors in the gamma-secretase complex. Nature. $\underline{422}, 438-441$.

128. Tan, C.C., Yu, J.T., Wang, H.F., Tan, M.S., Meng, X.F., Wang, C., Jiang, T., Zhu, X.C., and Tan, L. (2014). Efficacy and Safety of Donepezil, Galantamine,

Rivastigmine, and Memantine for the Treatment of Alzheimer's Disease: A Systematic Review and Meta-Analysis. J Alzheimers Dis.41, 615-631.

129. Tanzi, R.E. (2012). The genetics of Alzheimer disease. Cold Spring Harb Perspect Med. 2 .

130. Thal, D.R., Rub, U., Orantes, M., and Braak, H. (2002). Phases of A beta-deposition in the human brain and its relevance for the development of AD. Neurology. $\underline{58}, 1791-$ 1800 .

131. Thal, D.R., Capetillo-Zarate, E., Del Tredici, K., and Braak, H. (2006). The development of amyloid beta protein deposits in the aged brain. Sci Aging Knowledge Environ. 2006, re1.

132. Treisman, J.E. (2013). Retinal differentiation in Drosophila. Wiley Interdiscip Rev Dev Biol. 2, 545-557.

133. Tyan, S.H., Shih, A.Y., Walsh, J.J., Maruyama, H., Sarsoza, F., Ku, L., Eggert, S., Hof, P.R., Koo, E.H., and Dickstein, D.L. (2012). Amyloid precursor protein (APP) regulates synaptic structure and function. Mol Cell Neurosci. 51, 43-52.

134. Wagner, J., Ryazanov, S., Leonov, A., Levin, J., Shi, S., Schmidt, F., Prix, C., PanMontojo, F., Bertsch, U., Mitteregger-Kretzschmar, G., et al. (2013). Anle138b: a novel oligomer modulator for disease-modifying therapy of neurodegenerative diseases such as prion and Parkinson's disease. Acta neuropathol. 125, 795-813.

135. Walker, L.C., and LeVine, H., 3rd (2012). Corruption and spread of pathogenic proteins in neurodegenerative diseases. J Biol Chem. 287, 33109-33115.

136. Walsh, D.M., and Selkoe, D.J. (2007). A beta oligomers - a decade of discovery. J Neurochem. 101, 1172-1184.

137. Weingarten, M.D., Lockwood, A.H., Hwo, S.Y., and Kirschner, M.W. (1975). A protein factor essential for microtubule assembly. Proc Natl Acad Sci U S A. 22 , 18581862.

138. Weintraub, S., Wicklund, A.H., and Salmon, D.P. (2012). The neuropsychological profile of Alzheimer disease. Cold Spring Harb Perspect Med. 2, a006171.

139. Wischik, C.M., Edwards, P.C., Lai, R.Y., Roth, M., and Harrington, C.R. (1996). Selective inhibition of Alzheimer disease-like tau aggregation by phenothiazines. Proc Natl Acad Sci U S A. 93, 11213-11218.

140. Wittmann, C.W., Wszolek, M.F., Shulman, J.M., Salvaterra, P.M., Lewis, J., Hutton, M., and Feany, M.B. (2001). Tauopathy in Drosophila: neurodegeneration without neurofibrillary tangles. Science. 293, 711-714.

141. Wolf, F.W., and Heberlein, U. (2003). Invertebrate models of drug abuse. J Neurobiol. 54, 161-178.

142. Wu, L., Rosa-Neto, P., Hsiung, G.Y., Sadovnick, A.D., Masellis, M., Black, S.E., Jia, J., and Gauthier, S. (2012). Early-onset familial Alzheimer's disease (EOFAD). Can J Neurol Sci. $\underline{39}, 436-445$.

143. Yagi, Y., Tomita, S., Nakamura, M., and Suzuki, T. (2000). Overexpression of human amyloid precursor protein in Drosophila. Mol Cell Biol Res Commun. $\underline{4}, 43-49$. 
144. Yoshihara, M., Ensminger, A.W., and Littleton, J.T. (2001). Neurobiology and the Drosophila genome. Funct Integr Genomics. 1, 235-240.

145. Young-Pearse, T.L., Chen, A.C., Chang, R., Marquez, C., and Selkoe, D.J. (2008). Secreted APP regulates the function of full-length APP in neurite outgrowth through interaction with integrin beta1. Neural Dev. $\underline{3}, 15$.

146. Zheng, H., Zhao, Z., and Jiang, R. (2011). Integrative data analysis in systems biology. Int J Comput Biol Drug Des. $\underline{4}, 107-110$.

147. Zimmermann, M., Gardoni, F., and Di Luca, M. (2005). Molecular rationale for the pharmacological treatment of Alzheimer's disease. Drugs Aging. 22 Suppl 1, 27-37.

148. Zou, K., Gong, J.S., Yanagisawa, K., and Michikawa, M. (2002). A novel function of monomeric amyloid beta-protein serving as an antioxidant molecule against metalinduced oxidative damage. J Neurosci. 22, 4833-4841. 


\section{Anhang}

Chemische Strukturformeln der verwendeten Modulatoren

anle138b: 3-(1,3-Benzodioxol-5-yl)-5-(3-bromophenyl)-1H-pyrazole<smiles>Brc1cccc(-c2cc(-c3ccc4c(c3)OCO4)n[nH]2)c1</smiles>

anle138c: 3-(3-Bromophenyl)-5-(3,4-dihydroxyphenyl)-1 H-pyrazole<smiles>Oc1ccc(-c2cc(-c3cccc(Br)c3)n[nH]2)cc1O</smiles>

anle145c: 3-(3,5-Dibromophenyl)-5-(3,4,5-trihydroxyphenyl)-1H-pyrazole hydrobromide<smiles>Oc1cc(-c2cc(-c3cc(Br)cc(Br)c3)n[nH]2)cc(O)c1O</smiles> 
anle253b: 3-(3-Bromophenyl)-5-[4-(dimethylamino)phenyl]-1H-pyrazole<smiles>CN(C)c1ccc(-c2cc(-c3cccc(Br)c3)n[nH]2)cc1</smiles>

sery85: 3-(3,4-Dihydroxyphenyl)-5-(3-fluorophenyl)-1H-pyrazole<smiles>Oc1ccc(-c2cc(-c3cccc(F)c3)[nH]n2)cc1O</smiles>

sery118: 5-(3,4-Dihydroxyphenyl)-3-(4-hydroxyphenyl)isoxazole<smiles>Oc1ccc(-c2cc(-c3ccc(O)c(O)c3)on2)cc1</smiles> 
sery313b: 3-(1,3-Benzodioxol-5-yl)-5-(3-hydroxyphenyl)-1H-pyrazole<smiles>Oc1cccc(-c2cc(-c3ccc4c(c3)OCO4)n[nH]2)c1</smiles>

sery335b: 3-(1,3-Benzodioxol-5-yl)-5-(3-chlorophenyl)-1H-pyrazole<smiles>Clc1cccc(-c2cc(-c3ccc4c(c3)OCO4)n[nH]2)c1</smiles>

sery392b: 3-(1,3-benzodioxol-5-yl)-5-(3-bromophenyl)-1-methyl-1H-pyrazole<smiles>Cn1nc(-c2ccc3c(c2)OCO3)cc1-c1cccc(Br)c1</smiles> 


\section{Auswertung der Überlebensanalyse mittels SPSS}

Tab. 11: Mittelwerte und Mediane für die Überlebenszeit verschiedener Linien

Tabellarische Aufzeichnung der Mittelwerte und Mediane für die Überlebenszeit der F1-Generation der Linien elavGal4;tubGal80[ts],lacz (lacz), elavGal4/arc2e;tubGal80[ts] (arc2e) und elavGal4/alz3; tubGal80[ts]/alz8 (alz3/alz8) unter Verwendung der Wirkstoffe anle138b und 138c sowie unter DMSO

\begin{tabular}{|c|c|c|c|c|c|c|c|c|c|}
\hline \multicolumn{10}{|c|}{ Mittelwerte und Mediane für die Überlebenszeit } \\
\hline \multirow{3}{*}{\multicolumn{2}{|c|}{ lacz vs. acr2e vs. alz3/alz8 }} & \multicolumn{4}{|c|}{ Mittelwert $^{\mathrm{a}}$} & \multicolumn{4}{|c|}{ Median } \\
\hline & & \multirow[b]{2}{*}{ Schätzer } & \multirow[b]{2}{*}{$\begin{array}{c}\text { Standardfehl } \\
\text { er }\end{array}$} & \multicolumn{2}{|c|}{ 95\%-Konfidenzintervall } & \multirow[b]{2}{*}{ Schätzer } & \multirow[b]{2}{*}{$\begin{array}{c}\text { Standardfehl } \\
\text { er }\end{array}$} & \multicolumn{2}{|c|}{ 95\%-Konfidenzintervall } \\
\hline & & & & $\begin{array}{l}\text { Untere } \\
\text { Grenze }\end{array}$ & $\begin{array}{l}\text { Obere } \\
\text { Grenze }\end{array}$ & & & $\begin{array}{l}\text { Untere } \\
\text { Grenze }\end{array}$ & $\begin{array}{l}\text { Obere } \\
\text { Grenze }\end{array}$ \\
\hline \multirow[t]{4}{*}{ lacz } & DMSO & 31,179 & , 497 & 30,205 & 32,154 & 33,000 & ,448 & 32,122 & 33,878 \\
\hline & anle $138 b$ & 32,930 & 401 & 32,143 & 33,717 & 33,000 & ,320 & 32,374 & 33,626 \\
\hline & anle $138 c$ & 32,349 & , 415 & 31,536 & 33,162 & 33,000 & 391 & 32,234 & 33,766 \\
\hline & Gesamt & 32,149 & ,255 & 31,650 & 32,649 & 33,000 & ,221 & 32,567 & 33,433 \\
\hline \multirow[t]{4}{*}{$\operatorname{arc2e}$} & DMSO & 11,423 & ,131 & 11,166 & 11,680 & 12,000 & ,088 & 11,828 & 12,172 \\
\hline & anle $138 b$ & 13,695 & ,150 & 13,401 & 13,989 & 13,000 & , 150 & 12,705 & 13,295 \\
\hline & anle $138 c$ & 13,753 & ,152 & 13,456 & 14,050 & 14,000 & , 178 & 13,651 & 14,349 \\
\hline & Gesamt & 12,915 & ,091 & 12,736 & 13,094 & 13,000 & ,083 & 12,836 & 13,164 \\
\hline \multirow[t]{4}{*}{ alz3/alz8 } & DMSO & 21,775 & ,231 & 21,322 & 22,228 & 22,000 & , 165 & 21,677 & 22,323 \\
\hline & anle $138 b$ & 22,004 & ,296 & 21,424 & 22,584 & 22,000 & ,219 & 21,570 & 22,430 \\
\hline & anle $138 c$ & 21,652 & ,253 & 21,156 & 22,149 & 22,000 & ,213 & 21,582 & 22,418 \\
\hline & Gesamt & 21,811 & ,152 & 21,512 & 22,109 & 22,000 & ,112 & 21,781 & 22,219 \\
\hline Gesamt & Gesamt & 22,075 & ,194 & 21,694 & 22,455 & 21,000 & ,235 & 20,539 & 21,461 \\
\hline
\end{tabular}

Tab. 12: Mittlere Überlebenswahrscheinlichkeit im paarweisen Vergleich unter Zugabe von Modulatoren

Tabellarische Darstellung der Signifikanztestung im paarweisen Vergleich in Bezug auf die mittlere Überlebenswahrscheinlichkeit der F1-Generationen der Linien elavGal4;tubGal80[ts],lacz (lacz), elavGal4/arc2e;tubGal80[ts] (arc2e) und elavGal4/alz3;tubGal80[ts]/alz8 (alz3/alz8) unter Verwendung der Wirkstoffe anle138b und 138c sowie unter DMSO

\begin{tabular}{|c|c|c|c|c|c|c|c|c|}
\hline \multicolumn{9}{|c|}{ Paarweise Vergleiche } \\
\hline \multirow{2}{*}{\multicolumn{3}{|c|}{ lacz vs. acr2e vs. alz3/alz8 }} & \multicolumn{2}{|c|}{ DMSO } & \multicolumn{2}{|c|}{ anle 138b } & \multicolumn{2}{|c|}{ anle 138c } \\
\hline & & & Chi-Quadrat & Sig. & Chi-Quadrat & Sig. & Chi-Quadrat & Sig. \\
\hline \multirow{9}{*}{$\begin{array}{l}\text { Log Rank } \\
\text { (Mantel-Cox) }\end{array}$} & \multirow[t]{3}{*}{ lacz } & DMSO & & &, 960 & ,327 & ,068 & ,794 \\
\hline & & anle $138 b$ & ,960 & ,327 & & & ,863 &, 353 \\
\hline & & anle 138c &, 068 & ,794 & ,863 & ,353 & & \\
\hline & \multirow[t]{3}{*}{$\operatorname{arc2e}$} & DMSO & & & 149,410 &, 000 & 151,348 &, 000 \\
\hline & & anle 138b & 149,410 &, 000 & & & ,089 & ,765 \\
\hline & & anle $138 \mathrm{c}$ & 151,348 &, 000 & ,089 & ,765 & & \\
\hline & \multirow[t]{3}{*}{ alz3/alz8 } & DMSO & & & 12,003 &, 001 & 1,310 & ,252 \\
\hline & & anle $138 b$ & 12,003 & ,001 & & & 4,900 & ,027 \\
\hline & & anle $138 c$ & 1,310 & ,252 & 4,900 & ,027 & & \\
\hline
\end{tabular}




\section{Danksagung}

Zu guter Letzt möchte ich mich bei den Personen bedanken, die maßgeblich an dem Gelingen der Dissertation beteiligt gewesen sind.

An erster Stelle gilt mein Dank meiner Doktormutter Professor Anja Schneider, die mich während der gesamten Zeit betreut hat.

Ein großer Dank geht an meine gesamte Arbeitsgruppe, insbesondere an Marcel Kunadt und Anne Stündl, die mir jederzeit mit Rat und Tat (laborchemisch aber auch computertechnisch) zur Seite standen.

Darüber hinaus möchte ich mich bei Tina Kling für ihre großartige Unterstützung im Umgang mit Drosophila melanogaster bedanken. Ihre Hilfe und die vielen Diskussionen trugen wesentlich zum Erfolg der Experimente bei.

Danke für Eure Hilfe, danke für Eure Freundschaft.

Zum Abschluss möchte ich zudem meiner Familie, insbesondere auch meiner Oma, die die Fertigstellung der Arbeit nicht mehr miterleben konnte, danken. Sie alle hatten während der langen Zeit immer ein offenes Ohr und haben das Abschließen der Dissertation fortwährend positiv beeinflusst. Es ist geschafft!! 